\title{
Use of the aging effect to change the local properties of structure components
}

\author{
Mehdi Asadi ${ }^{a}$, Nicole Schulze ${ }^{b}$, Heinz Palkowski ${ }^{c}$ \\ Institute of Metallurgy (IMET), Metal Forming and Processing, Clausthal University of Technology \\ (TUC), Robert-Koch-Str. 42, 38678 Clausthal-Zellerfeld, Germany \\ amehdi.asadi@tu-clausthal.de, ${ }^{b}$ nicole.schulze@tu-clausthal.de, ${ }^{c h}$ einz.palkowski@tu-clausthal.de
}

Keywords: aging effect, multiphase steel, local deformation, local heat treatment

\begin{abstract}
This research deals with processes leading to local strengthening effects in Advanced High Strength Steels (AHSS). Dual phase (DP), retained austenite (RA) - both hot and cold rolled and complex phase (CP) steels have been investigated to examine the effect of thermal and mechanical processing parameters on local properties. For this purpose, a method has been investigated to achieve local strengthening, namely local deformation and local heat treatment. Samples were locally deformed by bending and embossing processes. A local deformation with defined pre-strains leads to enhanced hardness and strengthening. A subsequent aging treatment leads to a further increase in mechanical properties. Local heat treatment was applied using a laser and an electron beam. Following local heat treatment with selected parameters, the microstructure of the surface and the cross section as well as the mechanical properties were evaluated by light optical, scanning as well as transmission electron microscopy, hardness measurement, tensile testing and thermal modelling. It can be stated that with partial heat treatment, local high strengthening can be produced. At lower heat treating temperatures, this effect could be attributed to bake hardening. With increased heat treating temperature, the initial microstructure near the surface is affected. A model can be improved, which defines the correlation between the influencing parameters and the local properties. The influence of over-aging in locally strengthen regions has been studied. For this investigation, parameters are stable to locally adjust the strengthening effect. Partial strengthening of AHSS by local deformation or local heat treatment can open up new fields of applications for locally using the strengthening effect to only influence relevant areas of interest, thus providing the potential for saving energy and designing the component's behaviour.
\end{abstract}

\section{Introduction:}

To combine fuel saving with increased safety of vehicles, the automotive industry was led to develop Advanced High Strength Steels (AHSS). Their high yield and tensile strengths enable a decrease in sheet thickness (weight saving) and, at the same time, maintaining or even improving crash behavior (safety) [1-4]. This is achieved by micro-alloying [5] and a thermo-mechanical treatment [6]. AHSS have been widely used in the automotive industry in the last decade. These AHSS steels, which are mostly multiphase steels, are characterized by good formability, high strength and the bake hardening $(\mathrm{BH})$ effect. Multiphase steels have proved a good compromise between strength and ductility [7-8]. The multiphase steels exhibit a continuous yielding behavior, low yield point, and a high strain-hardening coefficient [9-10]. This has been attributed to an increase in the work hardening limits through forming mobile dislocations due to the martensite transformation during heat treatment and martensite twinning during forming [11-12].

Structures consist of connected nodal as well as surface elements, organized in such a way that follow the path of force transmission, which requires the material input to remain minimal. Currently, the separate structural elements are mainly produced from a material with homogeneous properties, or from composites of different materials or materials with different thicknesses (e.g. Tailored Blanks). The next step is to adapt not only the geometry to the strain, but also to trim the material as much as possible to correspond to the requirements. This will be attained by targeted use of the aging effect. 
The aging of steel is a process by which the mechanical properties of the material change with time. BH benefits from this effect and increases the strength of a finished part by means of a heat treatment. $\mathrm{BH}$ is a strengthening mechanism which exploits the controlled diffusion of interstitial atoms to pin dislocations thereby raising the yield strength of the material [13].

The aging of special steel qualities is technically used in AHSS, where e.g. the increase in strength is realized in the final heat treatment [14-15]. Our previous investigations showed the aging effect of AHSS is much stronger than that for conventional BH steels [16-17]. This property provides new possibilities for designing structural components which, for example, are used in the automotive industry. By means of targeted local deformation together with subsequent thermal treatment, it is possible to obtain a well-defined local behavior. On the other hand, graded strength behavior can be produced by a local, limited thermal treatment. For example, the application of a laser beam is one of the possibilities to locally influence the properties of metals.

Laser beams provide the controlled localized heat treatment in AHSS [18-19]. The main advantages of laser treatments over other alternative technologies essentially arise from the highly focused energy density supplied by the laser source. This effect generates high heating and cooling rates and allows localized surface treatments in reduced thickness with a minimum change inside the bulk material. In addition to this, from a metallurgical point of view, these particular conditions produce special microstructures with a high degree of grain refinement [20-21].

Hillebrand [22] has reported the effect of local heat treatment by means of a laser on surface modification in $\mathrm{BH}$ steels. The heat treatment was conducted in a temperature range of $100-400^{\circ} \mathrm{C}$. Owing to the BH effect, an increase in strength of up to $120 \mathrm{MPa}$ was reported for the $\mathrm{BH}$ steel. In [19, 23] laser heat treatment and induction heat treatment on sheets of DP steel having a tensile strength of about $600 \mathrm{MPa}$ were conducted. The authors reported a decrease in yield and tensile strength and an increase in elongation after laser heat treatment. The effect is due to tempering of martensite. Tempering of martensite occurs at temperatures below the lower critical $\mathrm{Ac}_{1}$ and was also reported as the main reason for softening in martensitic steels [24-26].

With a local, restricted initiation of the aging effect, the properties of an originally homogenous material can be locally changed with the aim of adapting them to the required load. As the aging effect significantly depends on the degree of deformation and the downstream thermal treatment [2728], it is possible to obtain ductile and high-strength neighboring regions within one component without using sophisticated joining-technologies to combine different materials. Based on these basic investigations, models and processes are to be developed and optimized to compute this effect as well as to exploit their potential for actual use in high-strength structures.

This paper presents the results of the research activities undertaken regarding the utilization of the aging effect in multiphase steels as well as to outline future studies. The investigations are part of a project within the Collaborative Research Center SFB 675 "Creation of high strength metallic structures and joints by setting up scaled local material properties". The goals of the project are to analyze the effect of the local influence and to develop processes which are able to induce a locally restricted $\mathrm{BH}$ effect for multiphase steels. The potential and efficiency of different methods and procedures of local forming processes will be determined and optimized. A special aspect is the analysis of the influence of forming based load paths on the evolution of the strength parameters. 


\section{Work agenda}

The utilization of the aging effect to obtain local strengthening is investigated. Extensive basic research allows the calculation of the aging potential as a function of the relevant variables. Material models have already been developed to calculate the locally induced strengthening effect in designed structural elements. Here, the aim is to make it possible to use the available materials to the limit of their potential, and to produce capable structures with minimal material expenditure. The project is divided into four main research topics:

- local deformation,

- local heat treatment,

- stability of strengthening and ductility through aging,

- investigation of different deformation types.

The results of the project are to provide a computational basis for product developers, allowing them to evaluate the extended potential use of materials. While defining the boundaries and the field of the experiment for the processes, the production engineer will ensure to induce a graduated and locally limited strengthening effect, and to maintain it through the subsequent production steps.

\section{Material}

Within the scope of the project, the dual-phase steels DP-W 600 and DP-K 30/50, the retainedaustenite steels (RA-Steel) RA $700 \mathrm{~W}$ and RA $400 \mathrm{~K}$, and a hot-rolled complex-phase steel CP-W 1000 were investigated. "W" refers to hot-rolled steels and "K" to cold-rolled steels.

For these multiphase steels, the standard prEN 10336 is used. RA $700 \mathrm{~W}$ and RA $400 \mathrm{~K}$ are not currently standardized. RA $700 \mathrm{~W}$ denoted by the material number 1.0950 is also well known as S495MC*. In this work, the internal descriptions are used. The approximate chemical composition and the code of prEN 10336 of the materials used is given in Table 1. In this paper we present the results of DP-W 600 and CP-W 1000. The other types of steel had been investigated randomly. The publication had been done in [29-30].

Table 1: Chemical composition (wt-\%) of the steels

\begin{tabular}{llccccccc}
\hline Steel & prEN 10336 & $\mathrm{C}$ & $\mathrm{Al}$ & $\mathrm{Mn}$ & $\mathrm{Si}$ & $\mathrm{Cr}+\mathrm{Mo}$ & $\mathrm{P}$ & $\mathrm{Nb}+\mathrm{Ti}$ \\
\hline DP-W 600 & HDT580X & 0.09 & 0.04 & 1.00 & 0.06 & 0.48 & 0.021 & 0.005 \\
DP-K 30/50 & HCT500X & 0.08 & 0.03 & 1.49 & 0.09 & 0.54 & 0.012 & 0.026 \\
CP-W 1000 & HDT980C & 0.23 & 0.03 & 2.21 & 0.64 & 0.37 & 0.012 & 0.111 \\
RA 700 W & Internal & 0.18 & 1.41 & 1.95 & 0.70 & 0.05 & 0.011 & 0.034 \\
RA 400 K & description & 0.13 & 0.03 & 1.37 & 1.25 & 0.08 & 0.012 & 0.040 \\
\hline
\end{tabular}

The mechanical properties of the materials, as delivered, had already been measured according to standard DIN EN 10002-1. Samples had been taken in the $0^{\circ}, 45^{\circ}$ and $90^{\circ}$ directions relative to the rolling direction (RD). These measured properties are the starting basis for the preparation and analysis of the planned experiments. The parameters used for analysis are the yield strength, the tensile strength, the non-proportional deformation under maximum load (max. elongation) as well as the elongation at fracture. The mechanical properties of the investigated materials (as delivered) $0^{\circ}, 45^{\circ}$ and $90^{\circ}$ to the rolling direction and the hardness HV0.5 are listed in Table 2. The standard deviation of the hardness values was \pm 3 HV0.5. 
Table 2: The mechanical properties of the steels, $0^{\circ}, 45^{\circ}$ and $90^{\circ}$ to rolling direction

\begin{tabular}{|c|c|c|c|c|c|}
\hline $0^{\circ}$ to $\mathrm{RD}$ & DP-W 600 & RA $700 \mathrm{~W}$ & CP-W 1000 & DP-K 30/50 & RA $400 \mathrm{~K}$ \\
\hline Yield strength & $477 \pm 2$ & $590 \pm 9$ & $735 \pm 8$ & $333 \pm 10$ & $462 \pm 11$ \\
\hline Tensile strength & $631 \pm 2$ & $774 \pm 6$ & $898 \pm 9$ & $508 \pm 7$ & $806 \pm 12$ \\
\hline Max. elongation & $1.32 \pm 0.06$ & $21.47 \pm 0.33$ & $8.83 \pm 0.45$ & $5.77 \pm 0.53$ & $17.80 \pm 0.52$ \\
\hline Fracture elongation [\%] & $.09 \pm 0.63$ & $24.94 \pm 0.32$ & $2.87 \pm 0.43$ & $23.60 \pm 0.43$ & $22.67 \pm 0.32$ \\
\hline Hardness HV0.5 & $225 \pm 3$ & $259 \pm 5$ & $273 \pm 2$ & $177 \pm 3$ & $244 \pm 4$ \\
\hline $45^{\circ}$ to $\mathrm{RD}$ & 600 & $0 \mathrm{~W}$ & CP-W 1000 & DP-K 30/50 & RA $400 \mathrm{~K}$ \\
\hline Yield strength & $467 \pm 1$ & 618 & $780 \pm 9$ & $326 \pm 9$ & $473 \pm 2$ \\
\hline Tensile strength & $634 \pm 1$ & $786 \pm 3$ & $869 \pm 8$ & $500 \pm 10$ & $797 \pm 12$ \\
\hline Max. elongation & $1.42 \pm 0.52$ & $21.83 \pm 0.65$ & $9.10 \pm 0.37$ & $16.12 \pm 0.45$ & $17.13 \pm 0.41$ \\
\hline Fracture elongation [\%] & $18.34 \pm 0.26$ & $26.64 \pm 0.78$ & $15.45 \pm 0.51$ & $24.50 \pm 0.52$ & $22.16 \pm 0.27$ \\
\hline Hardness HV0.5 & $225 \pm 3$ & $259 \pm 5$ & $273 \pm 2$ & $177 \pm 3$ & $244 \pm 4$ \\
\hline $90^{\circ}$ to $\mathrm{RD}$ & DP-W 600 & RA $700 \mathrm{~W}$ & CP-W 1000 & DP-K 30/50 & RA $400 \mathrm{~K}$ \\
\hline Yield stren & $470 \pm 2$ & $659 \pm 28$ & $821 \pm 22$ & $334 \pm 4$ & $484 \pm 4$ \\
\hline Tensile strength & $642 \pm 1$ & 80 & $905 \pm 19$ & $512 \pm 3$ & $792 \pm 16$ \\
\hline Max. elongation & $1.00 \pm 0.20$ & $5.94 \pm 0.26$ & $7.67 \pm 0.30$ & $15.81 \pm 0.20$ & $16.52 \pm 1.10$ \\
\hline Fracture elongation [\%] & $17.80 \pm 0.92$ & $19.20 \pm 0.39$ & $11.85 \pm 0.30$ & $24.64 \pm 0.42$ & $21.60 \pm 0.78$ \\
\hline Hardness HV0.5 & $225 \pm 3$ & $259 \pm 5$ & $273 \pm 2$ & $177 \pm 3$ & $244 \pm 4$ \\
\hline
\end{tabular}

\section{Local deformation}

Two standard procedures are applied to induce local deformations into the selected materials:

1) bending, 2) embossing.

Local deformation by bending. Bending experiments were carried out in order to investigate the influence of local deformation on the aging effect. In this way, the deformation characteristics of the materials and the influence of the true strain could be qualitatively determined. Using bent metal sheets, the extent to which factors such as true strain, bending radius and bending angle influence the aging effect was investigated and how to determine them most efficiently.

Preliminary simulations had been made using FEM to determine the true strain and the resulting stresses corresponding to the bending radius and bending angle. Fig. 1 shows the simulated true strain with a bending radius $\mathrm{r}=3 \mathrm{~mm}$ and a sheet thickness of $2 \mathrm{~mm}$. The distribution of the load relative to the neutral fiber (true strain $\varphi=0.0)$ and the maximum deformation $(\varphi=0.2)$ is significant (Fig. 1).

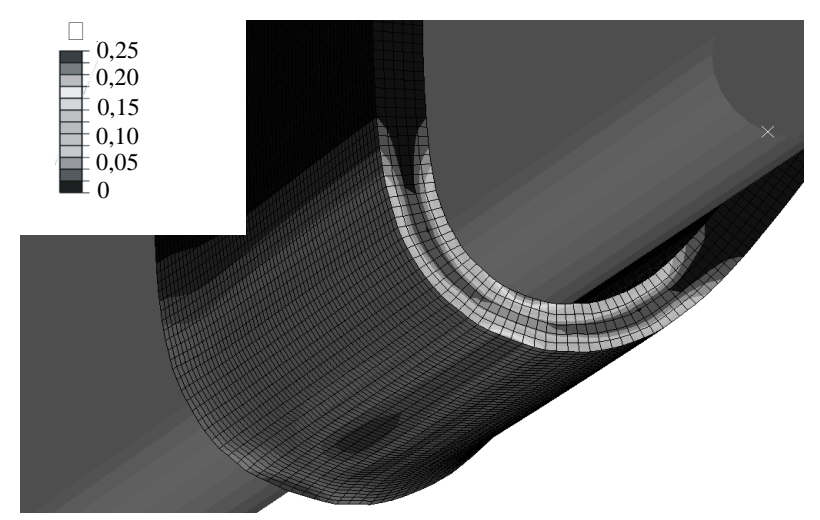

Fig. 1: True strain with a $3 \mathrm{~mm}$ bending radius (cut through sheet) 
The simulated results were verified after bending experiments by using the optical measurement system ARGUS, GOM. These show a very good correspondence between simulation and measurement. Fig. 2 shows the strain deviation of DP-W 600 for a bending angle $\alpha=32^{\circ}$. This angle corresponds to a true strain $\varphi=0.1$. The relation between true strain and strain is given in Eq. 1

$$
\varphi=\ln (1+\varepsilon)
$$

From Eq. 1 a true strain of $\varphi=0.11$ is calculated.

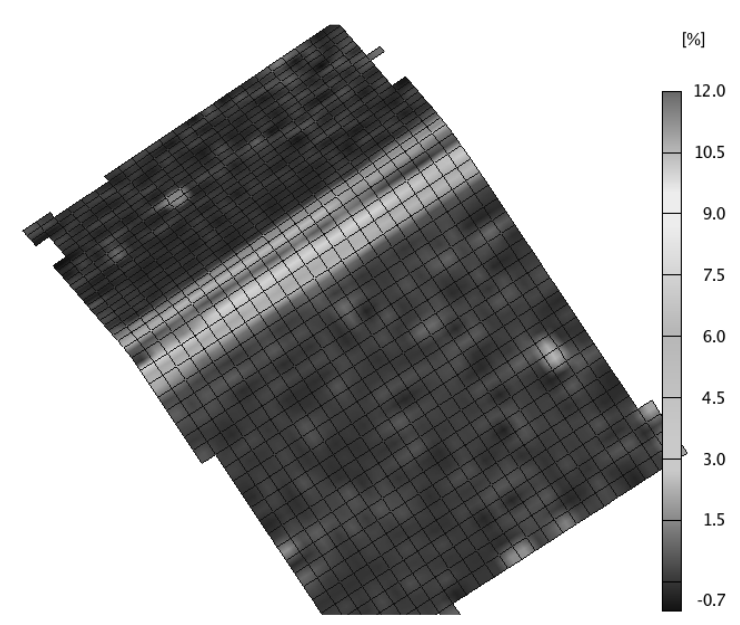

Fig. 2: Strain distribution over surface of DP-W 600

To determine the parameter field for characterizing work hardening $(\mathrm{WH})$ and aging, samples were prepared with a bending radius $r=3 \mathrm{~mm}$ and three bending angles $\alpha=10^{\circ}, 18^{\circ}$ and $32^{\circ}$. These angles correspond to the true strains $\varphi=0.02,0.05,0.10$.

Evaluation and discussion of the results for the local bending deformation. Following conditioning for raster-painting, the bent samples subsequently underwent a thermal treatment in a furnace at $170{ }^{\circ} \mathrm{C}(443 \mathrm{~K})$ for $20 \mathrm{~min}$. before being cooled down to room temperature (RT). A second hardness measurement (HV0.5) was performed to determine the influence of this thermal treatment. After bending, the hardness showed an increase due to WH. After the heat treatment procedure, a distinct increase in hardness could be observed.

As an example, Fig. 3 shows the increase in hardness of DP-W 600 under these conditions for $\varphi=0.1$. Hardness in the basic sheet was $225 \pm 2$ HV0.5, increasing to $245 \pm 3$ HV0.5 after bending and to $257 \pm 4 \mathrm{HV} 0.5$ after $\mathrm{BH}$ heat treatment. From the hardness difference, a WH of $20 \mathrm{HV} 0.5$ and a BH effect of $12 \mathrm{HV} 0.5$ resulted. The dependence of the mechanical properties on different deformations and treating conditions had been previously investigated [31]. 


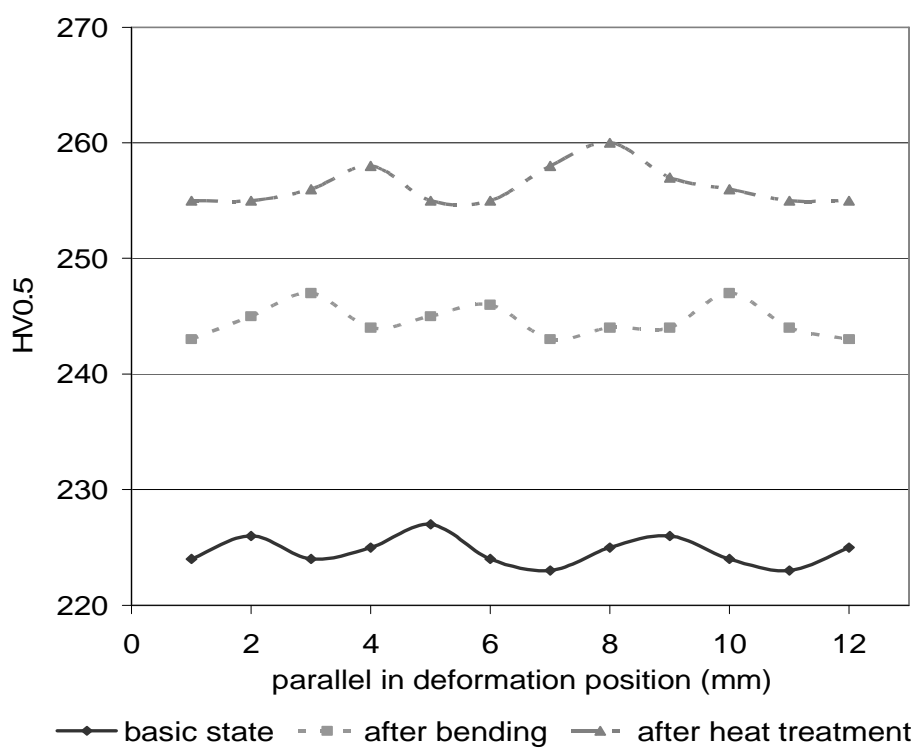

Fig. 3: Hardness distribution of DP-W 600, sample was bent to $\varphi=0.1$ and subsequently aged at $170{ }^{\circ} \mathrm{C}$ for $20 \mathrm{~min}$.

Fig. 4 shows the hardness distribution after bending with $\varphi=0.1$ and after aging treatment for $\mathrm{CP}-\mathrm{W} 1000$. Before bending, the material had a basic hardness of $273 \pm 3 \mathrm{HV} 0.5$. After bending, the hardness increased to $305 \pm 3 \mathrm{HV} 0.5$. After final heat treatment, the hardness value reached a level of $316 \pm 2 \mathrm{HV} 0.5$. From the hardness difference, a WH of $32 \mathrm{HVO} .5$ and a $\mathrm{BH}$ effect of $11 \mathrm{HV} 0.5$ can be calculated.

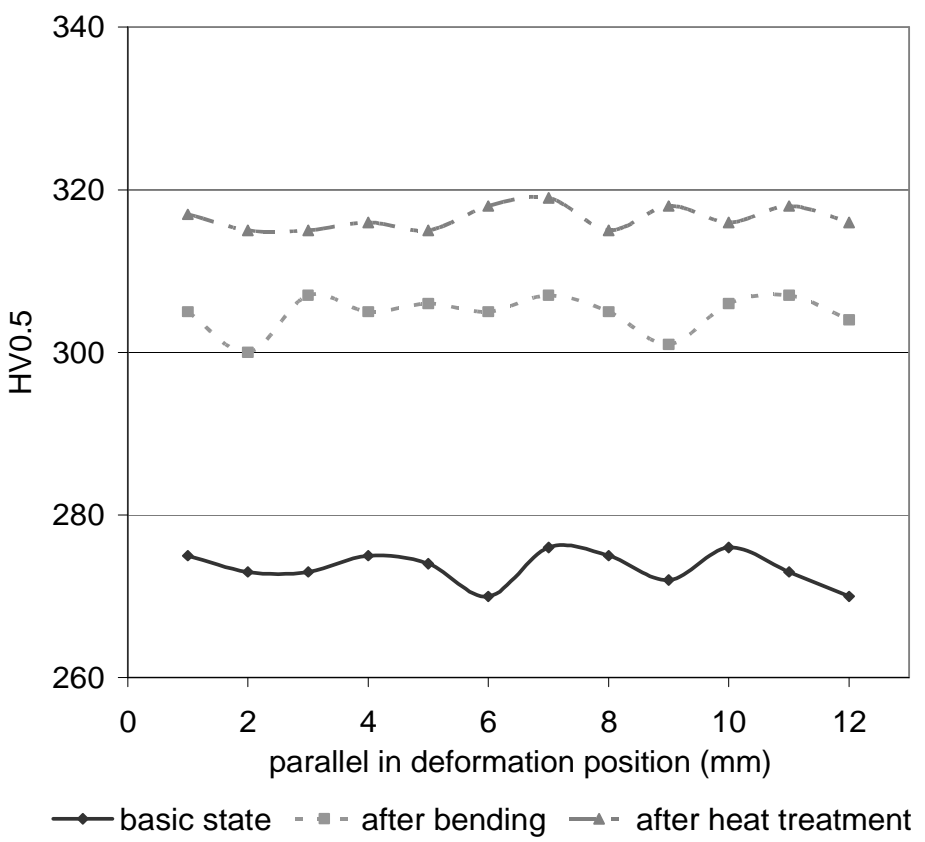

Fig. 4: Hardness distribution of CP-W 1000, sample was bent to $\varphi=0.1$ and subsequently aged at $170{ }^{\circ} \mathrm{C}$ for $20 \mathrm{~min}$.

In addition to this, the hardness HV0.2 had been determined over sheet thickness to calculate the difference and influence on the hardness between tensile and compressive regions, corresponding to the measuring examples in Fig. 5. 


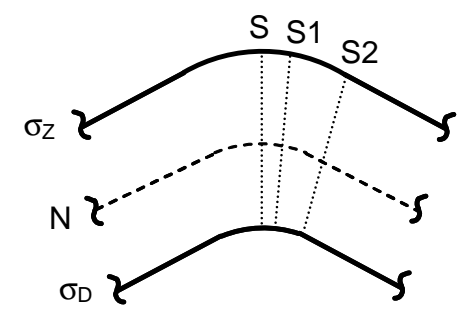

Fig. 5: Hardness measurement of DP-W 600 over sheet thickness at point $S$ in the middle of the bent sheet, S1 $2 \mathrm{~mm}$ and S2 $5 \mathrm{~mm}$ from S, N represents the neutral line

Fig. 6 shows the hardness distribution for DP-W 600 steel with a bending angle of $\alpha=32^{\circ}(\varphi=0.1)$ at point $\mathrm{S}$ and at distances of $2 \mathrm{~mm}(\mathrm{~S} 1)$ and $5 \mathrm{~mm}(\mathrm{~S} 2)$ from point $\mathrm{S}$ over the $1.95 \mathrm{~mm}$ sheet thickness. While the hardness in position $S$ indicates the highest values, the lowest hardness values were measured at the position S2. For all positions, the highest hardness values were obtained in the tensile stress and compressive stress regions, although the tensile stress region indicates higher hardness values than the deformation region. The neutral stress regions exhibited the lowest hardness values; even lower than the basic state.

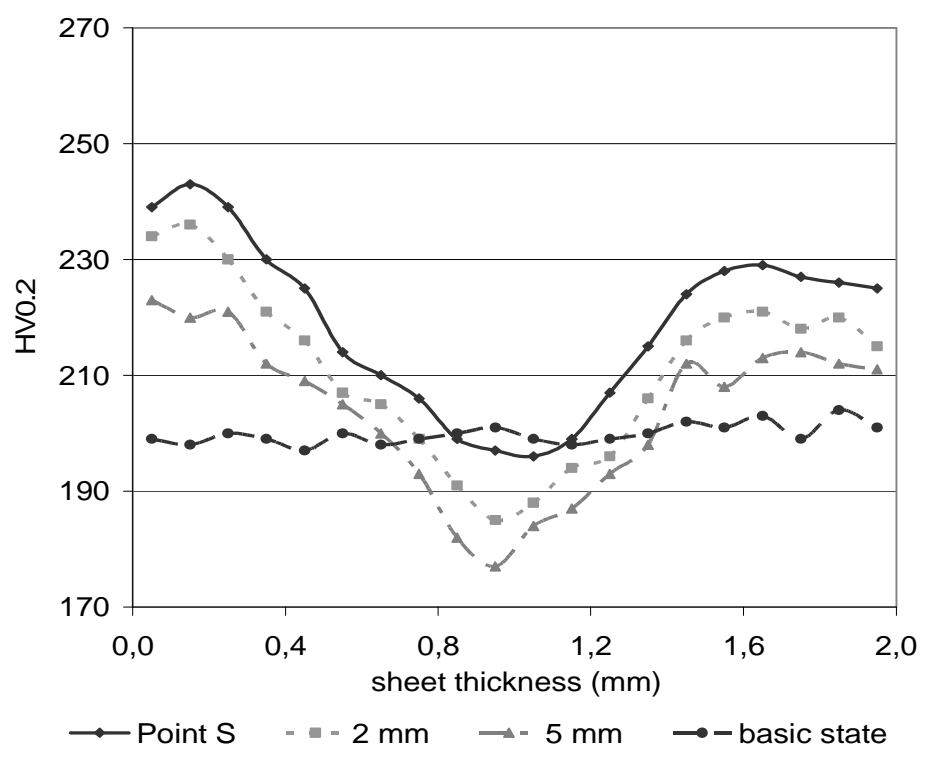

Fig. 6: Hardness distribution of DP-W 600 over sheet thickness after bending, $\varphi=0.1$

The hardness measurements were conducted at the same position on the bent samples after an aging treatment. Fig. 7 shows the hardness distribution of DP-W 600 over sheet thickness, bent with a deformation of $\varphi=0.1$, after an aging treatment at $170{ }^{\circ} \mathrm{C}$ for $20 \mathrm{~min}$. In principle, the same hardness behavior could be seen after aging as that before the aging treatment. An increase in hardness values was found for all three loading conditions after the aging treatment at all the positions. 


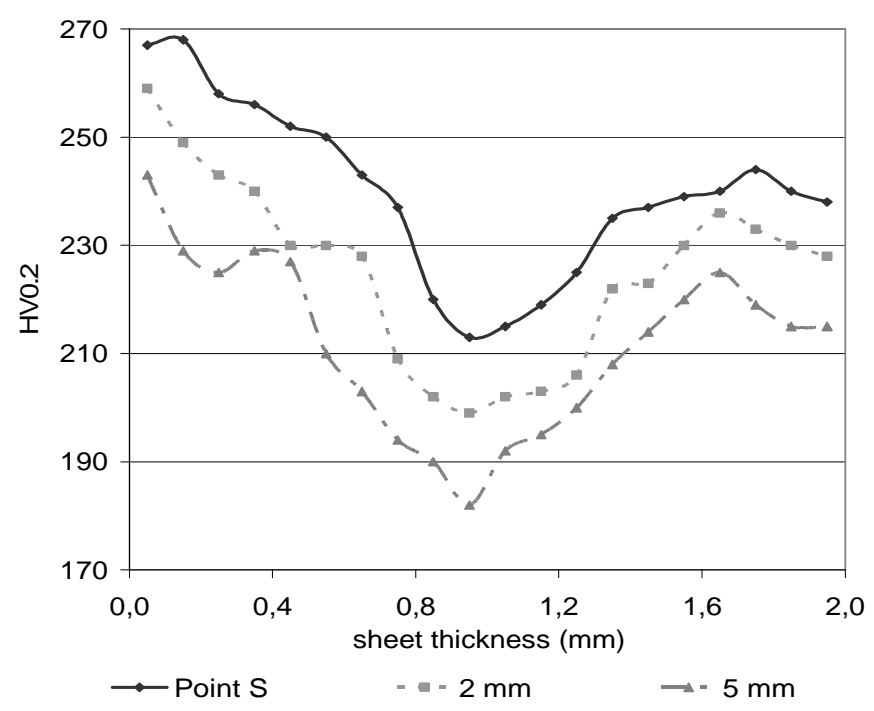

Fig. 7: Hardness distribution of DP-W 600 over sheet thickness after the aging treatment , $\varphi=0.1$, $\mathrm{T}=170{ }^{\circ} \mathrm{C}$ and $\mathrm{t}=20 \mathrm{~min}$.

Local deformation by embossing. For this study, an embossing machine was already available to induce local strengthening into a metal sheet. This embossing machine (Fig. 8) provides the option of rolling straight or curved contours into the sheets (Fig. 9). The aim is to affect the behavior of structural elements or components within a definite size and shape by means of a local deformation (increase in dislocation density).
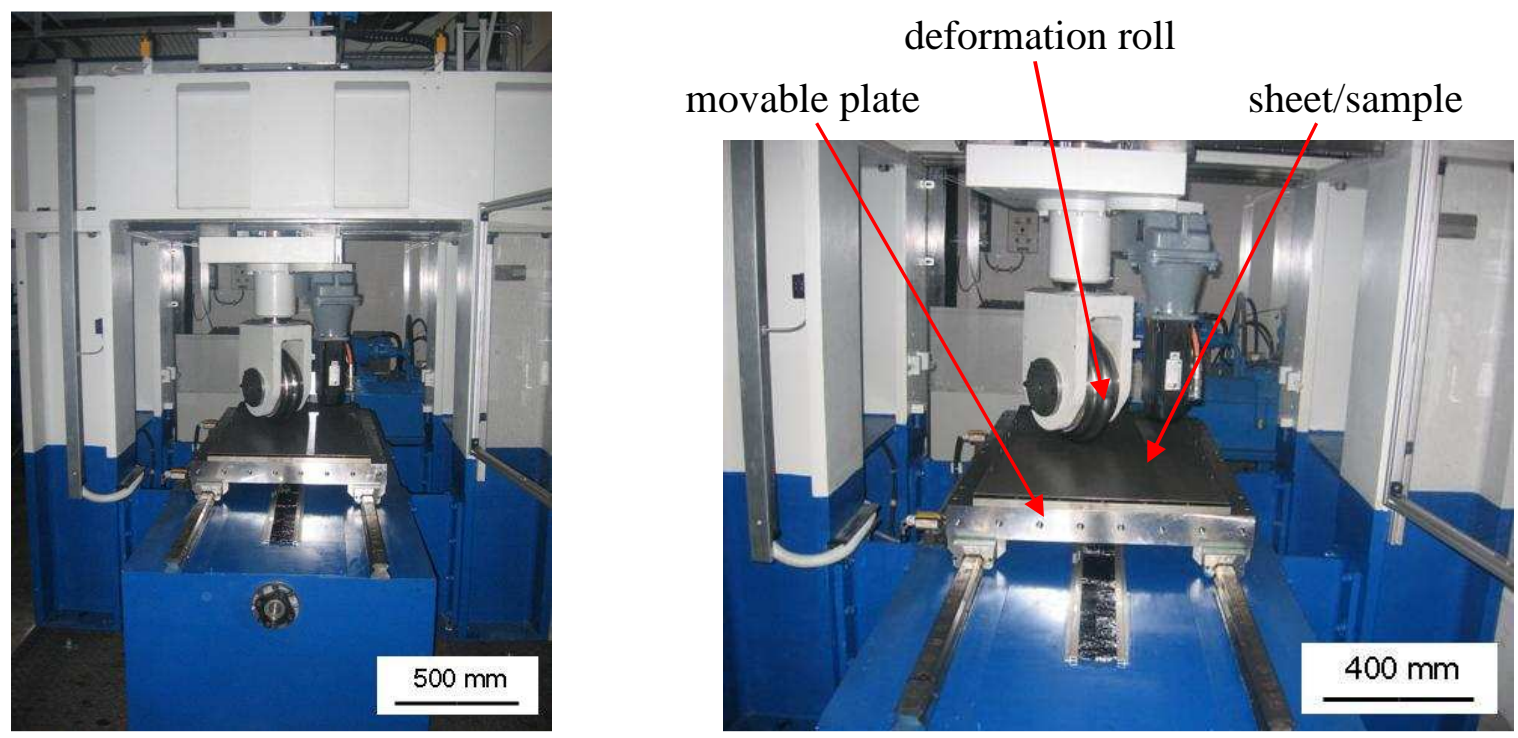

Fig. 8: Embossing machine to locally deform sheets
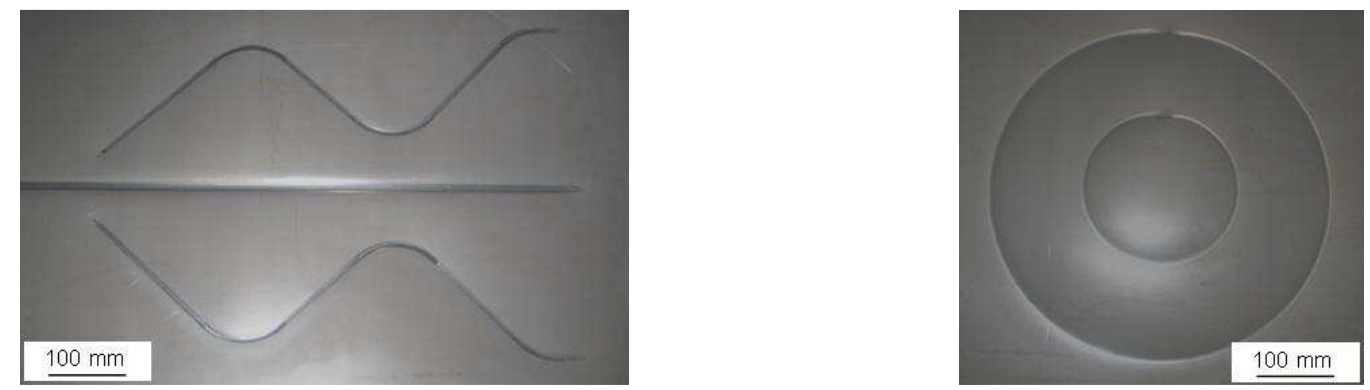

Fig. 9: Inducing different contours using the embossing machine 
The sheet is clamped onto a movable plate in the x-direction. Over the plate is an arm, which transmits the hydraulic forces to a deformation roll. The embossing depth, the hydraulic force as well as the movement of the arm are computer-controlled. Table 3 illustrates the specification of the machine.

Table 3: Specific data of embossing machine

\begin{tabular}{lll}
\hline Data & & Number \\
\hline Max. sheet geometry & {$[\mathrm{mm}]$} & $1100 \times 600$ \\
Min. / Max. force & {$[\mathrm{kN}]$} & $1-300$ \\
Max. deformation speed & {$[\mathrm{mm} / \mathrm{s}]$} & 18 \\
Diameter of deformation roll $[\mathrm{mm}]$ & 350 \\
\hline
\end{tabular}

The production of a definite deformation is made possible by setting the embossing depth. Table 4 shows the specified embossing depths as well as the corresponding true strains for the selected materials. The sheets were deformed locally with the specific deformations. The sheets were subsequently aged at different temperatures $\left(100^{\circ} \mathrm{C}, 170^{\circ} \mathrm{C}\right.$ and $\left.240{ }^{\circ} \mathrm{C}\right)$ for a holding time of $20 \mathrm{~min}$. The micro-hardness measurements as well as the tensile tests were carried out on the locally deformed samples before and after aging.

Table 4: The specified values of the embossing depths and the corresponding true strains for producing the local deformations in the sheets

\begin{tabular}{llllll}
\hline embossing depth & {$[\mathrm{mm}]$} & 0.05 & 0.35 & 0.50 & 1.00 \\
True strain $\varphi$ & {$[-]$} & 0.05 & 0.02 & 0.10 & 0.15 \\
\hline
\end{tabular}

Evaluation and discussion of results of local deformation by local embossing. Fig. 10 shows an example of the estimated hardness profiles as a function of different aging temperatures obtained for DP-W 600 with the embossing depth of $0.05 \mathrm{~mm}$. The hardness values were determined both in the locally deformed region as well as in the basic sheet. The figure shows an expected increase in hardness of about $20 \mathrm{HV} 0.1$ following local deformation. Heat treating at $100{ }^{\circ} \mathrm{C}$ produces no change in the hardness values compared to the initial state. At $170{ }^{\circ} \mathrm{C}$, an increase in hardness of about $15 \mathrm{HV} 0.1$ in the locally deformed region was obtained. In addition to this, there was also a hardness increase in the basic metal at this temperature. A further increase in the aging temperature to $240{ }^{\circ} \mathrm{C}$ shows no change in the hardness value compared to that at $170{ }^{\circ} \mathrm{C}$.

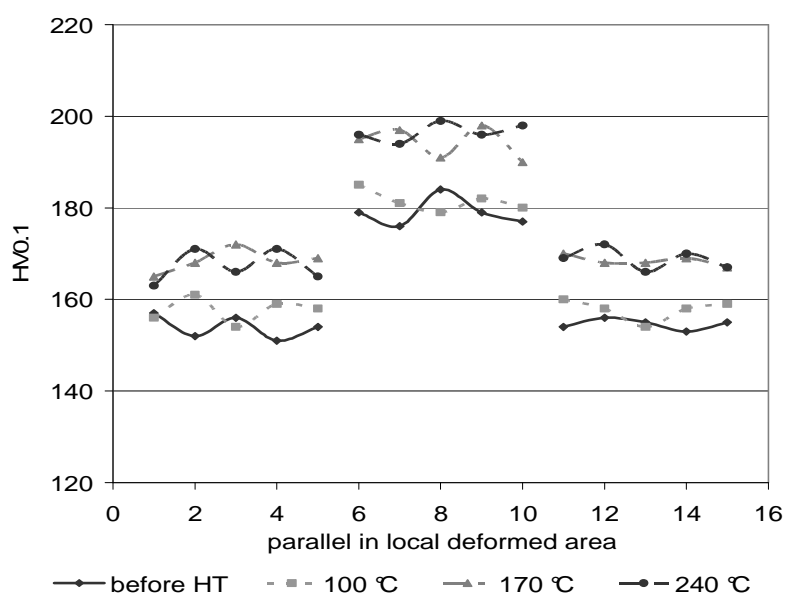

Fig. 10: Hardness values of DP-W 600 in the local deformed region and in the base sheet, at an embossing depth of $0.05 \mathrm{~mm}$ using a deformation speed of $18 \mathrm{~mm} / \mathrm{s}$

Fig. 11 presents the mechanical behavior of DP-steels with respect to the pre-strain $(\varphi)$ and the aging temperature. The yield and tensile strength values rose steeply as the pre-strain increased to $\varphi=0.1$, while the total elongation decreased with increasing pre-strain. This observation is valid for 
all aging conditions, without aging and with aging at different temperatures. The influence of the aging temperature can, in general, be described as to rapidly increase the strength values at high aging temperatures $\left(170{ }^{\circ} \mathrm{C}\right.$ and $\left.240{ }^{\circ} \mathrm{C}\right)$, while at lower aging temperature $\left(100{ }^{\circ} \mathrm{C}\right)$ no significant influence can be observed. Total elongation decreased with increasing the aging temperature.

(a)

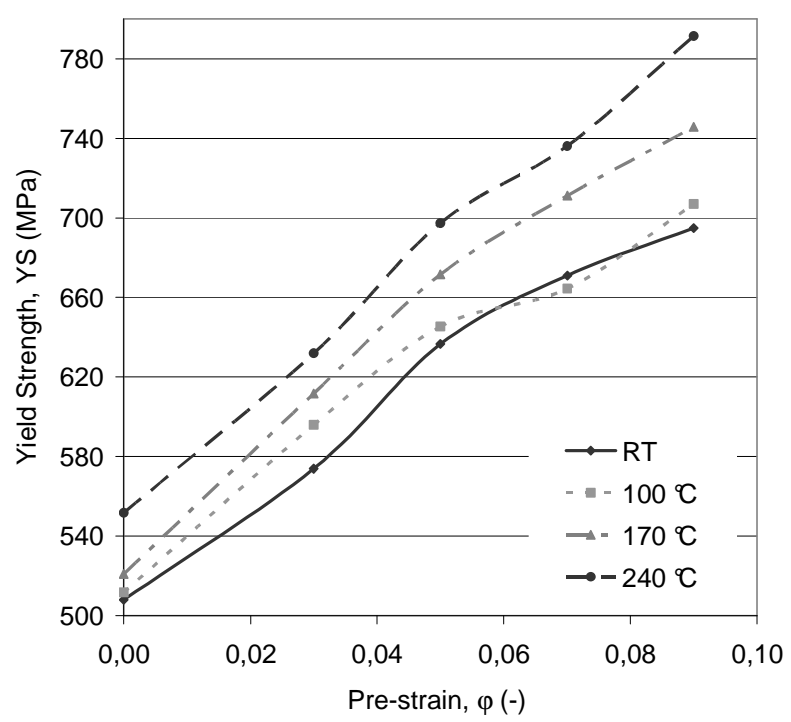

(b)

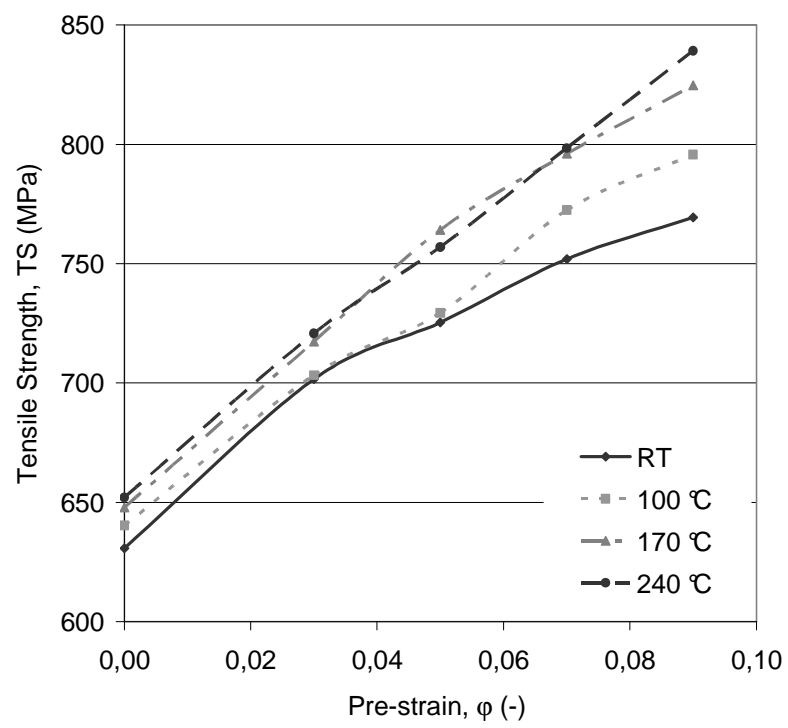

(c)

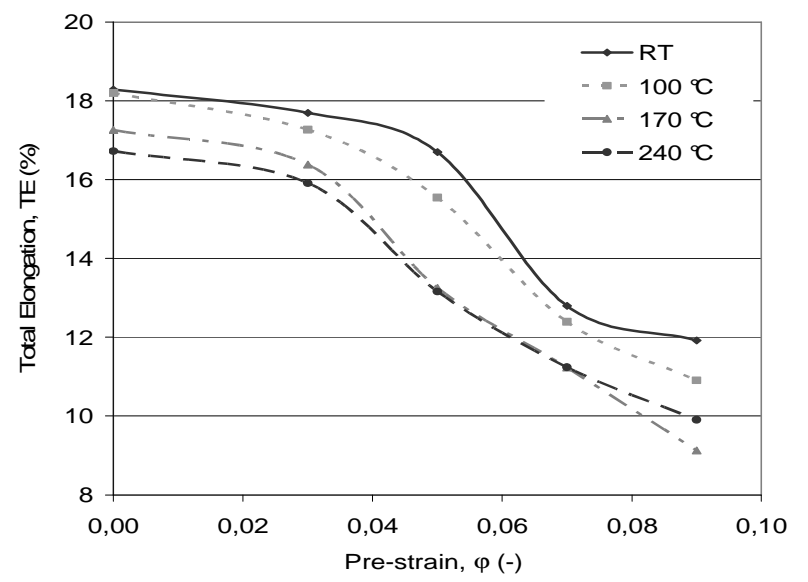

Fig. 11: Mechanical properties of DP-steel after local embossing to different degrees of pre-strain $(\varphi)$ and global aging treatment at different temperatures. The holding time of the aging treatment was set to 20 min.

\section{Local heat treatment}

After preliminary tests for heat-induced graduated strengthening by the aging effect, the next step is to partially and progressively strengthen a homogenous cold-rolled-preformed sheet metal. This part of the investigation will examine the possibility of locally inducing the strengthening effect by means of a local thermal treatment in homogeneous preformed metal sheets. Two methods were investigated for producing local strengthening by thermal treatment: 1) laser beam, 2) electron beam.

These investigations serve to verify the transferability of the model studies to the processes and to develop an adapted process for inducing locally limited strengthening effects.

Local heat treatment by laser beam. Local laser heat treatment (LHT) is a key technology currently available for enhancing the effective use of materials and to achieve the desired properties of components used in the automotive industry for improving vehicle performance. LHT is a directed, energy beam assisted, surface engineering technique that allows the controlled heating, followed by self-quenching, of steel components which leads to a limited depth surface hardening (martensitic and bainite transformation) without affecting the surrounding bulk material [32-33]. 
The high power heat source produced by a laser beam is ideal for modifying the local properties. Laser heating produces local changes at the surface of the material whilst leaving the properties of the component's bulk material unaffected. Laser heat treatment applications can be principally divided into those relying on metallurgical changes in the surface of the bulk material i.e. transformation hardening, annealing, grain refining, aging and those involving chemical modifications [19, 34, 35].

Heating without melting, commonly know as heat treating, involves solid-state transformation, such that surface of the metal is not melted. The fraction of the beam power absorbed by the material is controlled by the absorptivity of the material surface. Both mechanical (hardness, abrasion resistance etc.) and chemical properties (corrosion resistance etc.) can often be greatly enhanced through the metallurgical reactions produced during these heating and cooling cycles [36].

For this investigation, laser-remote-welding equipment is made available at the Laser Zentrum Hannover within the cooperative framework of the SFB 675. A scanning head is moved by a standard industrial robot during this process. The scanning mirror actually aims the laser beam. This allows greater flexibility of action on large work areas. Work pieces can be handled with high mobility.

Before laser treatment, the samples had been homogeneously strengthened by cold rolling to three degrees of deformation ( $\varepsilon=2 \%, 5 \%$ and $10 \%$ of the initial dimensions). Heat treatment was conducted with different laser powers and different laser traversing speeds. The laser power varied between $0.6 \mathrm{~kW}$ and $2.8 \mathrm{~kW}$ with a traversing speed of $5.0 \mathrm{~m} / \mathrm{min}$. The laser traversing speed varied between 0.5 and $5 \mathrm{~m} / \mathrm{min}$ with a laser power of $0.6 \mathrm{~kW}$.

The surface temperature was measured in the laser spot by means of an opto-electronic pyrometer from the company Maurer $\mathrm{GmbH}$. Thus, a computerized device can quickly adjust the power of the laser according to a definite set point. Table 5 shows the measured temperatures on the surface of samples for each laser power variation. Fig. 12 illustrates the position of laser tracks on the samples prepared for tensile testing with "a": cold rolled to $\varepsilon=10 \%$, laser-treated with $2.2 \mathrm{~kW}$; "b": $\varepsilon=5 \%$, laser-treated with $1.8 \mathrm{~kW}$.

Table 5: Measured temperatures on the surface of samples, following LHT with varied laser powers and laser traversing speeds

\begin{tabular}{llllllllll}
\hline & \multicolumn{3}{l}{$\begin{array}{l}\text { Variation of laser power }(\mathrm{kW}), \\
\text { laser traversing speed }=5.0 \mathrm{~m} / \mathrm{min}\end{array}$} & \multicolumn{4}{c}{$\begin{array}{l}\text { Variation of laser traversing speed } \\
(\mathrm{m} / \mathrm{min}), \text { Laser power }=0.6 \mathrm{~kW}\end{array}$} \\
\cline { 2 - 9 } & 0.6 & 1.4 & 1.8 & 2.2 & 2.8 & 0.5 & 1.0 & 3.0 & 5.0 \\
\hline $\begin{array}{l}\text { Temperature on } \\
\text { the surface }\left({ }^{\circ} \mathrm{C}\right)\end{array}$ & 300 & 600 & 800 & 1000 & 1150 & 900 & 700 & 500 & 300 \\
\hline
\end{tabular}

The microstructures in the laser track zone (LTZ) and the heat affected zone (HAZ) were investigated using light optical microscopy (LOM), scanning electron microscopy (SEM) and transmission electron microscopy (TEM). Tensile tests were performed on the samples with the laser tracks in the tension direction using an Instron $250 \mathrm{kN}$ machine. For an initial overview of the expected effects, hardness measurements had been carried out by Omnimet MHT Buehler using a Vickers micro-indenter according to the standard DIN 50133.

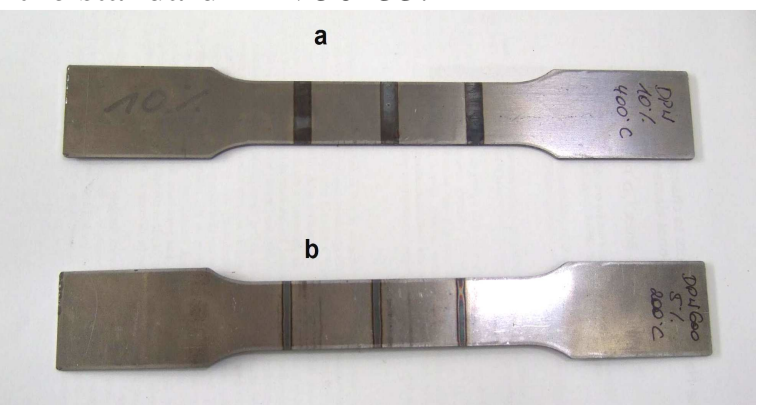

Fig. 12: Position of laser tracks for the tensile test samples (a) cold rolled to $\varepsilon=10 \%$, laser treated with $2.2 \mathrm{~kW}$, (b) $\varepsilon=5 \%$, laser treated with $1.8 \mathrm{~kW}$ 
Influence of LHT on the surface properties. In this part of the present investigation, an attempt has been made to enhance surface hardness of selected steels by LHT and correlate the microstructure and the surface mechanical properties with the LHT parameters. The laser-treated samples' surface were also subjected to detailed microstructural examinations by LOM, SEM and TEM. The results of the microstructural analyses will be discussed in detailed in this part.

Influence of laser power variation. Hardness measurements HV0.5 according to DIN 50133 were used to measure the changes in the mechanical properties and to determine the strengthening effect. Firstly, the results for the DP-W 600 are presented and the results for the CP-W 1000 are discussed in a further part of this paper.

Fig. 13 presents the hardness distribution for DP-W 600 following a deformation by cold rolling to $\varepsilon=5 \%$, which was laser treated with different laser powers. After cold rolling to a deformation of $\varepsilon=5 \%$, the measured hardness was $235 \mathrm{HV} 0.5$. For laser powers of $0.6 \mathrm{~kW}$ and $1.4 \mathrm{~kW}$, a minor increase in hardness was observed. For the laser power of $2.2 \mathrm{~kW}$, the highest hardness increase of 135 HV0.5 and, consequently, local strengthening was measured. For the laser power of $2.8 \mathrm{~kW}$, a significant hardness increase of $120 \mathrm{HV} 0.5$ could be observed, but not as high as for $2.2 \mathrm{~kW}$. The decreasing hardness distribution in the middle of laser treated region can be interpreted as an overheating effect. Similar hardness distributions could be measured for DP-steels with $\varepsilon=2 \%$ and $10 \%[6-7]$.

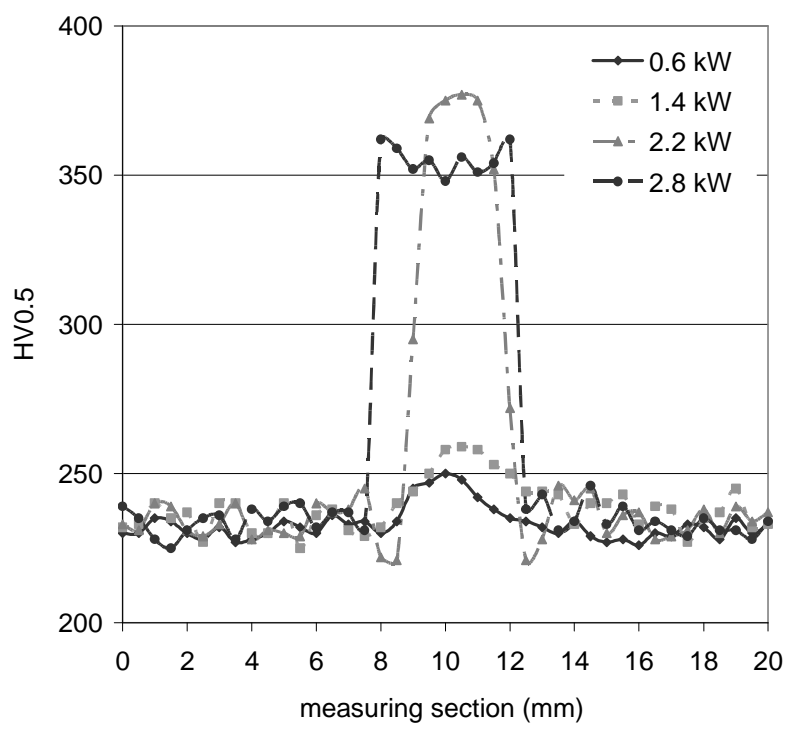

Fig. 13: Hardness distribution of DP-W 600 for different laser powers, samples were homogeneously cold rolled to $\varepsilon=5 \%$

The next results show the changes in the mechanical properties of CP-W 1000 after LHT. Fig. 14 shows the hardness distribution for CP-W 1000 after deformation by cold rolling to $\varepsilon=10 \%$ and treated with different laser powers. The measured hardness after cold rolling to $\varepsilon=10 \%$ was $284 \pm 9 \mathrm{HV} 0.5$. For the laser power of $0.6 \mathrm{~kW}$ no significant effect was observed. The highest hardness increase of $202 \mathrm{HV} 0.5$ and, consequently, local strengthening was measured for the laser power of $2.2 \mathrm{~kW}$. For the laser power of $2.8 \mathrm{~kW}$ a significant hardness increase of $169 \mathrm{HV} 0.5$ could be observed, but not as high as for $2.2 \mathrm{~kW}$. The decreasing hardness distribution in the middle of laser treated region can be also interpreted as an overheating effect. 


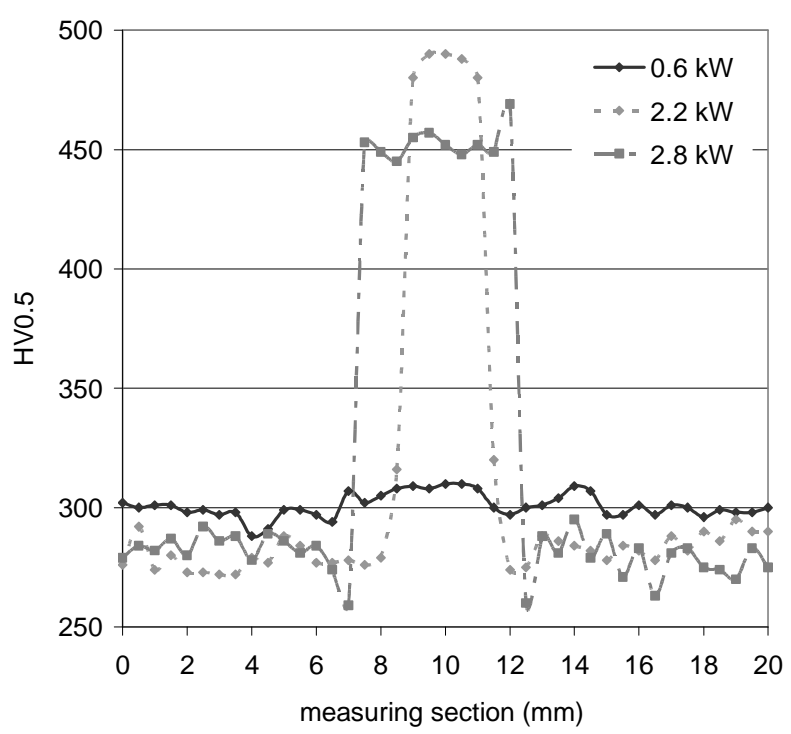

Fig. 14: Hardness of CP-W 1000 for different laser powers, samples were homogeneously cold rolled with $\varepsilon=10 \%$

To investigate the changes in the mechanical properties through local heat treatment, tensile tests were also carried out. The tensile tests were evaluated using the optical measuring system by ARAMIS, GOM, in order to determine the local strengthening.

Fig. 15 shows the strain the analysis for the tensile test on DP-W 600 which was deformed by cold rolling to $\varepsilon=5 \%$ and laser treated with a laser power of $2.8 \mathrm{~kW}$ and a laser traversing speed of $5 \mathrm{~m} / \mathrm{min}$. The intensive hardening in LTZ is significant (to see in Fig. 15). The partial heat treatment with the laser leads to a reduced deformation in the tensile test and to local reinforcement.
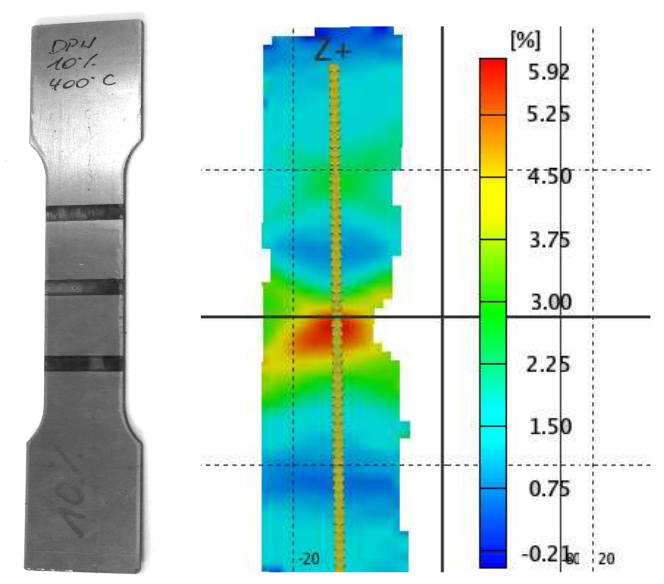

Fig. 15: Local strengthening by laser in DP-W 600, cold rolled to $\varepsilon=5 \%$, laser treated with a laser power of $2.8 \mathrm{~kW}$ and a laser traversing speed of $5 \mathrm{~m} / \mathrm{min}$

Fig. 16 shows the local strengthening and the reduced deformation in the laser treated regions in tensile tests. LHT leads to improved material properties measured in tensile tests. 


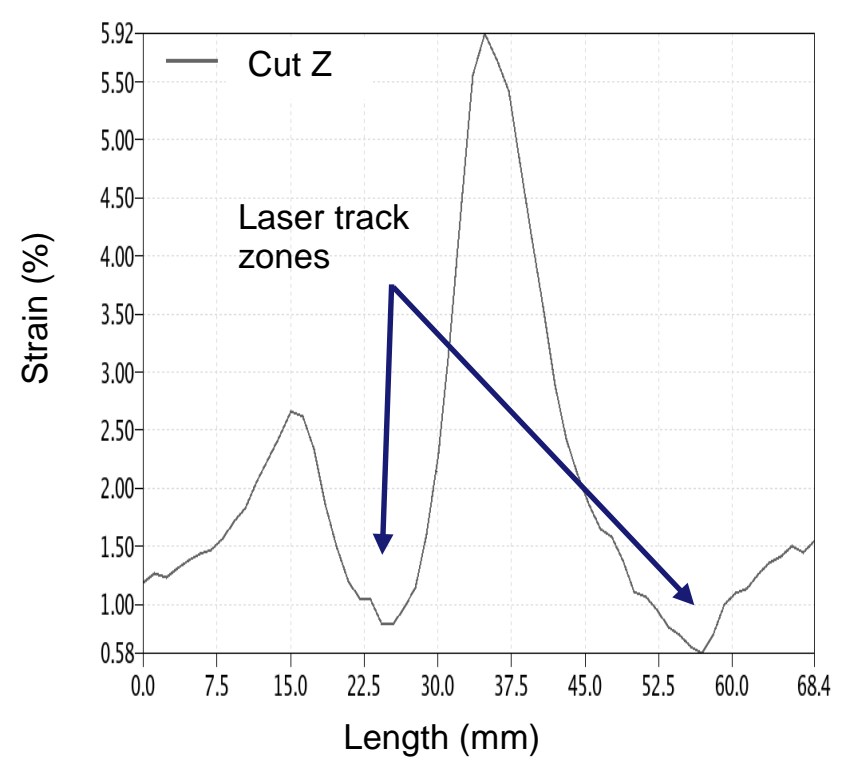

Fig. 16: Reduced deformation in strengthened region in DP-W 600, cold rolled to $\varepsilon=5 \%$, laser treated with a laser power of $2.8 \mathrm{~kW}$ and a laser traversing speed of $5 \mathrm{~m} / \mathrm{min}$

Microstructural investigation of the surfaces. In this part of the research, the influence of LHT on the surface's microstructure has been investigated. We present the results of DP-W 600 cold rolled to $\varepsilon=5 \%$ followed by LHT with three values of laser power. The laser power values were $0.6 \mathrm{~kW}, 1.8 \mathrm{~kW}$ and $2.2 \mathrm{~kW}$. The laser traverse speed was set to $5.0 \mathrm{~m} / \mathrm{min}$. Mechanical properties of the surface were investigated by microhardness measurements (HV0.3).

Examination of the microstructure by LOM. Fig. 17 (a)-(d) shows representative microstructures of the experimental samples cold rolled to $\varepsilon=5 \%$, the surface formed due to the different temperatures during by LHT was etched with LePera reagent.

All treated conditions show the presence of ferrite, bainite and martensite with different volume fractions. The volume fractions of the different phases and the corresponding microhardness values are listed in Table 6. The microhardness value was found to vary for the different conditions. The initial condition exhibited the lowest hardness value, whereas the highest value corresponded to the sample heat treated at $1000{ }^{\circ} \mathrm{C}$. In order to avoid repetition of sample conditions in this paper, the samples were designated names. These are shown in Table 6.

Table 6: Distribution of the phase volume fractions and the microhardness values

\begin{tabular}{clcc|cc|cc|cc}
\hline Name & Condition & \multicolumn{2}{c|}{ Ferrite [\%] } & \multicolumn{2}{c|}{ Bainite [\%] } & \multicolumn{2}{c|}{ Martensite [\%] } & \multicolumn{2}{c}{ HV0.3 } \\
\cline { 3 - 9 } & & LTZ & HAZ & \multicolumn{2}{c|}{ LTZ } & HAZ & LTZ & HAZ & \multicolumn{2}{c}{ LTZ } & HAZ \\
\hline S1 & Without LHT & $75 \pm 6$ & \multicolumn{2}{|c|}{$2 \pm 1$} & \multicolumn{2}{c|}{$20 \pm 4$} & \multicolumn{2}{c}{$221 \pm 5$} \\
S2 & $300^{\circ} \mathrm{C}$ & $73 \pm 5$ & $73 \pm 6$ & $2 \pm 1$ & $2 \pm 1$ & $22 \pm 4$ & $21 \pm 6$ & $233 \pm 5$ & $228 \pm 6$ \\
S3 & $800^{\circ} \mathrm{C}$ & $17 \pm 3$ & $36 \pm 6$ & $62 \pm 3$ & $51 \pm 6$ & $21 \pm 5$ & $13 \pm 2$ & $264 \pm 4$ & $266 \pm 4$ \\
S4 & $1000{ }^{\circ} \mathrm{C}$ & $5 \pm 2$ & $37 \pm 4$ & $55 \pm 6$ & $38 \pm 3$ & $40 \pm 3$ & $25 \pm 4$ & $296 \pm 6$ & $258 \pm 6$ \\
\hline
\end{tabular}

The microstructure of $\mathrm{S} 1$ consisted of $\sim 20 \pm 4 \%$ of globular martensite embedded in a ferrite matrix phase (Fig. 17 (a)). Retained austenite grains $(<1 \mu \mathrm{m})$ are observed partially inside the ferrite grains. The microstructure of S2 is similar to that of S1, as can be seen in Fig. 17 (b), however, here the hardness is higher than for S1. This can be attributed to the BH effect. After LHT at $800{ }^{\circ} \mathrm{C}$ (Fig. 17 (c)) and $1000{ }^{\circ} \mathrm{C}$ (Fig. 17 (d)) the fraction of bainite and martensite continuously increased. Table 6 shows that a significantly large volume fraction of the bainitic phase is present after using the LHT at $800{ }^{\circ} \mathrm{C}$ and $1000{ }^{\circ} \mathrm{C}$. During the LHT, with temperatures from $300{ }^{\circ} \mathrm{C}$ to $800{ }^{\circ} \mathrm{C}$, the 
amount of bainite formed in the final microstructure also increases to 50-60\%. Simultaneously, the volume fraction of polygonal ferrite decreases. This leads to an increase in hardness. Thus, the higher the heat treatment temperature, a larger amount of austenite is available for the shear mode phase transformation which leads to a higher amount of bainite and martensite [37-38]. The fraction of bainite and martensite was increased significantly, particularly by LHT at $1000{ }^{\circ} \mathrm{C}$ (Fig. 17 (d)).

(a)

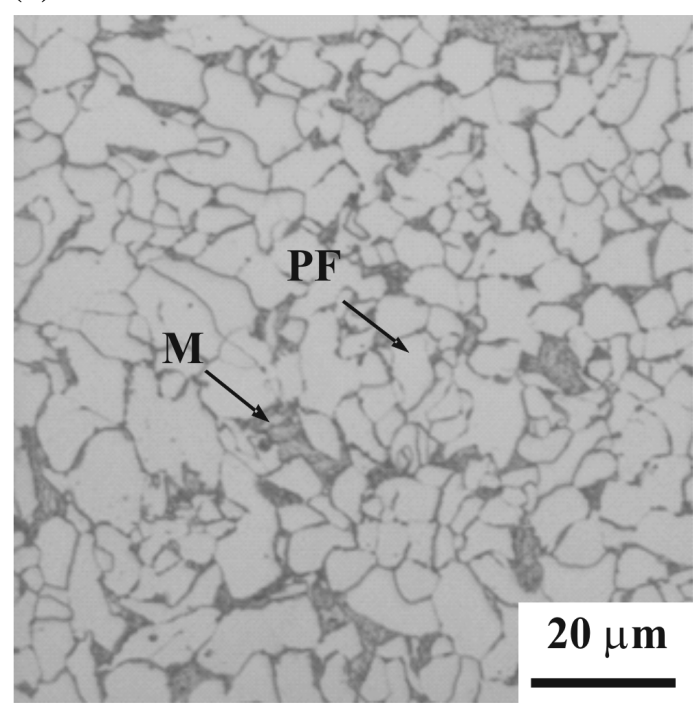

(b)

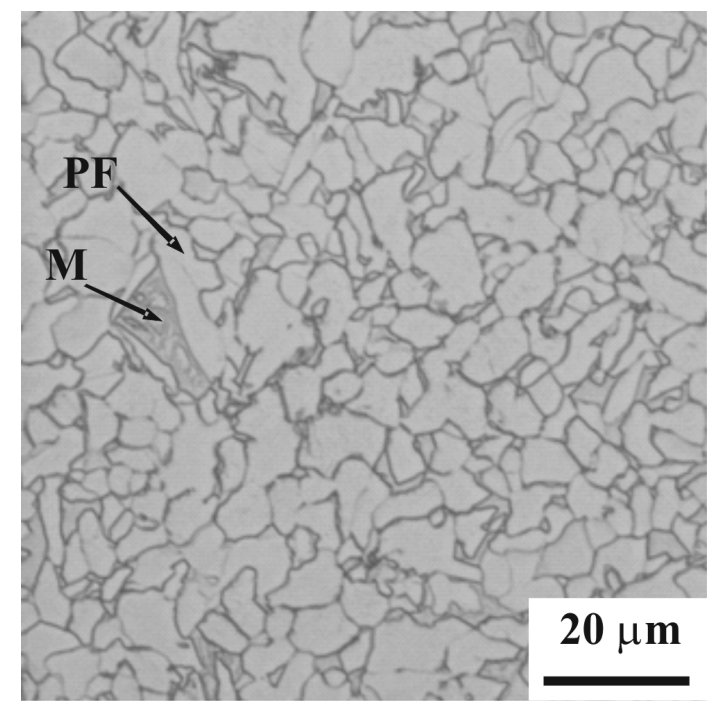

(c)

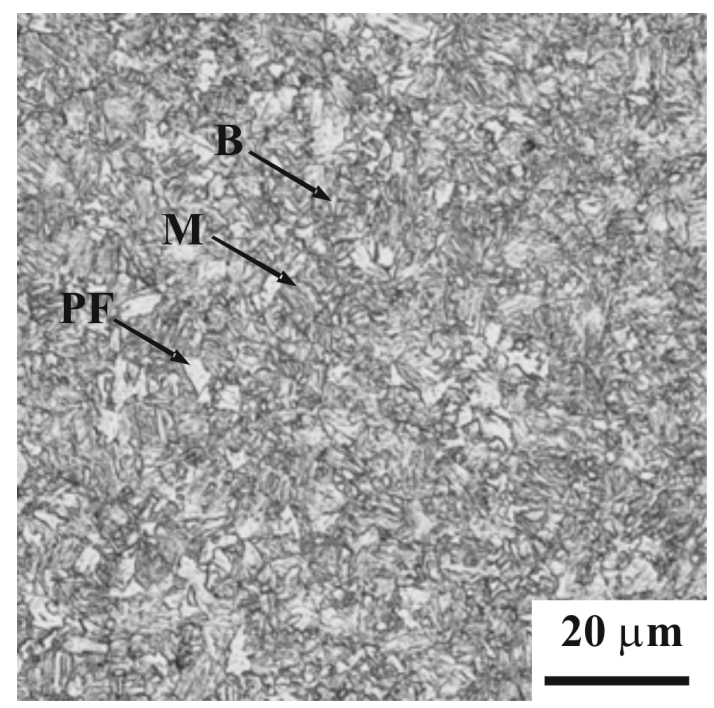

(d)

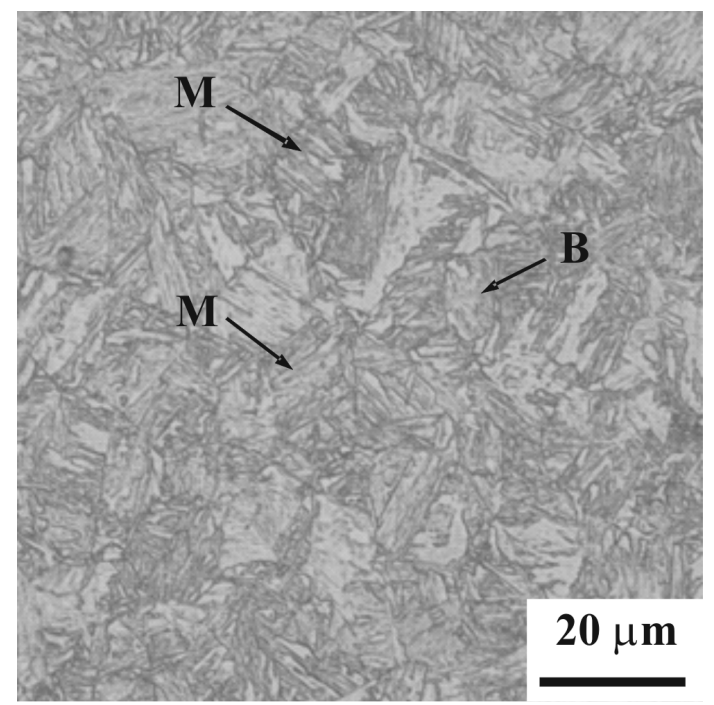

Fig. 17: Microstructure of DP-steel after cold rolling to $\varepsilon=5 \%$ in LTZ, LOM images: (a) steel S1, (b) steel S2, (c) steel S3 and (d) steel S4. PF: polygonal ferrite, M: martensite, B: bainite

Fig. 18 (a)-(d) show the final microstructures of the HAZ for the various heat treatment parameters. A significant difference in the phase distribution in the HAZ can be discerned. Fig. 18 (a) represents the microstructure of S1, consisting of polygonal ferrite and martensite. The structure of the HAZ 
for S2 consists of polygonal ferrite and martensite (Fig. 18 (b)). It is similar to microstructure without LHT. For S3 a large volume fraction of bainite and/or martensite is found in the HAZ Fig. 18 (c). Such a dark phase can also be observed at the boundaries between two neighbouring ferrite grains. It is difficult to distinguish between martensite and bainite phases by LOM, therefore TEM analyses were also carried out.

The influence of the increased heat treatment temperature on the microstructure in HAZ is significant. Fig. 18 (d) depicts a continuous increase in bainite and martensite volume fractions for S4. Higher intercritical annealing regimes followed by accelerated cooling leads to the largest bainite and martensite volume fractions (Fig. 18 (d)) [39]. The microhardness of S4 in the HAZ is higher than that in S3 because some substrates were transformed into austenite at high temperature and then transformed into martensite or bainite by locally accelerated cooling [40].

(a)

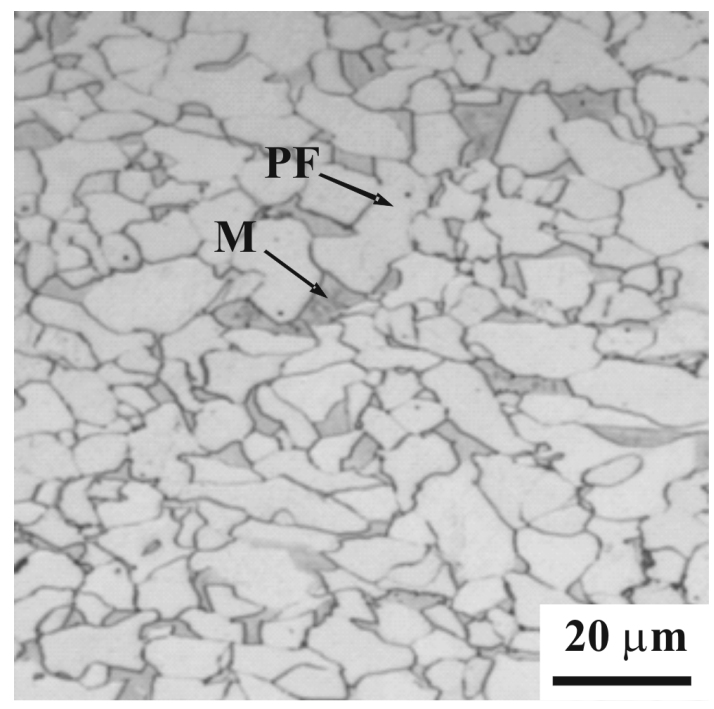

(b)

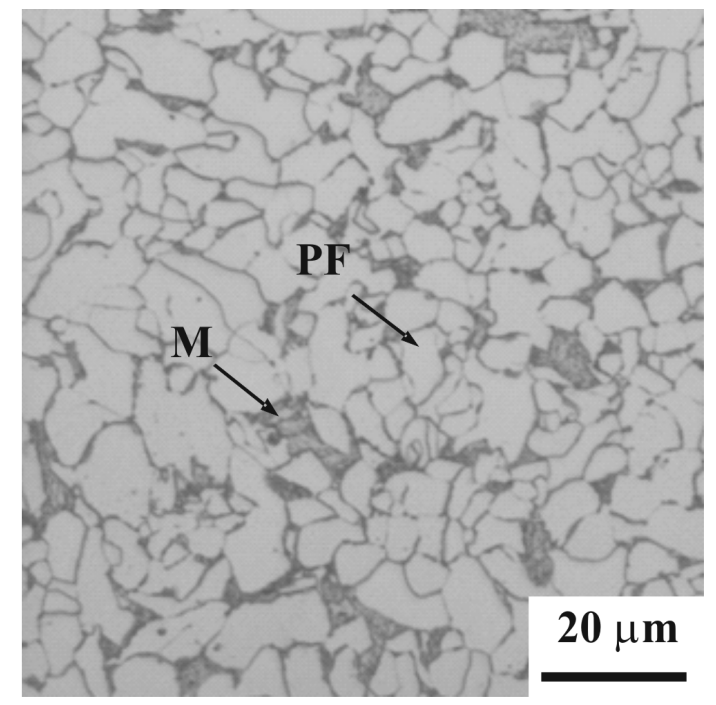

(c)

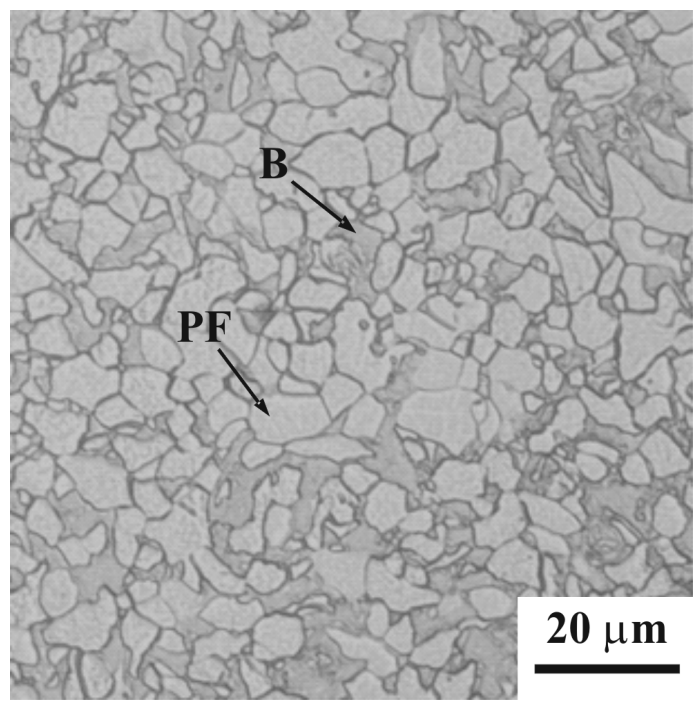

(d)

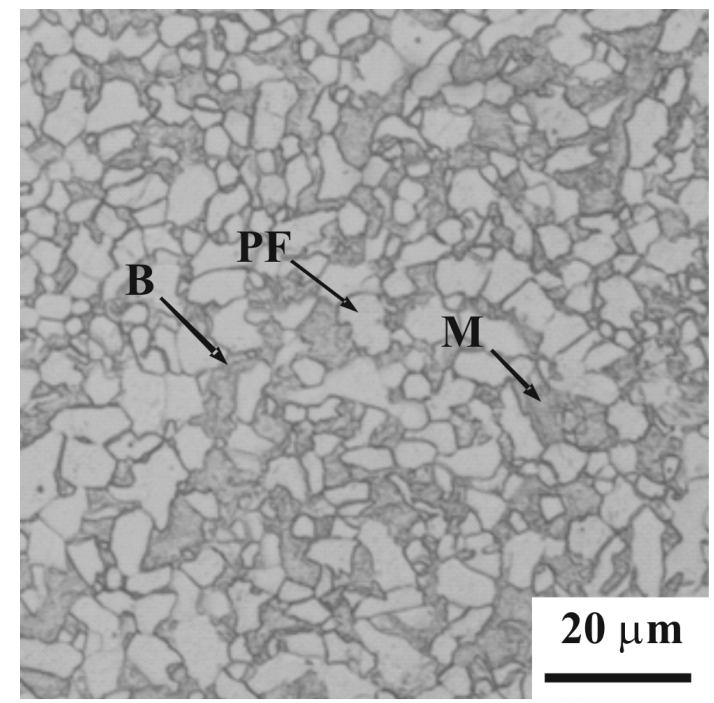

Fig. 18: Microstructure of DP-steel after cold rolling to $\varepsilon=5 \%$ in the HAZ, LOM images: (a) steel S1, (b) steel S2, (c) steel S3 and (d) steel S4. PF: polygonal ferrite, M: martensite, B: bainite 
Examination of the microstructure by TEM. More detailed observations of the microstructural evolution in the LTZ with difference heat treatment temperatures were obtained using TEM. TEM specimens were prepared from $3 \mathrm{~mm}$ disks which were ground and polished to a thickness smaller than $0.1 \mathrm{~mm}$ to reduce the magnetic mass of the specimens [41]. These disks were subsequently electropolished using a standard double-jet procedure (TunelPol-5, Struers). An electrolyte consisting of $5 \%$ perchloric acid $\left(\mathrm{HCLO}_{4}\right)$ in methanol $\left(\mathrm{CH}_{3} \mathrm{OH}\right)$ was used. Electropolishing was performed at $-40{ }^{\circ} \mathrm{C}$ at a voltage of $30 \mathrm{~V}$.

Fig. 19 provides an overview of the sample S1. The bright grains can be clearly identified as the ferrite phase, while the dark ones are attributed to martensite Fig. 19(a). The dominant martensite morphology of low carbon steel grades like DP steels is of lath type, which is characterised by a high dislocation density [42-43], leading to a strong contrast in the TEM micrograph as can be seen in Fig. 19(b). The most affected areas of ferrite were in the vicinity of martensite crystals (Fig. 19(b)). However, the dislocation cells occasionally formed with complex dislocation tangles into cell walls and free dislocations inside the cells (Fig. 19(c)). Dislocations inside the ferrite are distributed irregularly while in the interior of the grains a relatively low dislocation density is usually observed. At the ferrite/martensite interfaces, a significantly higher dislocation density is present (Fig. 19(d)), due to the volumetric expansion from austenite to martensite by accelerated cooling after annealing [44-45]. Fig. 19(e) reveals the presence of a small amount of bainite in between polygonal ferrite phases. Retained austenitic islands could also be observed. It should be noted that retained austenitic islands, which are located in the vicinity or between martensitic islands, exhibit twinning (Fig. 19(f)). Diffraction patterns from the twinned austenite show that the zone axis is along [110] direction, the twin plane is (111) and twin zone is [110] (Fig. 19(g)).

(a)

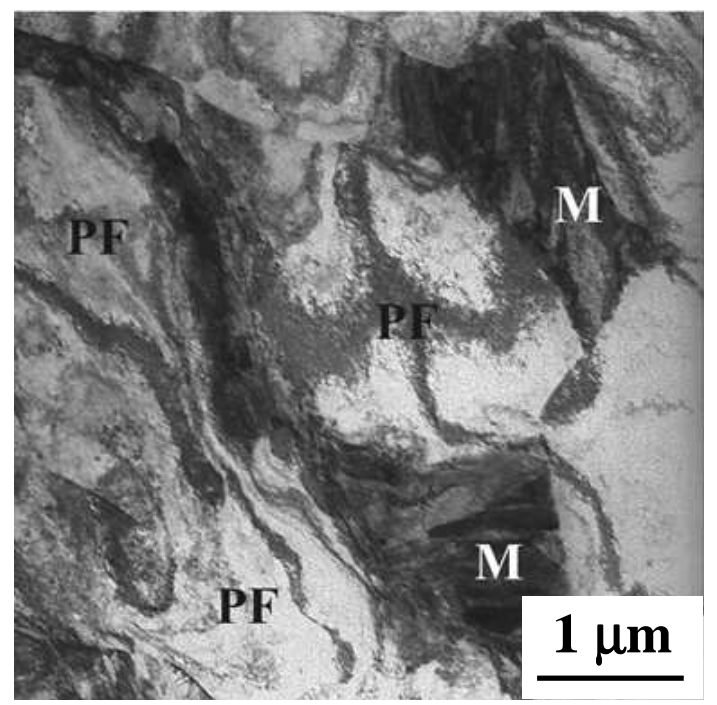

(b)

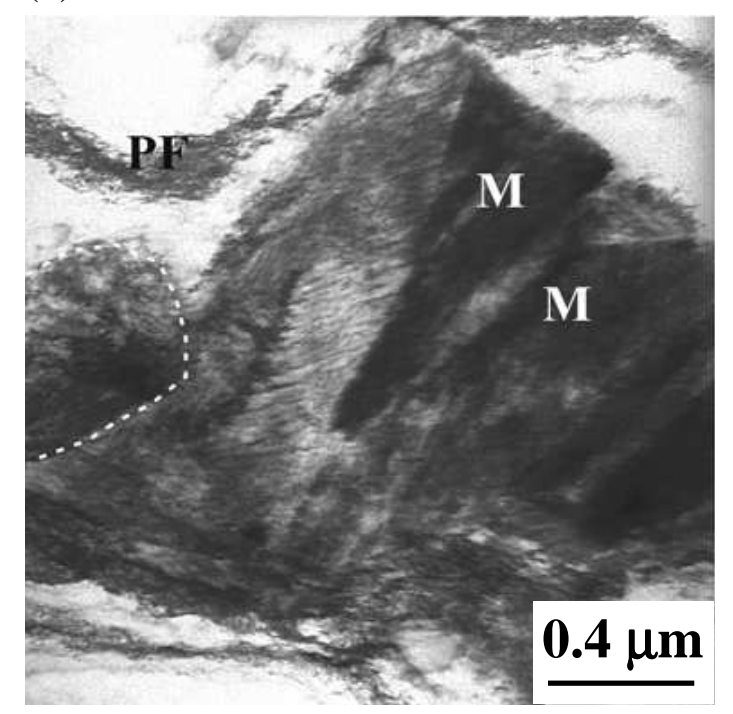


(c)

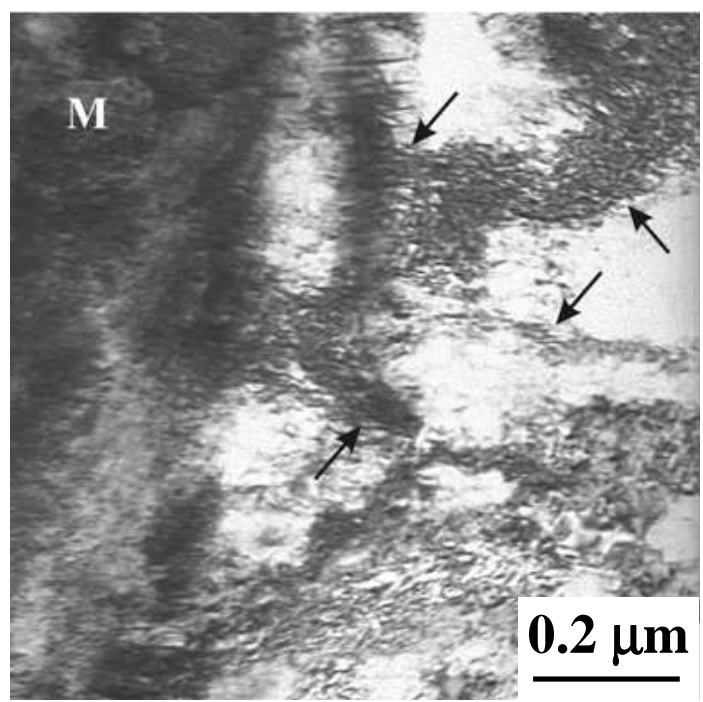

(e)

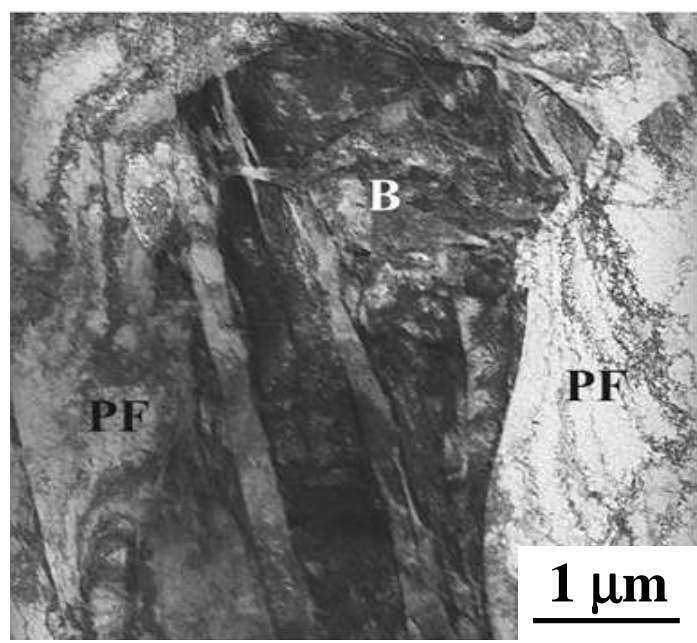

(d)

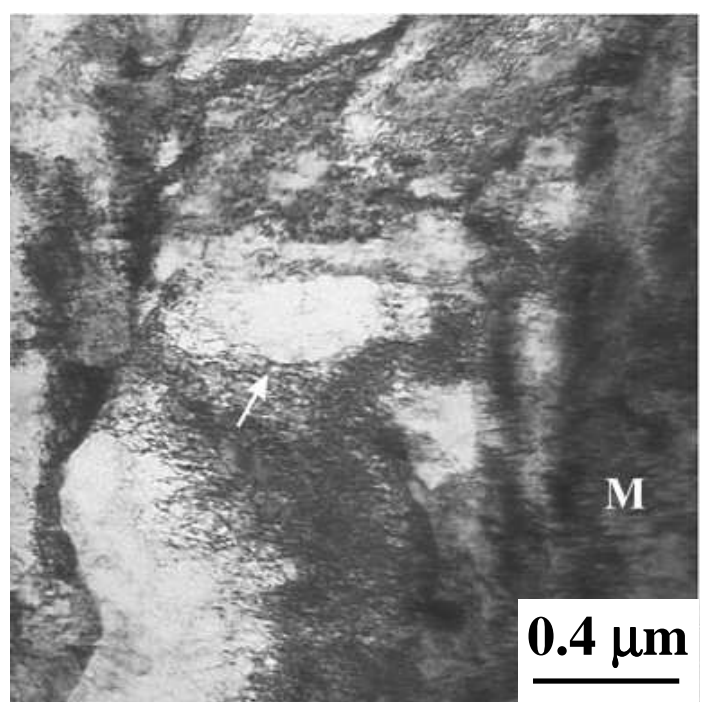

(f)

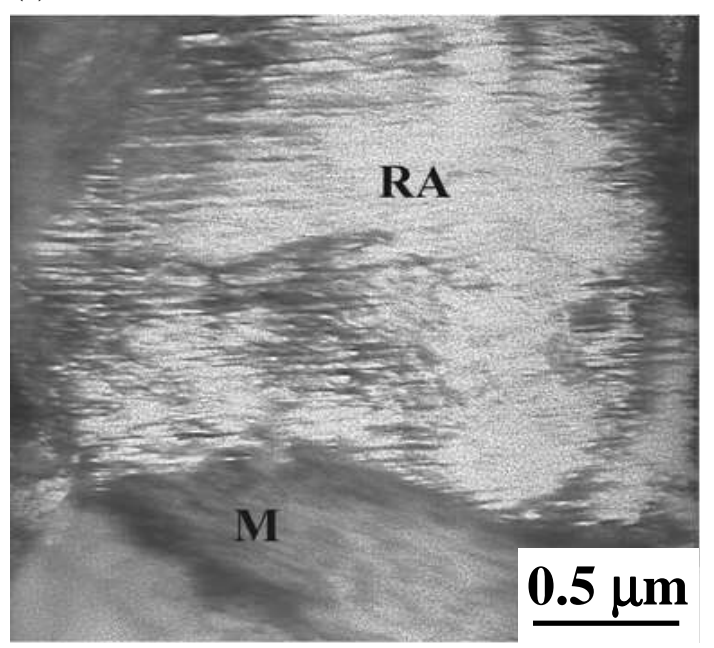

(g)

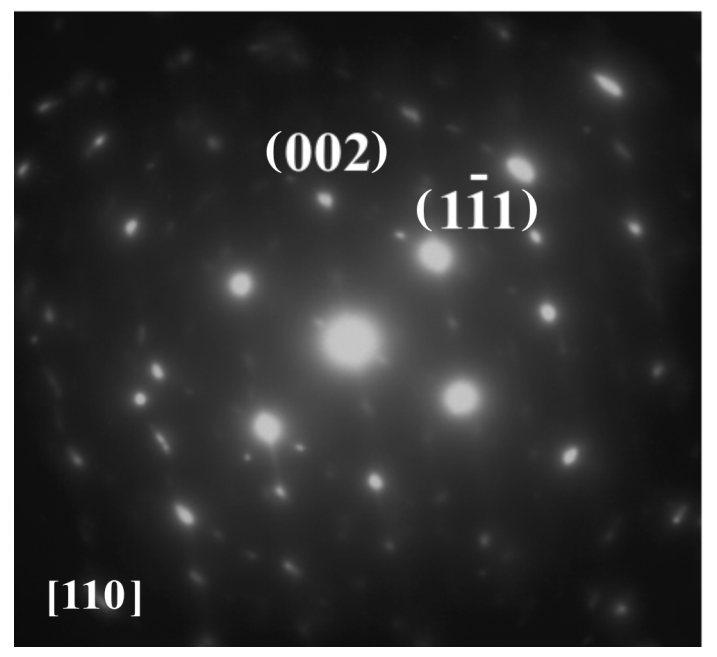

Fig. 19: TEM micrographs of S1: (a) general view, (b) martensite in polygonal ferrite and a local increase in dislocation density (dashed line) near the ferrite/martensite interface, (c, d) dislocation substructure formed in ferrite, (e) bainite in polygonal ferrite, (f) bright field TEM images of twinned austenite, (g) diffraction patterns from twinned austenite. PF: polygonal ferrite, M: martensite, B: bainite and RA: retained austenite 
A similar microstructure was observed in S2. Fig. 20(a) displays the dominant phase of polygonal ferrite and martensite for this sample. Polygonal ferrite showed an increased dislocation density compared to the condition following cold rolling and without heat treatment. Fig 20(b) provides a closer view of the martensite structure. The martensite morphology, showing packets of laths with different orientations, can be seen more clearly from this figure. In addition to this, a number of very small particles, most probably carbides, within single laths can be observed (marked by arrows). They indicate possible martensite aging as a result of the ongoing local heat treatment $[46,47]$. Clear changes in the martensite phase were observed for S2. In contrast to the martensite morphology without heat treatment, strong tendencies for the martensite phase to decompose were found in heat treated state (Fig. 20(b)). Fig. 20(b) shows carbide formation in S2 after relatively low temperatures. Diffraction patterns confirmed the carbides were cementite.

(a)

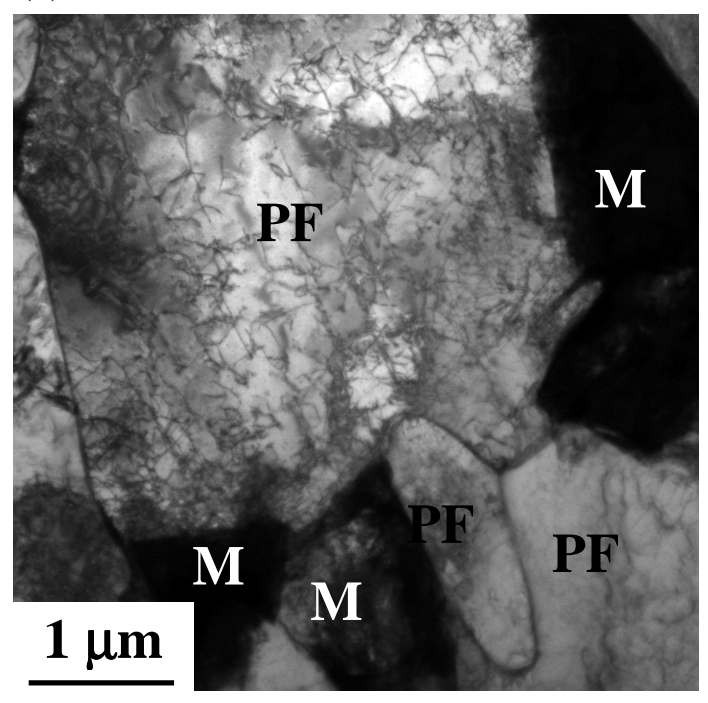

(b)

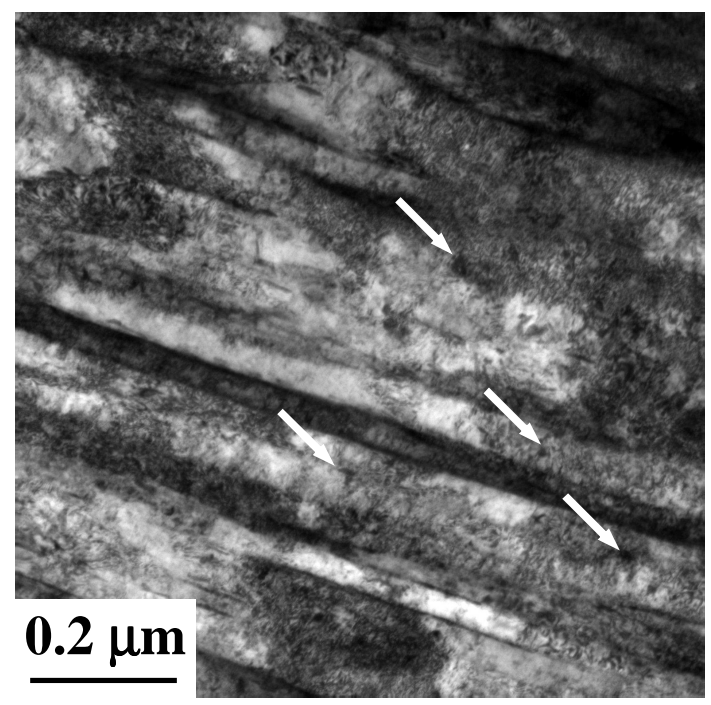

(c)

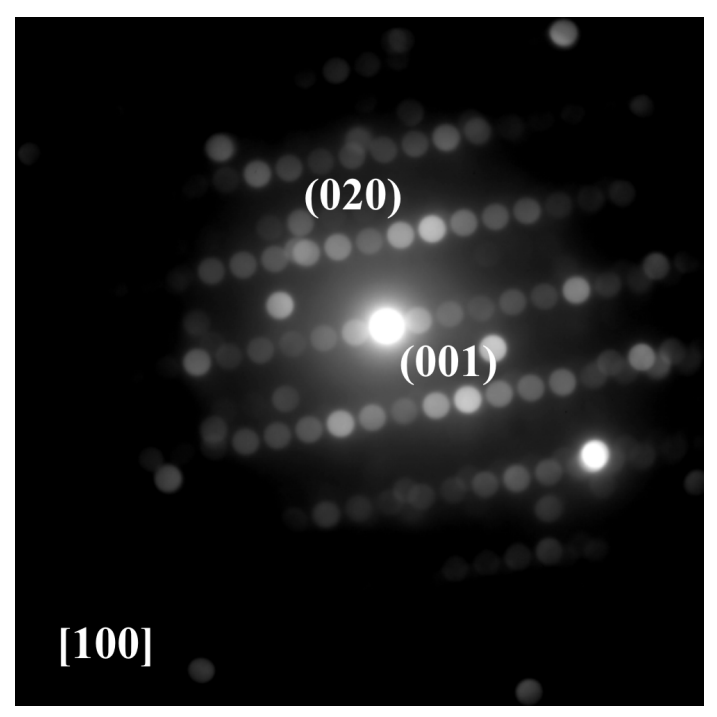

Fig. 20: Bright-field image micrographs of S2 in LTZ: (a) general view, (b) martensitic island showing lath morphology (arrows indicate small particles of cementite), (c) diffraction pattern from cementite within single laths. PF: polygonal ferrite, M: martensite

It is evident that by increasing the temperature from $300{ }^{\circ} \mathrm{C}$ up to $800^{\circ} \mathrm{C}$, the volume fraction of bainite increases (Figs. 21). S3 indicates higher volume fractions of acicular ferrite. Contrastingly, 
the amount of polygonal ferrite is lower in this sample. At $800{ }^{\circ} \mathrm{C}$, the presence of bainitic phases dominates the two morphologies as (1) lower bainite (2) granular bainite.

Fig. 21(a) shows lower bainite consisting of cementite precipitates as rod-like shapes (dark features) in between ferrite platelets. Lower bainite of platelet morphology contains finely-dispersed $\varepsilon$-carbide particles [48].

Fig. 21(b) shows LTZ at $800^{\circ} \mathrm{C}$. Granular bainite with darkly shining cementite rods between ferrite platelets can be detected. This figure also exhibits distributions of fine $\varepsilon$-carbide particles within the granular bainite regions.

TEM studies reveal that a complex dislocation structure forms in polygonal ferrite with the presence of a cell-structure (Fig. 21(c)). The dislocation network in the ferrite grains adjacent to the bainitic regions can be clearly seen. The most affected grains are located in the vicinity of or between the bainite regions. Furthermore, bainite grains with an extremely fine structured incoherent dislocation network were present at the periphery of the ferrite grains (marked by arrows). The formation of bainite and martensite at higher temperatures is accompanied by the generation of high density mobile dislocations as a result of the shear component in the mechanism of these phase transformations [49].

(a)

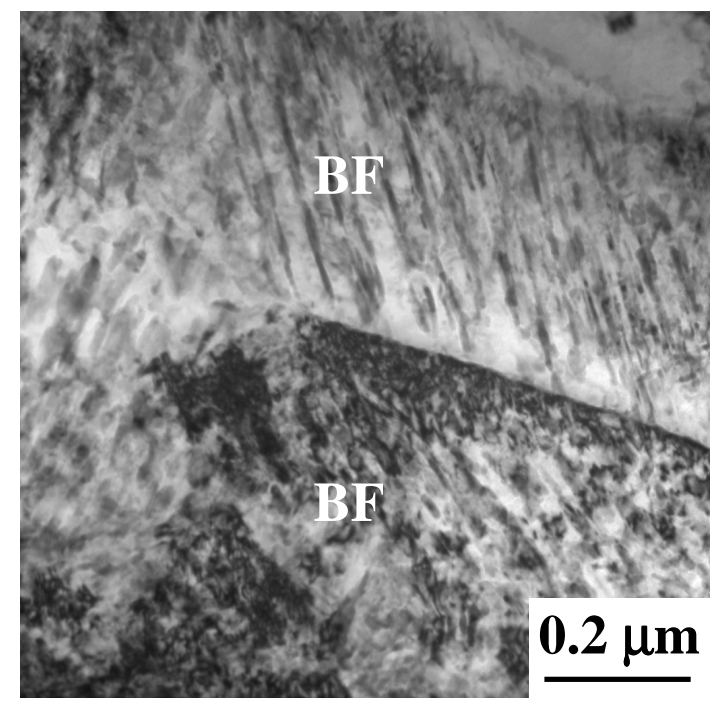

(b)

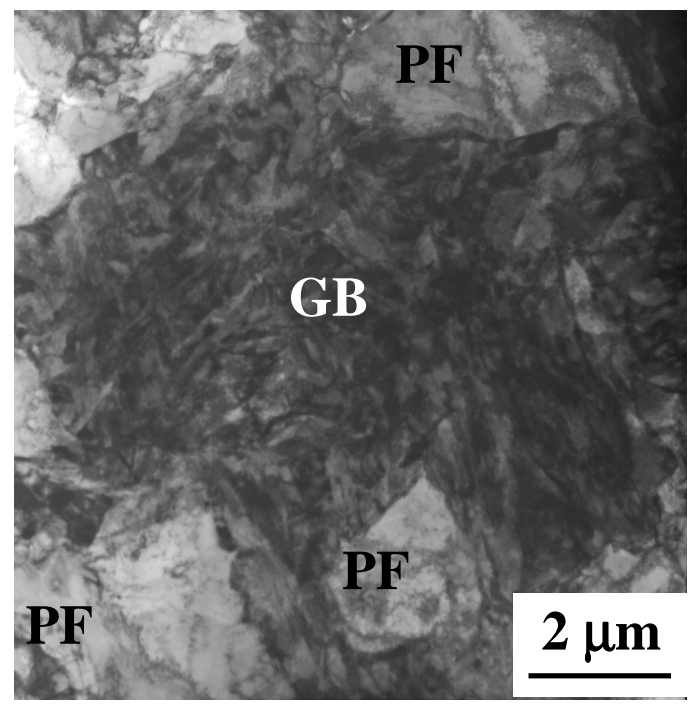

(c)

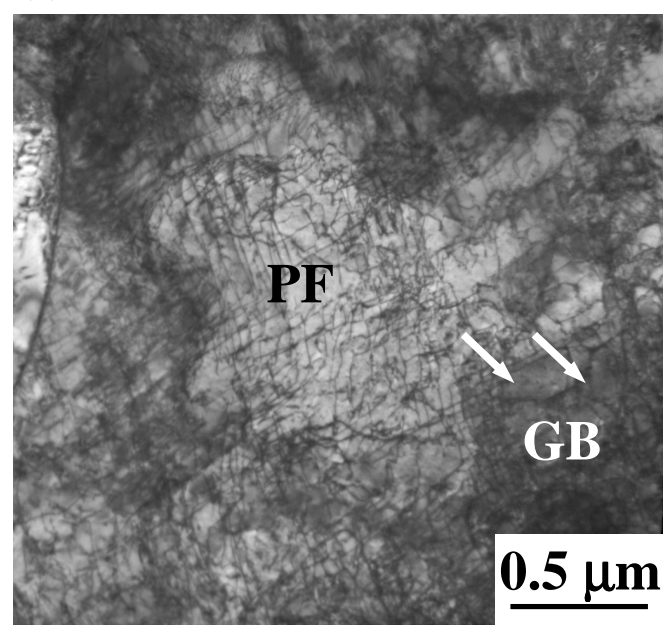

Fig. 21: TEM micrographs of S3 in LTZ: (a) lower bainite with carbide formation between the bainitic ferrite laths, (b) granular bainite, (c) Formation of cell structure in polygonal ferrite. BF: bainitic ferrite, GB: granular bainite, PF: polygonal ferrite 
Further increases in the heat treatment temperature up to $1000{ }^{\circ} \mathrm{C}$ produced a microstructure mainly consisting of lower bainite and martensite with small amounts of acicular ferrite and granular bainite (Fig. 22(a)-(d)). Approximately $40 \%$ of the martensitic islands are present in the microstructure. In the lower part of Fig. 22(a), these islands show an irregular lath morphology without a preferential orientation while, on the right side, the martensite constituent is of acicular shape. Some martensite laths (up to $0.3 \mu \mathrm{m}$ in width) are of the same orientation and parallel to each other. On the right hand side of this figure, martensite with plate morphology can be seen.

Fig. 22(b) shows a bainitic ferrite structure with platelet morphology in LTZ. It decisively affirms that the ferrite component of bainite is composed of groups of thin parallel laths with a welldefined crystallographic inclination. The bainite itself inhibits a lath structure. The laths are separated by low-angle boundaries in which no carbide inclusions could be observed.

Fig. 22(c) exhibits bainite (dark) at the inner periphery of a primary austenitic grain with a polygonal ferrite core. While these plates nucleate at austenitic grain boundaries, there is also much nucleation within the grains, i.e. intra-granular nucleation, and secondary plates from primary plates remote from the grain boundaries [50]. Finally, the most advanced formation of carbides is displayed in Fig. 22(d). This figure shows regularly oriented carbide precipitations in the core of a bainite grain. Using an EDX analysis, these particles were identified as cementite. 
(a)

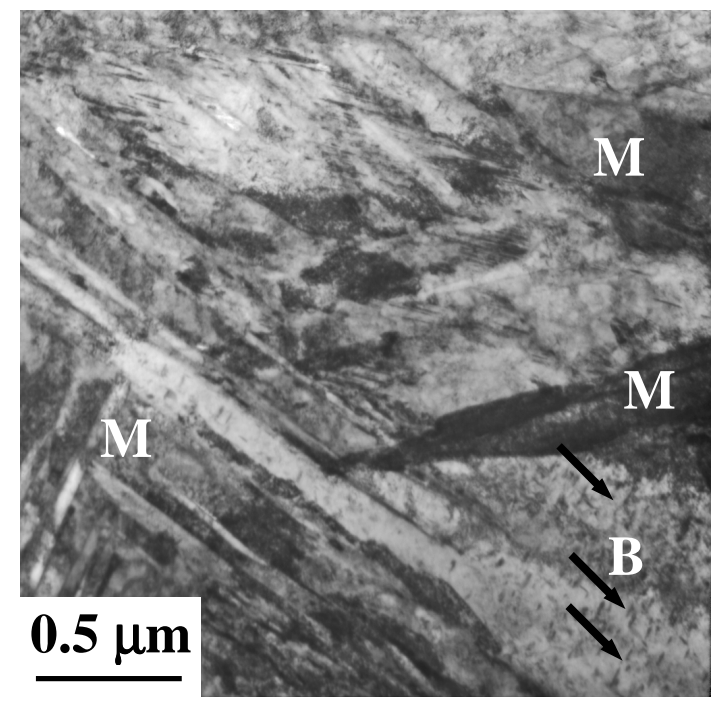

(c)

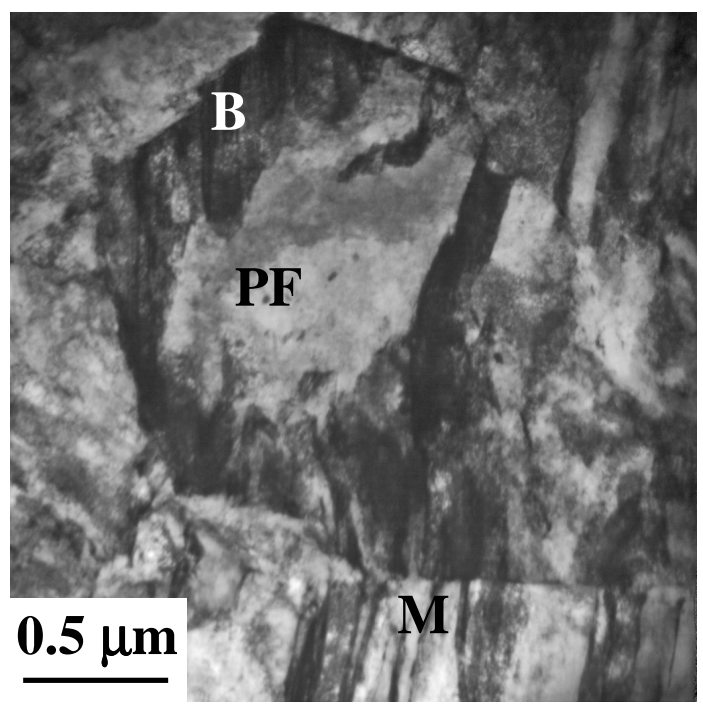

(b)

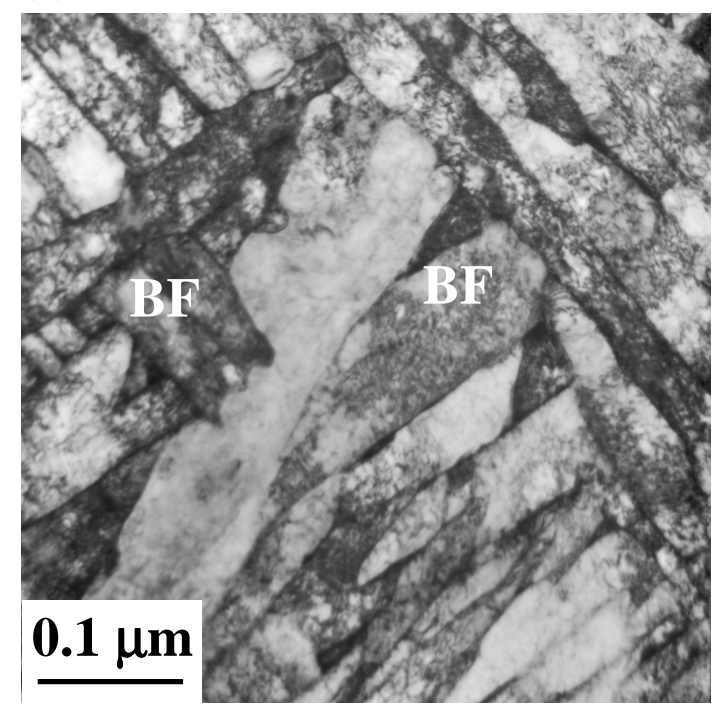

(d)

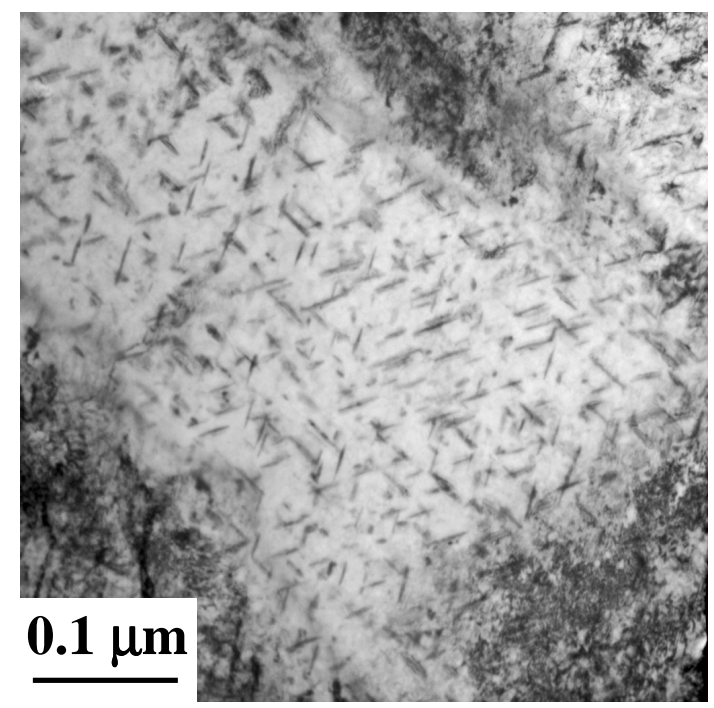

Fig. 22: TEM micrographs of S4 in LTZ: (a) martensite showing lath and plate morphology and bainite with carbide formation, (b) bainitic ferrite structure with platelet morphology, (c) bainite at the inner periphery of a primary austenite grain with a polygonal ferrite core, (d) regularly oriented cementite particles in the core of a bainite grain. B: bainitie, M: martensite, PF: polygonal ferrite

TEM micrographs of S1 and S2 in the HAZ showed a comparable microstructure to S1 in the LTZ. The microstructure of S3 shows a region in the HAZ which is made up of the polygonal ferrite phase and a profusion of bainite platelets (Fig. 23(a)-(c)). The bainite grain is divided into subgrains between polygonal ferrite grains. The middle part of the bainite reveals a mid-rib, which is associated with lower bainite (Fig. 23(a)). The sub-grains on the right hand side of this figure partly show acicular ferrite, consisting of lath-like carbide-free ferrite grains with retained austenite or martensite layers between them [51].

Fig. 23(b) shows the position of the HAZ at $800{ }^{\circ} \mathrm{C}$, where bainite segments surrounded polygonal ferrite on the grain boundaries (see arrows). The formation of upper bainite can be observed on the right hand side. Fig. 23(c) provides a closer view of the upper bainite structure (marked with a rectangle in Fig. 23(b)). A distribution of cementite particles (dark features) can be seen clearly between ferrite platelets. 
(a)

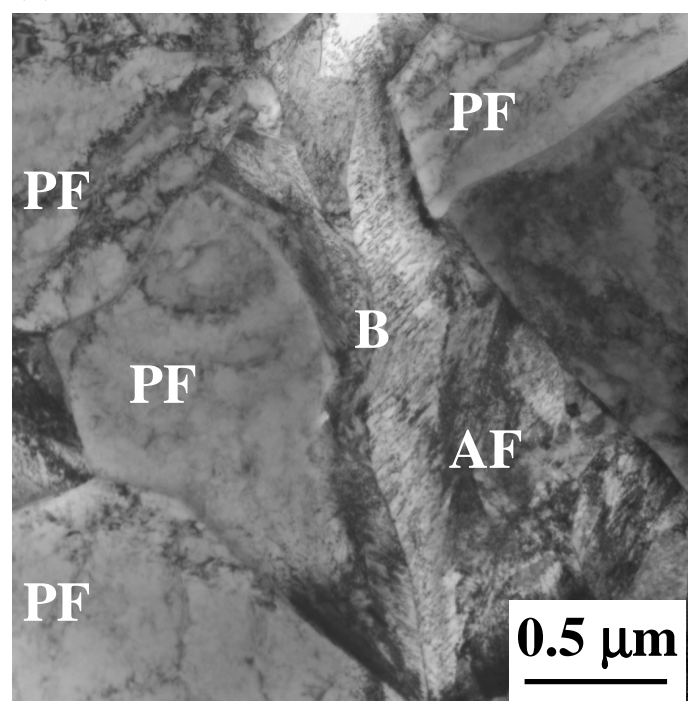

(b)

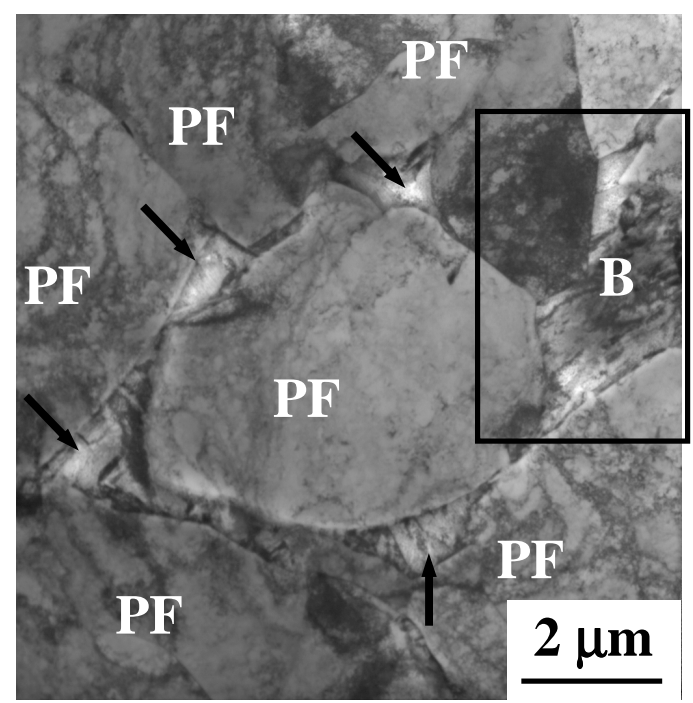

(c)

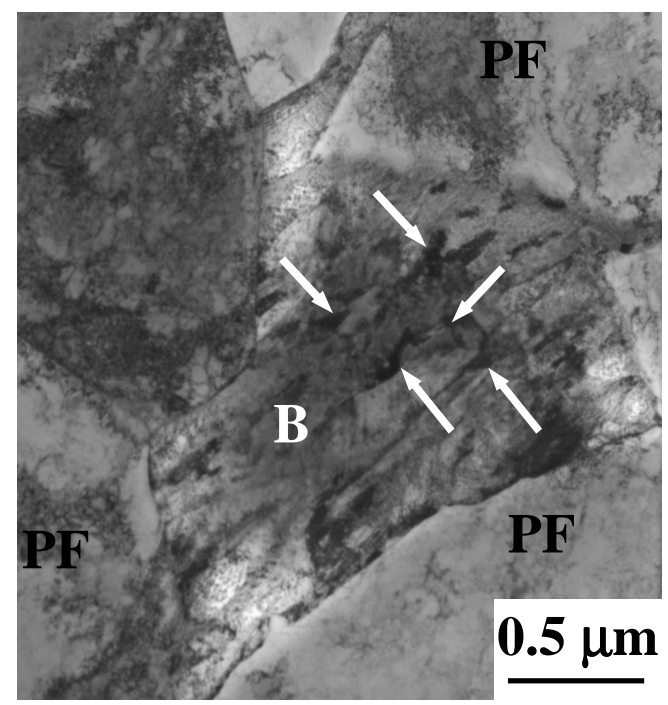

Fig. 23: TEM micrographs of S3 in HAZ: (a) polygonal ferrite, bainite and acicular ferrite, (b) bainite segments surrounded by polygonal ferrite on the grain boundaries (arrows indicate bainite segments), (c) upper bainite and polygonal ferrite (arrows indicate cementite particles). B: bainitie, PF: polygonal ferrite, AF: acicular ferrite

Fig. 24 depicts the microstructure of S4 in the HAZ with (a): polygonal ferrite coexisting with a multifaceted bainitic morphology (lower bainite, upper bainite and granular bainite). The most affected regions of ferrite were in the vicinity of the bainite crystals. Moreover, the formation of dislocation cells with complex dislocation tangles in the cell walls and regions free of dislocations inside the cell was observed. This can be seen in Fig. 24(b), where such fine-structured lower bainite was formed. This is composed of subtle or super-subtle fine chunks [52]. Moreover, there are fine structures and finer subchunks and ripples or lamellar structures in the bainite. 
(a)

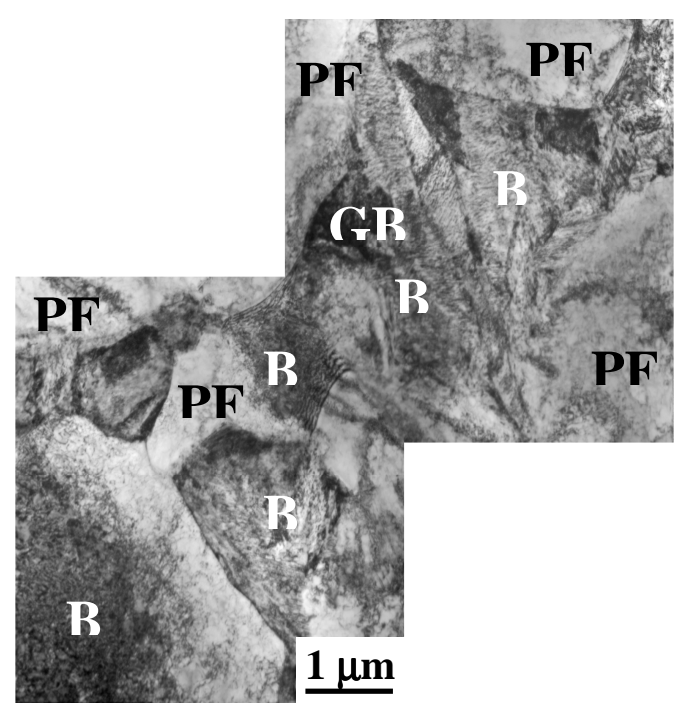

(b)

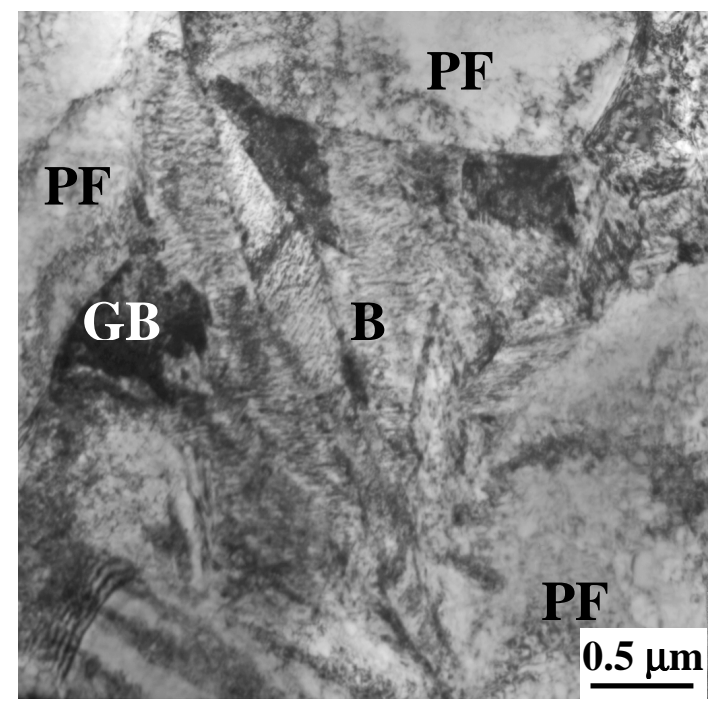

Fig. 24: TEM micrographs of S4 in the HAZ: (a) polygonal ferrite, bainite and granular bainite, (b) fine-structured lower bainite. B: bainite, GB: granular bainite, PF: polygonal ferrite

Mechanical properties. Fig. 25 describes the mechanical properties of locally heat treated samples at different temperatures with respect to the pre-strain level. The tensile strength values rise steeply when the pre-strain increases to $\varepsilon=10 \%$ (Fig. 25(a)). High tensile strength indices of up to $750 \mathrm{MPa}$ are achieved at $1000{ }^{\circ} \mathrm{C}$. For a given pre-strain, the tensile strength increases with increasing temperature. The effect of pre-strain on tensile strength varies with the heat treatment temperature. For S2, slightly larger tensile strength levels are achieved compared to S1. A substantial incremental increase in tensile strength is found with increasing temperature.

Fig. 25(b) shows a clear influence of heat treatment temperature and pre-straining level on the development of yield. An increase can be observed from about $500 \mathrm{MPa}$, without pre-straining or laser treatment, to approximately $730 \mathrm{MPa}$ at $1000{ }^{\circ} \mathrm{C}$ with $10 \%$ pre-straining. A steep increase with increasing pre-strain is observed for S3 and S4, but only slightly increases are found for S1 and S2.

After pre-straining, the samples show a clear decrease in elongation with a reduction of $\varepsilon=10 \%$, cf. Fig. 25(c) with rising temperature. While for S1 a level of around $17 \%$ is finally reached; the level for $\mathrm{S} 4$ decreases to $10 \%$. The elongation values tend to decrease for higher temperatures, especially for the highest pre-strain used. For S3 these values are significantly reduced. The elongation values for S2 are close to those for S1. For S2 pre-strained to $10 \%$, a lower elongation value is found. The laser treatment leads to an increase in tensile and yield strengths. For the CP-W 100 steel, the same mechanical behaviour could be observed. 
(a)

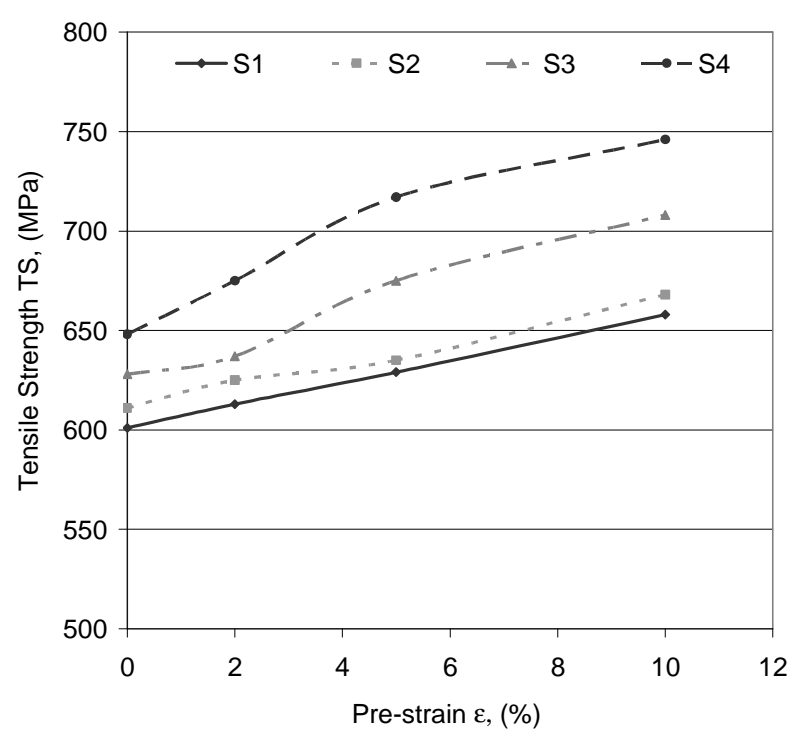

(b)

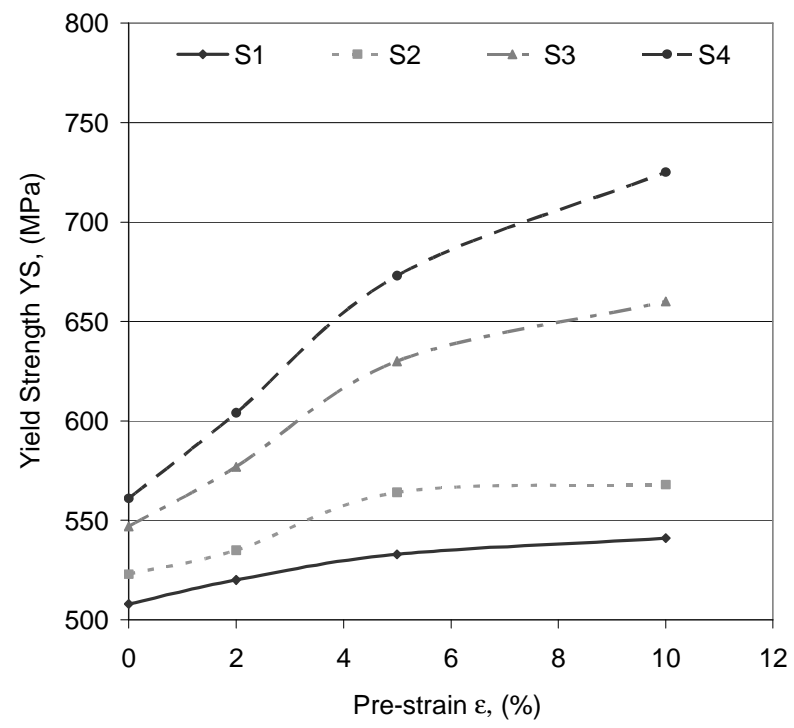

(c)

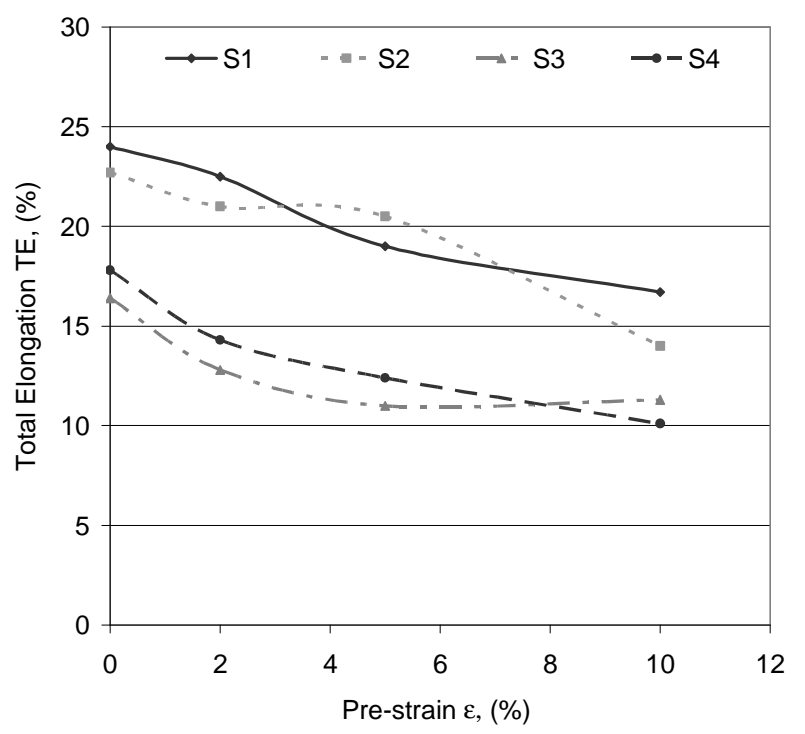

Fig. 25: Mechanical properties of DP steel after cold rolling with different degrees of pre-straining and subsequent LHT at different temperatures, (a) tensile strength TS, (b) yield strength YS, (c) total elongation TE

Investigations of LHT effect in the cross section. Addition investigations across the samples' sheet thickness of following LHT were performed to determine the depth and width of the material changes. The samples cross-sectional planes were also subjected to detailed microstructural examination by means of SEM. Mechanical properties of the cross section were studied by careful microhardness measurements. For this part of the research, the results for the steels S1, S3 and S4 will be presented.

Fig. 26(a) shows the characteristic ferrite and martensite microstructure of steel S1 with a thickness of $1.9 \mathrm{~mm}$. It is apparent that martensite phases are embedded in wide ferrite sheaves with a lath-like morphology. 
Fig. 26(b) and (c) show the cross sectional microstructures of S3 and S4. From these images, it can be observed that for both samples, a certain zone is affected by the LHT. Comparing the microstructures of S3 and S4 shows that the HTZ of S3 is smaller than that of S4.

Fig. 26(d) provides a closer view of S3 obtained at a depth between $0.3 \mathrm{~mm}$ and $0.5 \mathrm{~mm}$ from the top surface. The microstructure consists of bainite, and possibly martensite, obtained by the partial transformation of austenite to bainite and martensite on quenching to room temperature during the LHT. However, no direct evidence of martensite, other than the microstructure, could be obtained due to its low tetragonality (indistinguishable by means of diffraction from the bainitic ferrite). Earlier, Young and Bhadeshia [53] obtained a similar partial bainitic microstructure with identical features to those shown in Fig. 26(d). It may be noted that martensite plates are extremely fine and randomly oriented. Previously, a similar predominantly martensitic microstructure was obtained by the LHT in different grades of steels that resulted in extremely high hardness [54-55].

Fig. 26(e) depicts a closer view of S4 obtained at a depth between $0.3 \mathrm{~mm}$ and $0.5 \mathrm{~mm}$ from the top surface. For this steel, the fraction of bainite and martensite continuously increases within the HTZ. SEM analyses confirm that the ferritic/martensitic microstructure is converted to martensite and predominantly bainite by the LHT at a depth where the laser heating profile can only induce rapid heating and cooling. Indeed, a hardened layer with a predominantly martensitic microstructure was obtained for S4 in the present LHT experiments at a depth of up to $\sim 0.6 \mathrm{~mm}$ below the surface. It is of interest to note that a martensitic microstructure with a residual compressive stress is ideally suited for greater wear and fatigue resistance [56]. It should be noted that by not employing the optimized LHT parameters, e.g. a lower laser power and/or a higher traversing speed, led to inadequate heating/quenching or hardening of the surface in the present experiments.

(a)

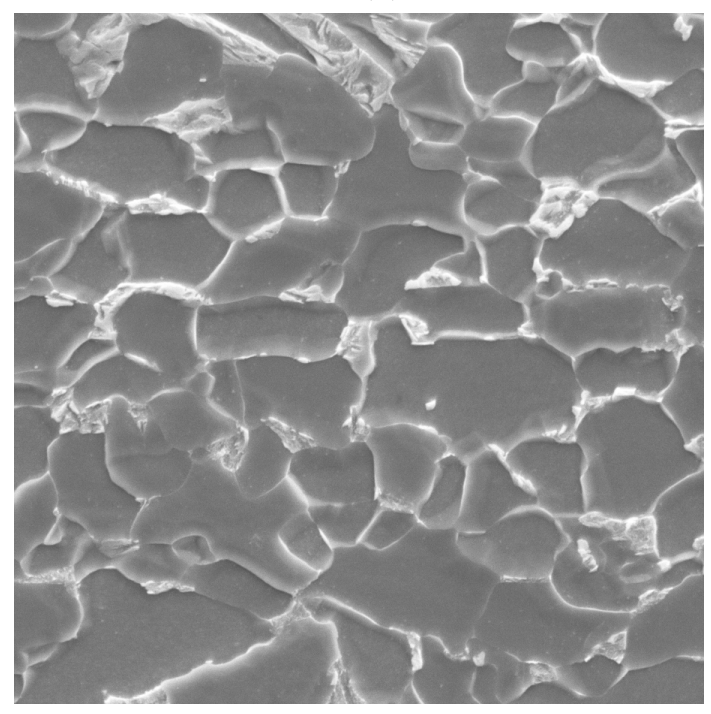

(b)

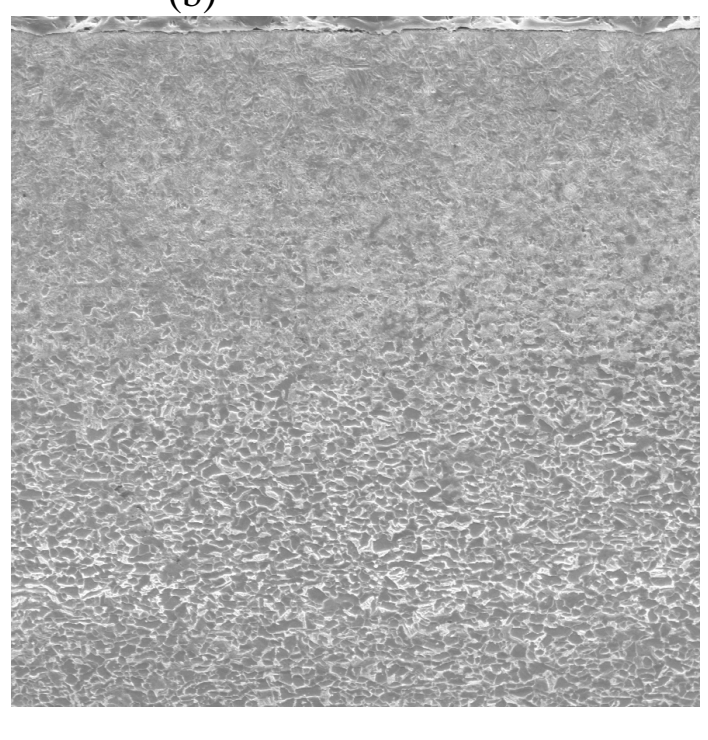


(c)

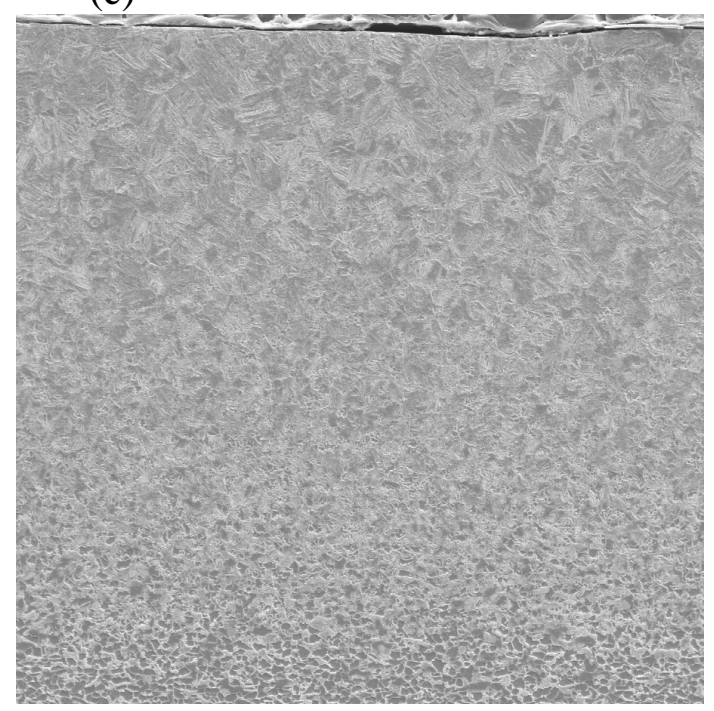

(d)

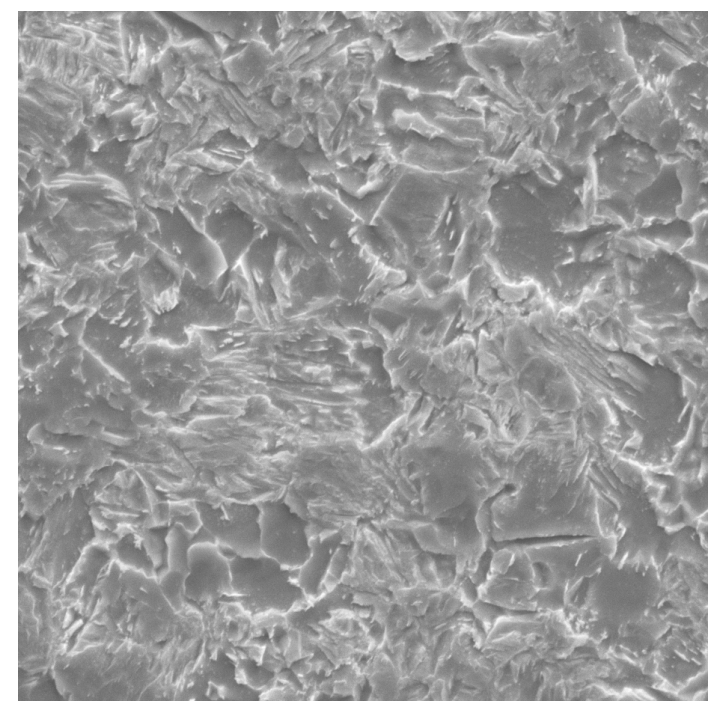

(e)

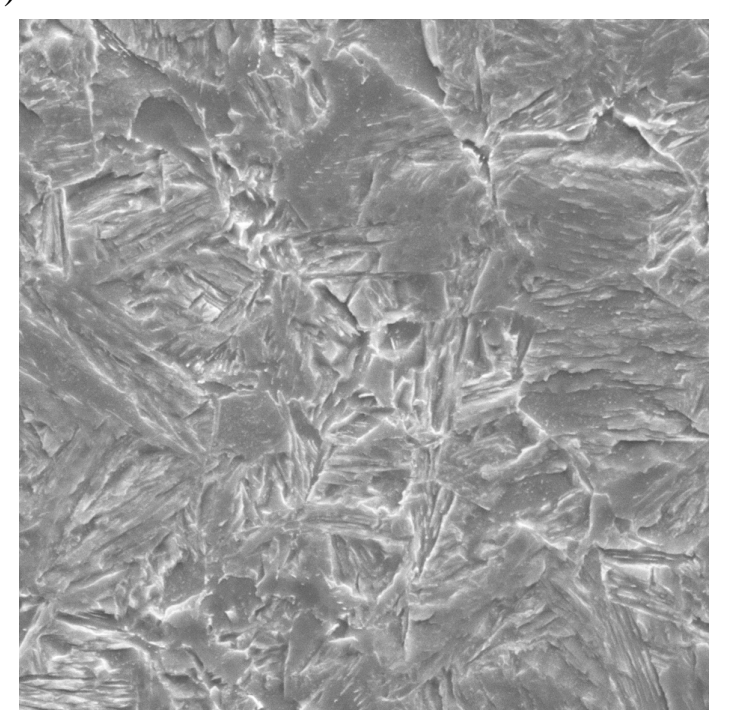

Fig. 26: SEM micrograph of the cross-sectional surface of laser-hardened DP-W 600 steel (a) steel S1, (b) general view of steel S3 (c) general view of steel S4, (d) steel S3 at a depth of $0.2 \mathrm{~mm}$ below the surface, (e) steel S4 at a depth of $0.2 \mathrm{~mm}$ below the surface

To obtain a hardness profile over the cross section of samples, the hardness was measured below the surface at five different layers. The separation distance of each layer is $0.3 \mathrm{~mm}$ (Fig. 27). 


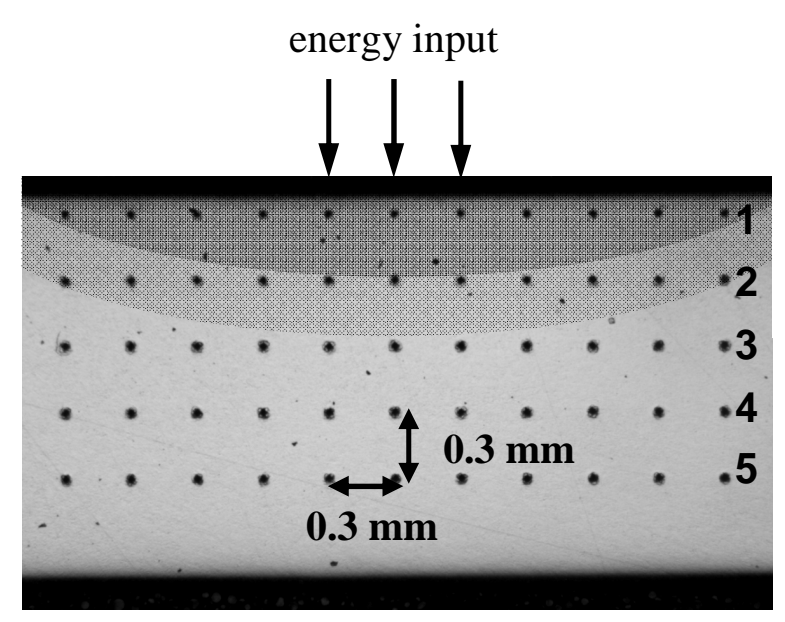

Fig. 27: Create of the hardness profile over the cross section of laser treated samples. The distance between the indenters is $0.3 \mathrm{~mm}$

Fig. 28 shows the hardness profile of the cross-sectional plane following LHT with $1.8 \mathrm{~kW}$ (steel S3) and $2.2 \mathrm{~kW}$ (steel S4) laser power but different traversing speeds. Each hardness value reported here is an average of 2-3 measurements taken on the same sample at an equivalent location (or vertical depth from the surface/sample edge).

Fig. 28(a) displays the hardness profile of steel S4 in laser treated region. From this figure, it is evident that the depth of the laser-irradiated/modified zone (hardened) increases with increasing laser power due to the larger heat input and longer interaction time at a given level of exposure (traversing time). It is interesting to note that a very narrow region near the surface (layer 1) shows an extremely high level ( $320 \mathrm{HV} 0.5)$ of hardness followed by a wide region showing approximately 260-290 HV0.5 hardness (layers 2 and 3) (Fig. 28(a)). The hardness of both layers is significantly higher than that of the base metal with a hardness value of 220 HV0.5 (layers 4 and 5). While the extremely high hardness in the narrow near-surface region may arise due to its carbide-rich martensite structure, the consistently high hardness in the next layer over a wide region may be attributed to a predominantly bainite microstructure, as shown in Fig. 26(a) and (e).

Fig. 28(b) shows the hardness profile of S3 in 5 different layers below the surface. In a region near the surface (layer 1) the highest hardness of $\sim 290$ HV0.5 was found. For steel S3 the hardness values in layer 1 are lower than that of steel S4 in the same layer. However, it is equal to the hardness value in layer 2 of steel S4. This can be explained by the different microstructures below the surface, which arise from different laser energy inputs. In layer 2 of steel S3 a hardness value of 260 HV0.5 was measured. It is interesting to note that the hardness profile (Fig. 28(b)) actually corroborated this prediction by recording an increased hardness ( $260 \mathrm{HV} 0.5)$ up to a depth of $\sim 0.5 \mathrm{~mm}$ from the surface (layer 3, 4 and 5), which is identical to that in the base metal. Thus, Fig. 28(b) corroborates the microstructural observations presented in Fig. 26(b). 
(a)

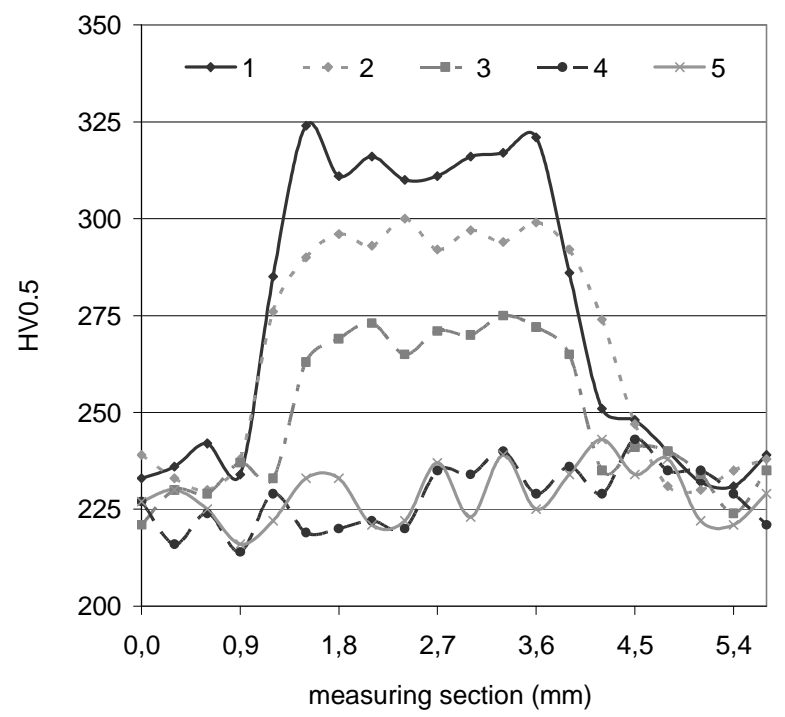

(b)

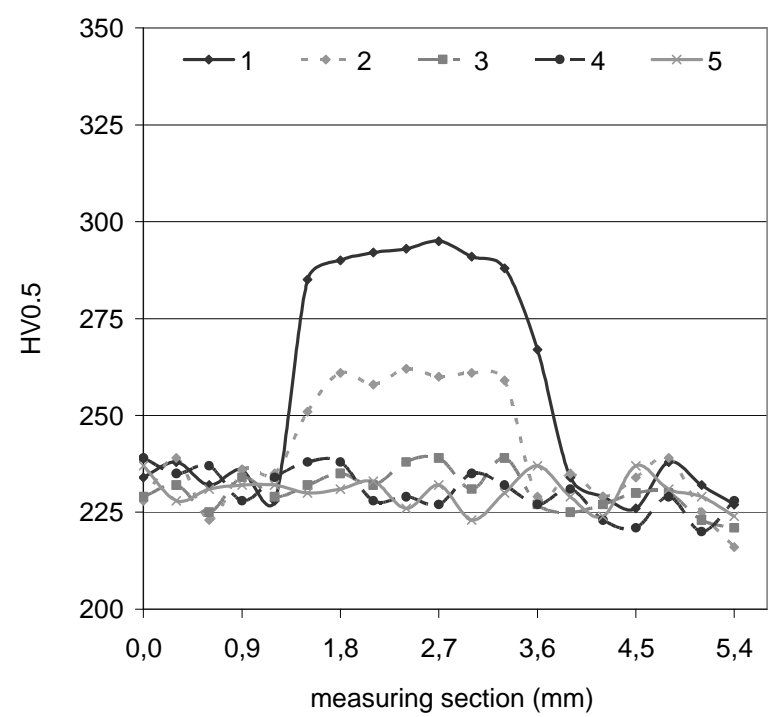

Fig. 28: Microhardness profile (on the cross-sectional plane) of laserhardened DP-W steel (a) S4 with $2.2 \mathrm{~kW}$ (b) S3 with $1.8 \mathrm{~kW}$ laser power. Laser traversing speed was set to $5 \mathrm{~m} / \mathrm{min}$.

To correlate the microstructure with the laser parameters employed, an attempt has been made to predict the thermal profile generated during the LHT by means of analytically solving the appropriate heat balance equation. With regard to this, it was assumed that: (i) the radiative heat loss from the sample surface is negligible; (ii) the thermal and optical properties of the steel are not functions of temperature; (iii) austenitization starts at the lower critical $\left(\mathrm{Ac}_{1}\right)$ temperature (ferrite to austenite transformation); and (iv) heat flow takes place in a quasi- stationary state, implying that a hot zone of constant volume moves together with the heat source at the same velocity. According to the Ashby and Easterling [57] model, the heat balance equation for heating/cooling a metallic sample being irradiated by a continuous-wave $\mathrm{CO}_{2}$ laser wave with a Gaussian energy distribution profile is given by:

$$
\nabla^{2} T-\frac{1}{\alpha} \frac{\partial T}{\partial t}+\frac{q_{r}}{\lambda}=0
$$

where $\mathrm{T}$ is the temperature, $\alpha$ is the thermal diffusivity, $\mathrm{q}_{\mathrm{r}}$ is the amount of heat energy injected into the samples per unit volume per unit time, $\lambda$ is the thermal conductivity of the sample and $t$ is the time. If $\mathrm{z}$ and $\mathrm{y}$ represent the respective directions along the vertical depth from the surface and perpendicular distance from the laser beam on the sample surface, Eq. 2 may be solved under the following boundary conditions:

$$
\begin{array}{llll}
\frac{\partial T}{\partial z}=0 & \text { for } & z=0, & T=0 \quad \text { at } \quad z=\infty \\
T=0 & \text { at } & t=0
\end{array}
$$

such that the analytical solution is

$$
T-T_{0}=\frac{A q / v}{2 \pi \cdot \lambda \cdot\left[t \cdot\left(t+t_{0}\right)\right]^{1 / 2}} \exp \left[-\frac{1}{4 \alpha} \cdot\left\{\frac{z^{2}}{t}+\frac{y^{2}}{t+t_{0}}\right\}\right]
$$


where $\mathrm{T}_{0}$ is the initial temperature of the substrate, $\mathrm{A}$ is the absorptivity at the sample surface, $\mathrm{q}$ is the incident laser power, $\alpha$ is the thermal diffusivity $(=\lambda / \rho c), \rho$ is the density, $\mathrm{c}$ is the specific heat, $\mathrm{v}$ is the laser traversing speed, $\mathrm{r}$ is the radius of the beam and $t_{0}\left(=r^{2} / 4 \alpha\right)$ is the time taken for heat to diffuse over a distance equal to half the beam width. Accordingly, the thermal profile, as a function of time, has been determined for different values of $\mathrm{z}$ at $\mathrm{y}=0$ using measures of absorptivity, conductivity, specific heat and density of the present alloy of $0.57,36.3 \mathrm{~J} \mathrm{~m}^{-1} \mathrm{~s}^{-1} \mathrm{~K}^{-1}, 452 \mathrm{~J} \mathrm{~kg}^{-1} \mathrm{~K}^{-1}$ and $7840 \mathrm{~kg} \mathrm{~m}^{-3}$, respectively [57-59].

Fig. 29 shows the thermal profile generated during the LHT with the laser powers of $2.2 \mathrm{~kW}$ and $1.8 \mathrm{~kW}$ and a laser traverse of $5 \mathrm{~m} / \mathrm{min}$. It is evident that the peak temperature and time to reach it decrease with depth from the surface.

Fig. 30 depicts the variation of temperature as a function of depth from surface (z) for the laser power of $1.8 \mathrm{~kW}$ and $2.2 \mathrm{~kW}$ with a laser traverse speed of $5 \mathrm{~m} / \mathrm{min}$. As can be seen from this figure, the temperature decreases with increasing depth from the surface for both laser powers. An effective cooling rate experienced by the laser-irradiated zone appears adequate to induce martensitic and bainite transformations to a certain depth of the sheet by self-quenching (depending on laser power). It is interesting to note that hardness profile (Fig. 28) actually corroborated this prediction by recording superior hardness (layer 1 and 2) to a depth from the surface which is identical to that in the basic sheet.

This model makes it possible to set optimized parameters of local heat treatment parameters and to characterize the optional local material properties on the surface and over the cross section. This model also enables a definite correlation to be made between mechanical properties, microstructural setting and temperature distribution in local regions.

(a)

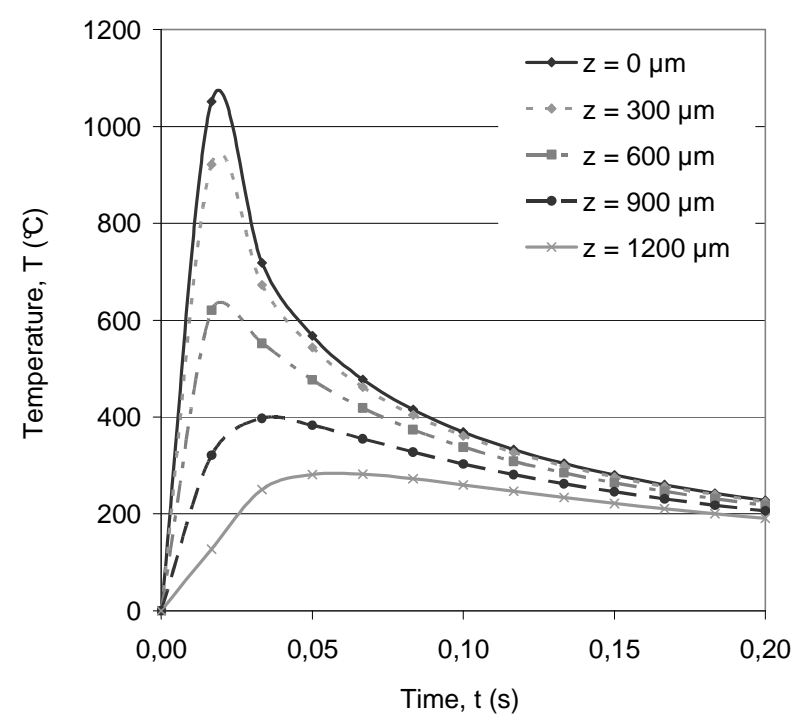

(b)

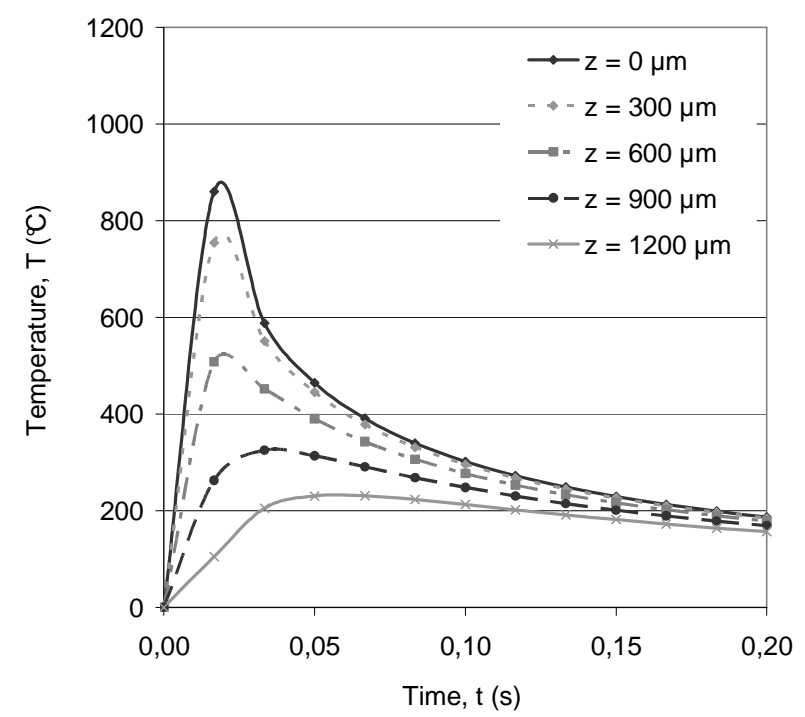

Fig. 29: Variation of temperature as a function of time at different depths (z) from the surface for a laser power of (a) $2.2 \mathrm{~kW}$ (b) $1.8 \mathrm{~kW}$. Laser traversing speed was set to $5 \mathrm{~m} / \mathrm{min}$. Note that the peak temperature and the time to attain this peak significantly change with $\mathrm{z}$ 


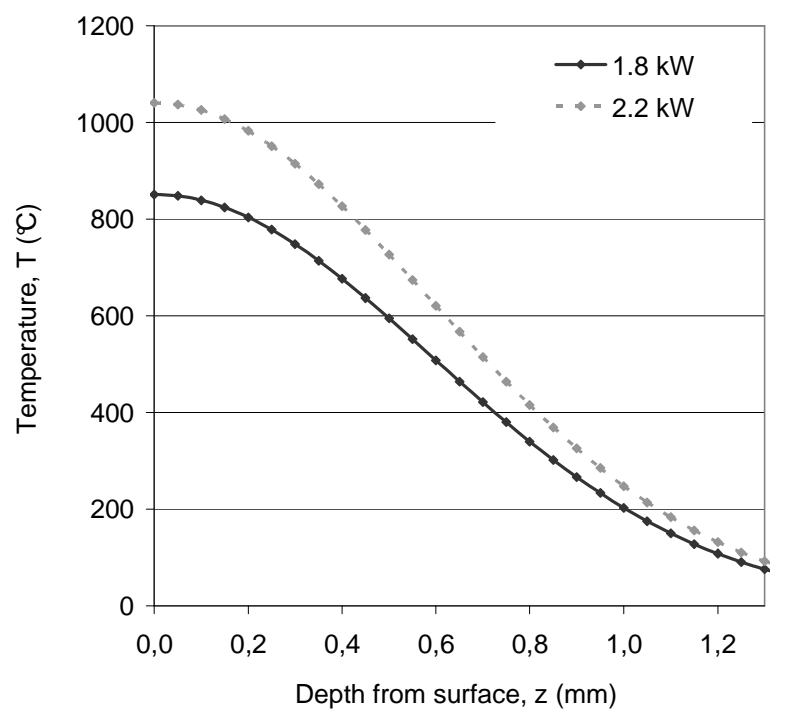

Fig. 30: Variation of temperature as a function of depth from surface (z) for the laser powers of $1.8 \mathrm{~kW}$ and $2.2 \mathrm{~kW}$ with a laser traverse of $5 \mathrm{~m} / \mathrm{min}$

Thus, this part of present research demonstrates that LHT could affect the microstructure of samples up to a certain depth from the surface and produce a predominantly martensitic and bainitic microstructure with high hardness, wear resistance and residual compressive stress at the surface of selected steels.

We believe that the combination of local deformation and local heat treatment could develop a superior assembly of local properties with a tougher core and a harder surface with higher fatigue and wear resistance.

Local heat treatment by electron beam. The non vacuum electron beam welding (NVEBW) technology was developed 40 years ago in Germany, but was used in the United States particularly for applications in the automotive industry. Here the advantages of this technology, especially the high welding speeds (>10 m/min possible), the high total efficiency (>50\%), a good gap bridging ability and a high tolerance to positioning inaccuracies as well as high process stability under manufacturing conditions were used for welding and heat treatment operations for high production rates. In the meantime, NVEBW is more frequently used in Europe [60-61].

New applications arise from lightweight concepts using aluminium alloys and AHSS with reduced sheet thicknesses. In contrast to vacuum electron beam welding, in case of NVEBW the highly accelerated electron beam is decoupled from the atmosphere via pressure stages after passing the anode and an electromagnetic system. Therefore, high vacuum is only necessary in the beam generator and the workpiece is situated in normal air atmosphere. When the beam enters the atmosphere, collisions between the electrons and air molecules take place which cause the beam to diverge. To decrease this effect, helium gas is fed into the last pressure stage. The divergence of the beam leads to a higher gap bridging ability and tolerance towards positioning errors.

As a second alternative method, the electron beam (EB) was selected to induce locally graduated strengthening in the experimental sheets. The main advantage of EB over the laser beam is that during the heat treatment of the sheets by EB, no surface reflection problems occur. In addition to this, it is possible to input much higher energy into the sheet than by using a laser beam [60].

The global cold-rolled sheets were treated by EB, which was available at the Institute of Materials Science (IW) in Hanover, Germany within the cooperative framework of the SFB 675. Fig. 31 shows a schematic of the EB. In order to reduce the temperature of heat treatment, the EB powers were set to a low power interval. The EB powers were varied from $0.6 \mathrm{~kW}$ and $0.8 \mathrm{~kW}$ to $1 \mathrm{~kW}$. The traverse speed varied between 0.5 and $5 \mathrm{~m} / \mathrm{min}$. 


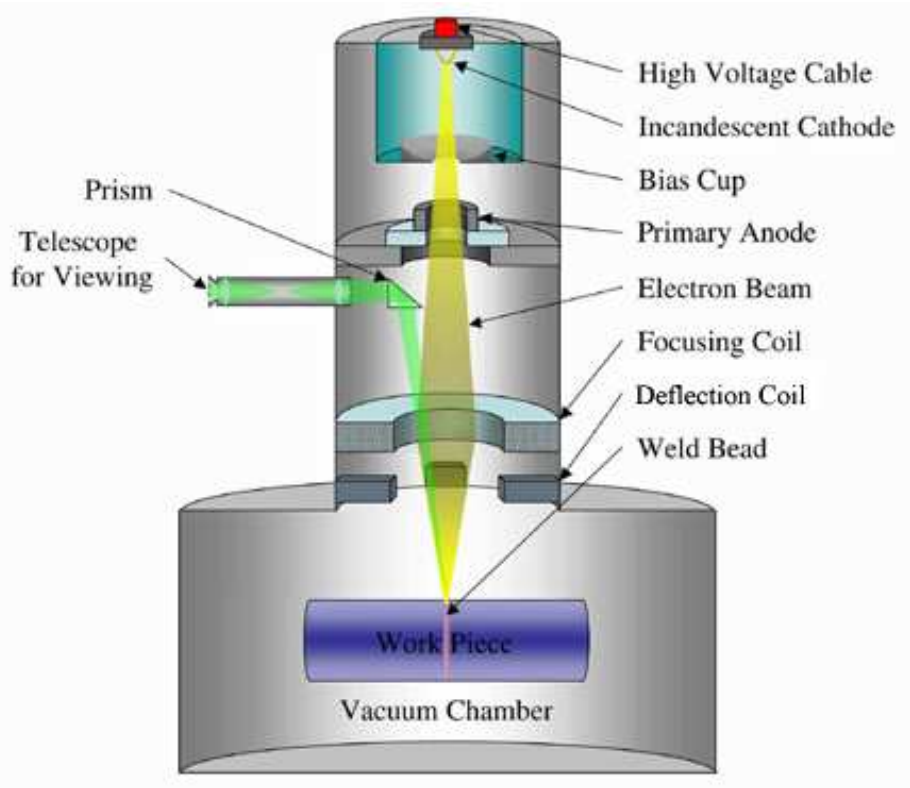

Fig. 31: Schematic image of the vacuum EB [61]

Evaluation and discussion of results for local heat treatment using EB. Hardness measurements HV0.2 according to DIN 50133 were used to evaluate the changes in the mechanical properties and to determine the strengthening effect.

Fig. 32 presents the hardness distribution for DP-W 600 after a pre-strain by cold rolling to $\varepsilon=5 \%$, followed by an EB treatment with different powers for a traversing speed of $5 \mathrm{~m} / \mathrm{min}$. For the non heat treated zone subsequent to cold rolling to a pre-strain of $\varepsilon=5 \%$, a hardness value of $190 \pm 6 \mathrm{HV} 0.2$ was measured. After the EB treatment with a power of $0.6 \mathrm{~kW}$, the hardness exhibited a value of $198 \pm 7$ HV0.2 in the HTZ. As can be seen in this figure, a minor hardness increase of between 4 and $6 \mathrm{HV} 0.2$ could be observed for the increased powers of $0.8 \mathrm{~kW}$ and $1.0 \mathrm{~kW}$.

The local heat treatment by EB leads to a slight increase in hardness. For this DP steel, an increase in hardness values of between $6 \mathrm{MPa}$ and $15 \mathrm{MPa}$ for different EB powers and traversing speeds could be calculated.

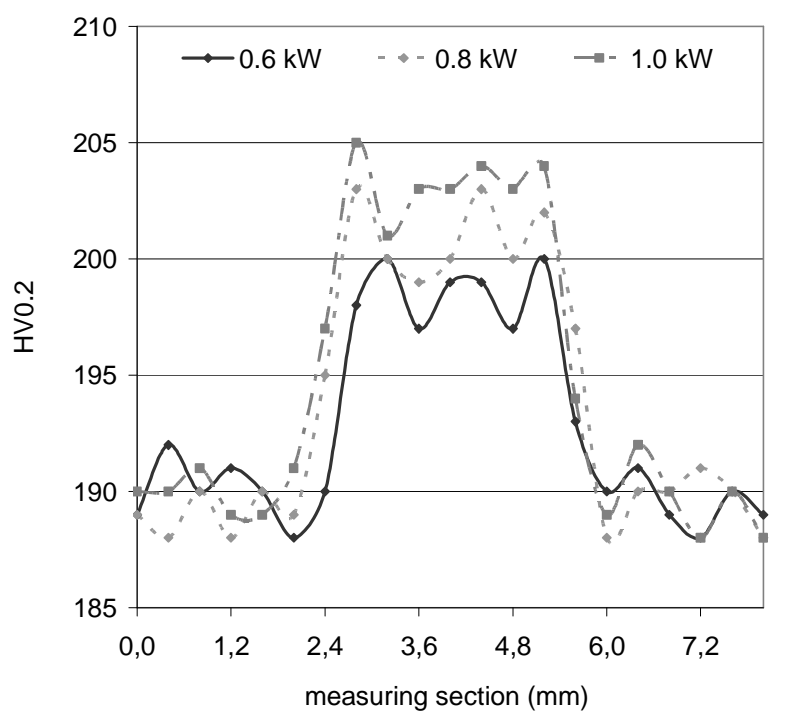

Fig. 32: Hardness distribution of DP-W 600, treating by EB with different powers. Samples were homogenously cold rolled to $\varepsilon=5 \%$ 
Fig. 33 depicts representative microstructures of the DP samples cold rolled to $\varepsilon=5 \%$ in the non treated condition and then treated by EB using a power of $1 \mathrm{~kW}$ and a traversing speed of $5 \mathrm{~m} / \mathrm{min}$. The samples were etched with LePera reagent. Fig. 33(a) shows the microstructure of the sample after $5 \%$ global deformation by cold rolling without EB treatment consisting of ferrite (bright) and martensite (dark). The microstructure following treatment by EB with $1 \mathrm{~kW}$ is similar to that in the non treated condition as observed by using LOM shown in Fig. 33(b). For all three powers, no change of microstructure despite the higher hardness values could be observed as compared with the non treated condition. Increased hardness values without microstructural change were found for the sample treated by the EB with the specified powers. This may attributed to the BH effect, in which the free interstitial carbon atoms are pinned by dislocations due to thermal activity [13].

(a)

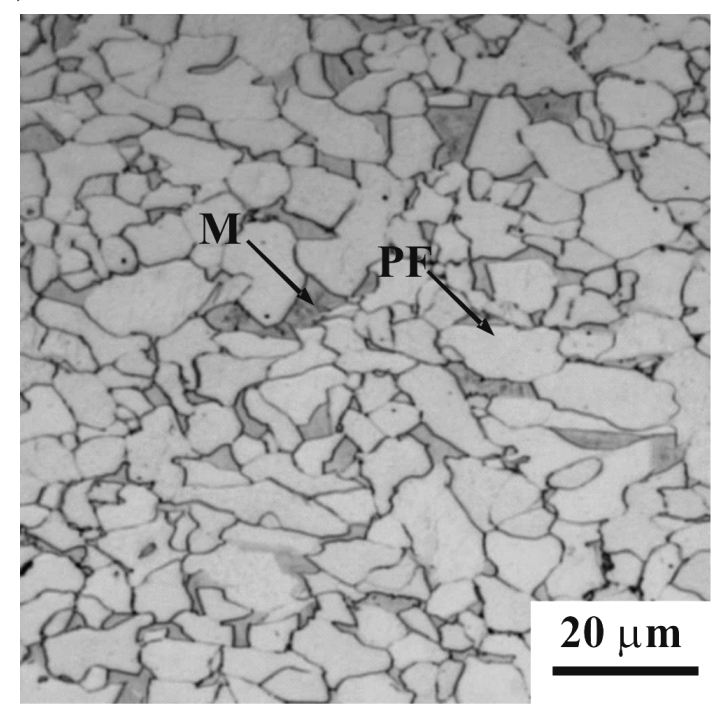

(b)

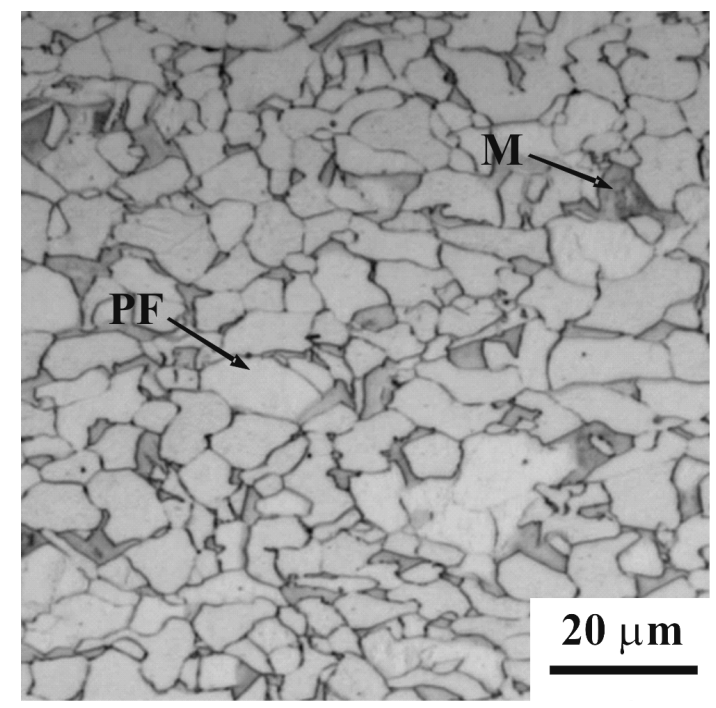

Fig. 33: Microstructure of DP steel in the HAZ cold rolled to $\varepsilon=5 \%$ (a) in non treated condition (b) heat treated by EB using a power of $1 \mathrm{~kW}$ and a traversing speed of $5 \mathrm{~m} / \mathrm{min}, \mathrm{PF}$ : polygonal ferrite, M: martensite

Fig. 34 shows the yield strength behavior of the locally EB treated DP samples with respect to the pre-strain level. The yield strength values rise steeply when the pre-strain increases to $10 \%$ (Fig. 34). High tensile strength indices of up to $630 \mathrm{MPa}$ are achieved for the samples treated using $1 \mathrm{~kW}$. For a given pre-strain, yield strength increases with increasing EB power. The effect of prestrain on yield strength varies with the EB power. Following the EB heat treatment using $0.6 \mathrm{~kW}$, the same or even slightly higher tensile strength levels are achieved such as those in the non-laser treated condition. A slight increment in yield strength is found when the EB power increases. 


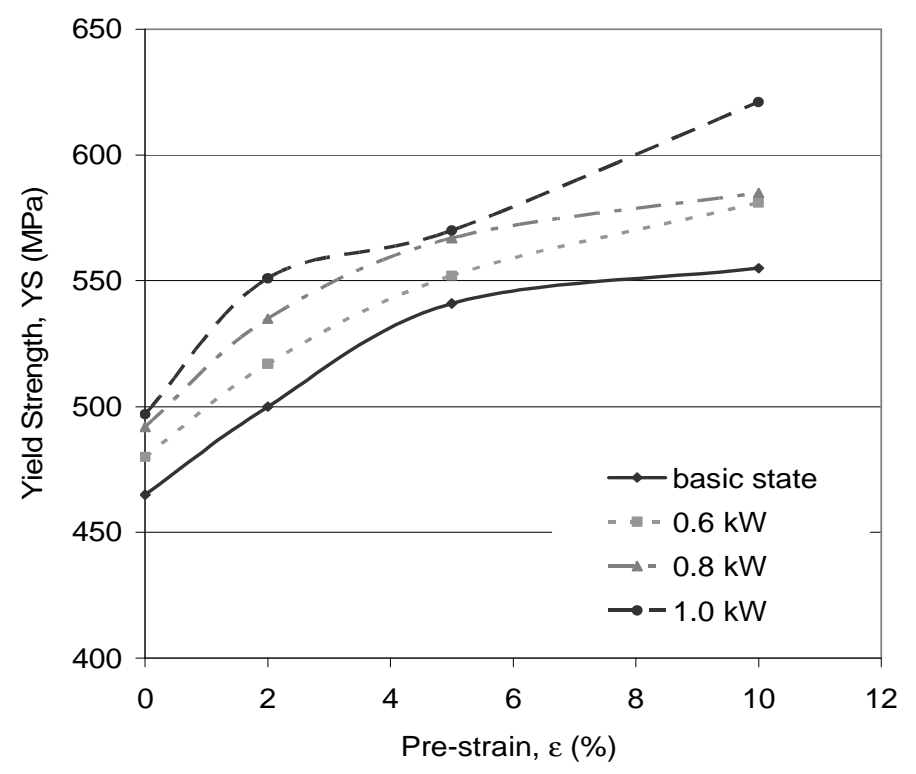

Fig. 34: Influence of EB power and pre-strain on YS of DP steel after cold rolling and local heat treatment using EB. The samples cold rolled to different levels of pre-strain and locally heat treated by EB using different powers.

\section{Influence of over aging}

Structural components of multiphase steels normally show a natural aging behavior. The questions to be answered now concern both the stability of the local aging by means of this natural aging process as well as the long-term behavior of the non- treated regions. In particular, it has to be examined to what extent the local influences can be stabilized and used to improve the material properties of the entire construction unit.

According to the literature, samples of DP and CP steels were aged for several days at a temperature of $\mathrm{T}=70{ }^{\circ} \mathrm{C}[28,62,63]$. As an example, Fig. 35 shows the results of hardness HV0.5 measurements after aging CP-W 1000, which had been pre-strained to $\varepsilon=10 \%$ and locally laser treated using $2.2 \mathrm{~kW}$ power. In the LTZ, no significant change of hardness could be measured; in the adjacent zones, a slight increase of approximately $4 \mathrm{HV} 0.5$ was found, so that subject to the parameters used, these zones are said to be stable.

Fig. 36 shows the measured hardness HV0.5 for DP-W 600 pre-strained by cold rolling to $\varepsilon=10 \%$ and partially laser treated with a laser power of $2.2 \mathrm{~kW}$ after the aging procedure. Following the aging heat treatment in a furnace at a temperature of $70{ }^{\circ} \mathrm{C}$, no change of hardness in the LTZ could be observed. In the non affected zone, an increase about $10 \mathrm{HV} 0.5$ could be measured by means of the hardness differences. For these investigation parameters, the locally adjusted strengthening effect is stable.

This aging stability could be also established for DP-W 600 and CP-W 1000 subject to other parameters (change in pre-strain and laser power). 


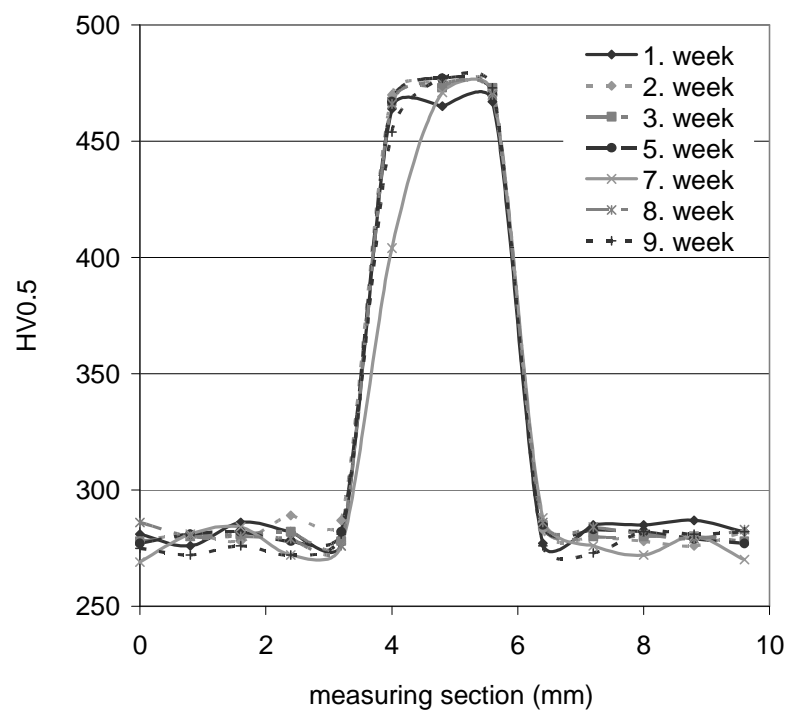

Fig. 35: Aging of laser treated CP-W 1000, pre-deformed to $\varepsilon=10 \%$ and locally laser treated using $2.2 \mathrm{~kW}$

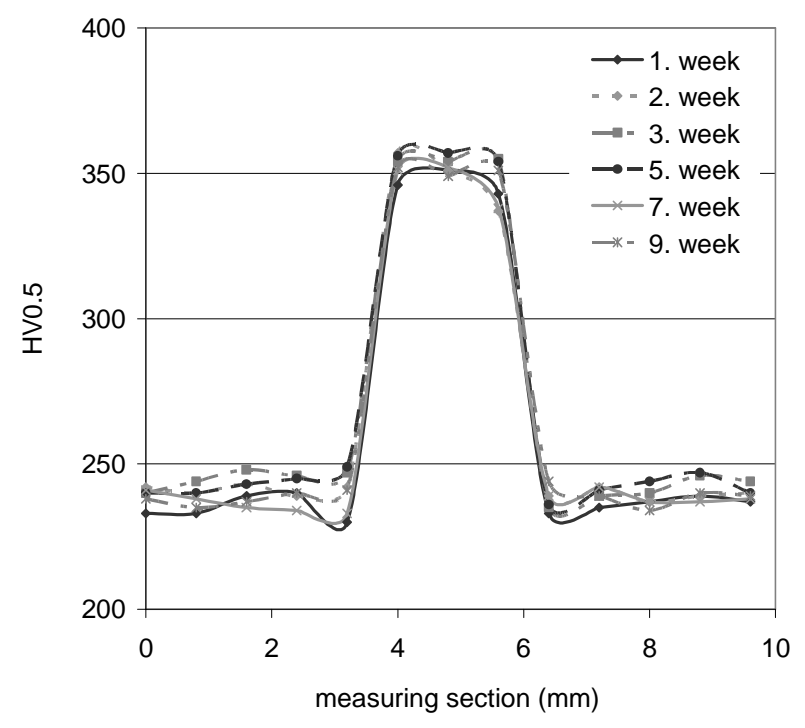

Fig. 36: Aging of laser treated DP-W 600, predeformed to $\varepsilon=10 \%$ and locally laser treated using $2.2 \mathrm{~kW}$

\section{Influence of type and level of pre-strain and aging conditions on the mechanical properties}

Strength and the amplitude of the deformability due to aging effects obviously depend on the degree of pre-strain and on the load path history $[17,64,65]$. If a structural element is inhomogeneously deformed, the activation of this effect through a final heat treatment also results in different strength values. One aim of this research project is to examine the deformation behavior of multiphase steels. The automotive industry in particular is responding with growing interest in the aging effect [66]. The aging procedure is based on the effect that in a shaped construction unit, dislocations are pinned by carbon and/or nitrogen atoms in solid solution following thermal treatment. This lack of dislocation mobility increases the unit's strength. In the automotive production process, the thermal treatment is carried out at the end of the production line by means of the paint baking process [27]. The combination of pre-strain, baking temperature and aging time results in an increase in the material's yield strength. If it is possible to compute this increase in yield strength, then a construction unit can be optimised for beneficial weight or crash characteristics. This requires an examination of the material specific shaping and heat treating processes since the $\mathrm{BH}$ effect in complex shaped construction units (e.g. tailored blanks, B-pillar or a crash protection unit), results in locally different strength behaviors following the thermal treatment of the units [67]. For this reason, the mechanical-technological properties were analysed particularly with regard to temperature, holding time and pre-strain. Two basic questions have to be answered:

- Where is the maximum increase of yield strength and tensile strength at a given pre-strain, and what influence does the load path (kind of pre-strain) have?

- When does the yield strength reach a maximum as a function of pre-strain, temperature and holding time and could this effect be computed?

By considering an actual shaped construction unit, it can be observed that the deformability behaviour of the material can not be completely described by using uniaxial tension tests (as described in $[64,68])$. On this basis, the influence of type of pre-strain on the aging effect was investigated. In order to generate different strain paths to cover the Forming Limit Diagram (FLD) (Fig. 37), different methods are used. 


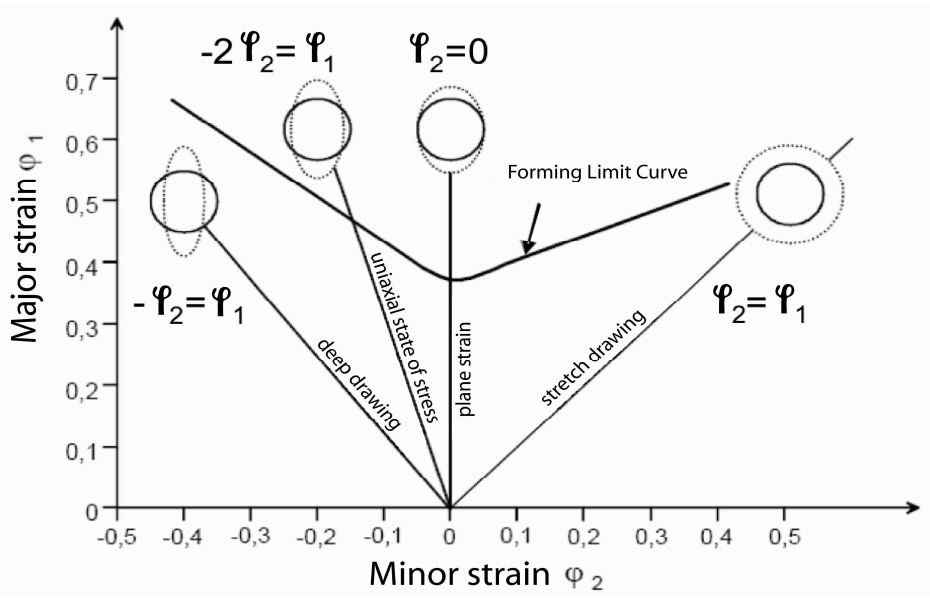

Fig. 37: Forming Limit Diagram

Uniaxial tests were conducted using a universal tensile machine $250 \mathrm{kN}$. The samples were stretched to specified pre-strains (Table. 7). The samples were subsequently aged at $100{ }^{\circ} \mathrm{C}, 170{ }^{\circ} \mathrm{C}$ and $240{ }^{\circ} \mathrm{C}$ for $20 \mathrm{~min}$. Finally, the tensile test was performed on the samples to determine the mechanical properties.

Considering the different choices to generate biaxial stress, the IMET chose a Marciniak forming tool (Fig. 38) with a diameter of $250 \mathrm{~mm}$ mounted on a $2500 \mathrm{kN}$ hydraulic press. Thus it is possible to produce biaxial pre-strained specimens. For the Marciniak test, the specimens were cut into $400 \times 400 \mathrm{~mm}$ square sheets. The specimens are strained by a flat-bottomed cylindrical punch. Between the punch and the specimen is a steel driver having a central hole. By means of this, frictionless deformation of the sheet takes place. When a large width specimen is used, the external forces that act on the sample are greater than the internal forces; this results in biaxial stretching [69].

To control the plastic deformation and adjustment, a non-contact measuring system ARGUS $(\mathrm{GOMmbH})$ was used. The ARGUS deformation measuring system is well suited for measuring three dimensional deformation and strain distributions in actual components subject to static or dynamic load, especially for small ranges of elongation.

The $240 \mathrm{~mm}$ long tensile specimens was taken from the stretched drawn regions of the sheets (Fig. 38). The tensile specimens were subsequently age treated under the same conditions as uniaxial pre-strained specimens. Finally, the tensile tests were performed on the samples to determine the mechanical properties of the pre-strained areas and thus ascertain the effect of pre-straining on the strengthening.
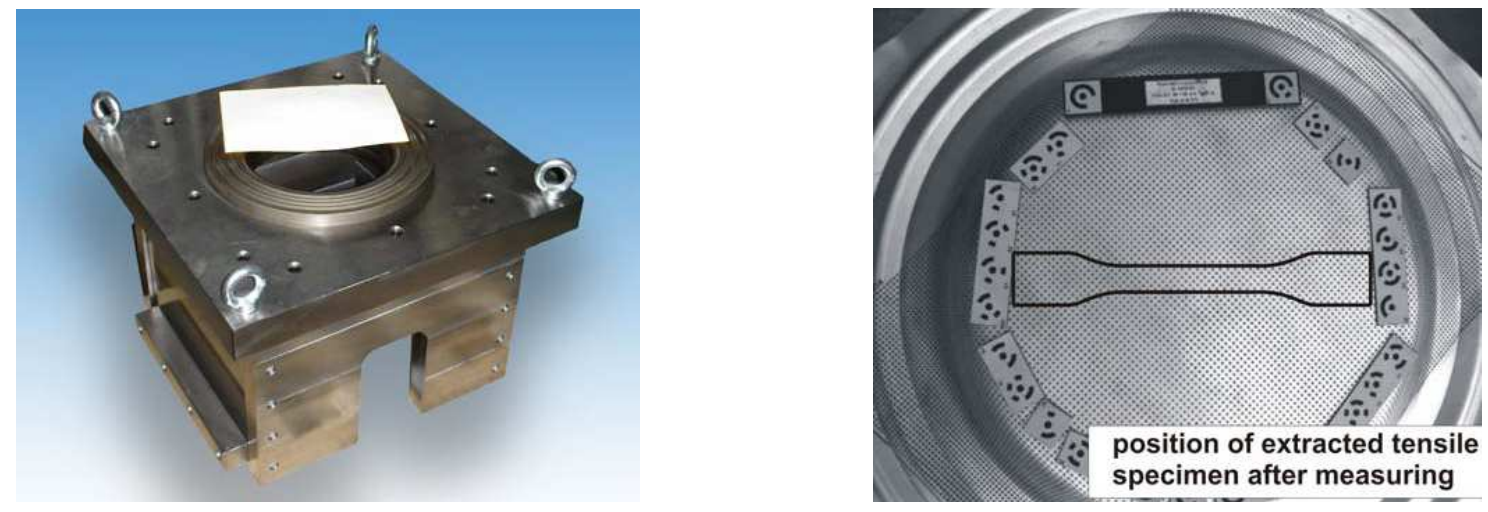

Fig. 38: Marciniak tool to produce the biaxial strain condition.

The specimens were cut into 400 x $400 \mathrm{~mm}$ sheets.

The model developed by Vegter [70] is used for the plane strain test. According to the Vegter model, a special specimen has been developed to measure the plane strain stress as a function of 
strain, see Fig. 39 [71-72]. The advantage of this specimen is that a plane strain test can be performed using an ordinary tensile testing machine. One of the difficulties is to achieve a uniform plane strain state across the specimen, as is shown in Fig. 40. Due to the existence of a uniaxial stress state at the edges of the specimen, deviations from a plane strain state always occur in this type of specimen. A correction has to be made to subtract this edge effect from the test results. A simple geometric average stress - strain curve over the whole width of the specimen would result in a $2 \%$ lower value of the plane strain stress. Even such a small difference will lead to significant differences in the prediction of FLD's and differences in the prediction of strain distribution for critical sheet formed products [73].

The plane strain specimens having specified pre-strains were stretched using a $1000 \mathrm{kN}$ hydrostatic universal testing machine. The ARAMIS program was used to measure the generated strain in the specimen. The $210 \mathrm{~mm}$ long tensile specimens were taken from the pre-stretched regions of the sheets (Fig. 41). The tensile specimens were subsequently aged under the same conditions as the uniaxial pre-strained specimens. Finally, the tensile test was performed on the samples to determine the mechanical properties of the pre-strained regions and thus ascertain the effect of pre-straining on the strengthening.
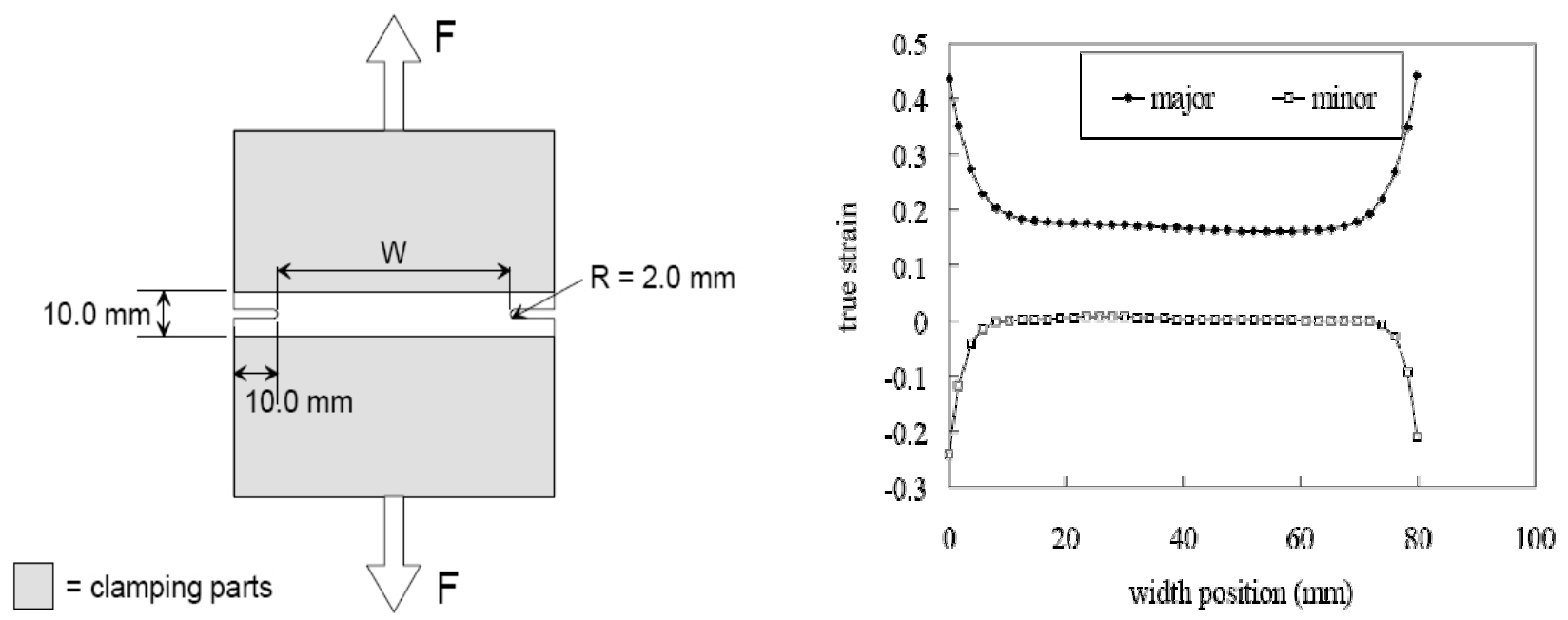

Fig. 39: Specimen for the plane strain tensile test according to the Vegter model.

The specimens were cut into $300 \times 300$ mm sheets.

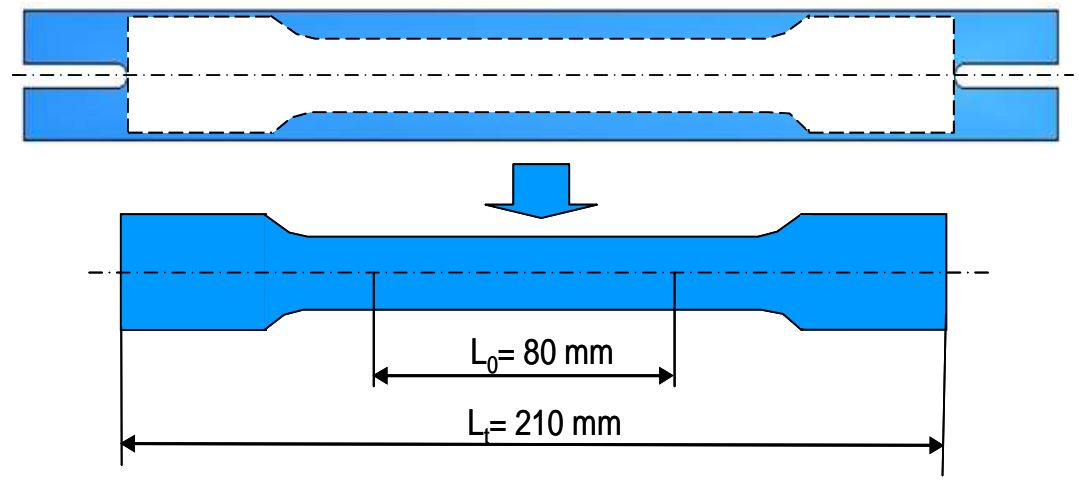

Fig. 41: Tensile specimen taken from pre-strained region having a plane strain state 
The change in length and the corresponding degree of pre-strain for the DP-steel for each type of strain path are listed in Table 7.

Table 7: The change in length and the corresponding degree of pre-strain for the DP steel for different types of pre-strain

\begin{tabular}{lll}
\hline Type of pre-strain & Change in the length $[\mathrm{mm}]$ & Degree of pre-strain $\varepsilon[\%]$ \\
\hline Uniaxial & - & $2,5,10$ \\
Biaxial & $5,10,15,20$ & $2,3,4,5,7$ \\
Plane-strain & $6,7,8,9,9.5$ & $0.50,0.75,1.50,2.25,4.00$ \\
\hline
\end{tabular}

Fig. 42 shows the mechanical properties of DP-W 600 conditioned with uniaxial pre-strains of up to $10 \%$ and aging temperatures of $100{ }^{\circ} \mathrm{C}, 170{ }^{\circ} \mathrm{C}$ and $240{ }^{\circ} \mathrm{C}$ for $20 \mathrm{~min}$. holding time. The strengthening effect is stronger with higher aging temperatures which improve diffusion conditions and thus yielding higher strengthening values. The pre-straining influences the strengthening values such that the strength increase becomes significantly higher for a higher degree of pre-straining (Fig. 42(a)(b)). It is seen that for all the aging temperatures, the yield and tensile strength increases exhibit a moderately linear dependence on the degree of pre-strain. The DP-W 600 steel reaches its highest strengthening values at $10 \%$ pre-strain, while total elongation decreases with increasing pre-strain and aging temperature (Fig. 42(c)).

(a)

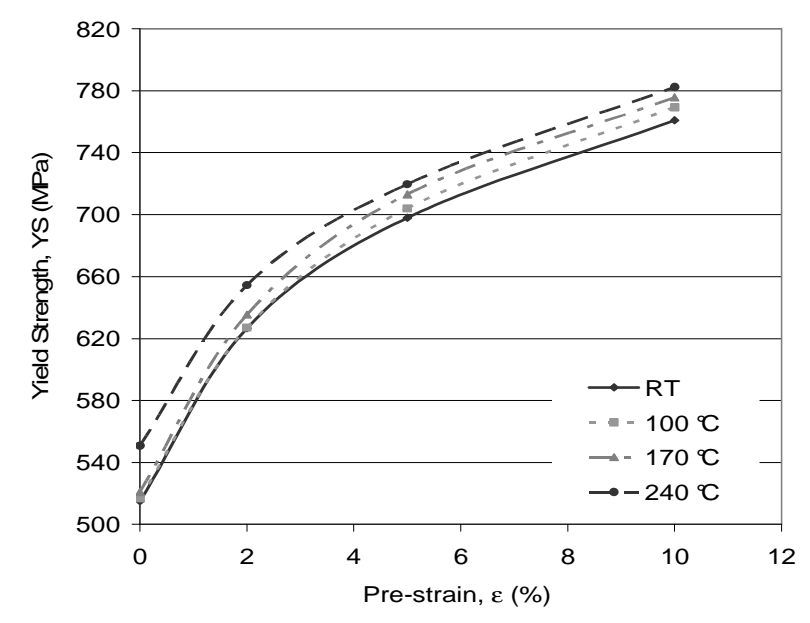

(b)

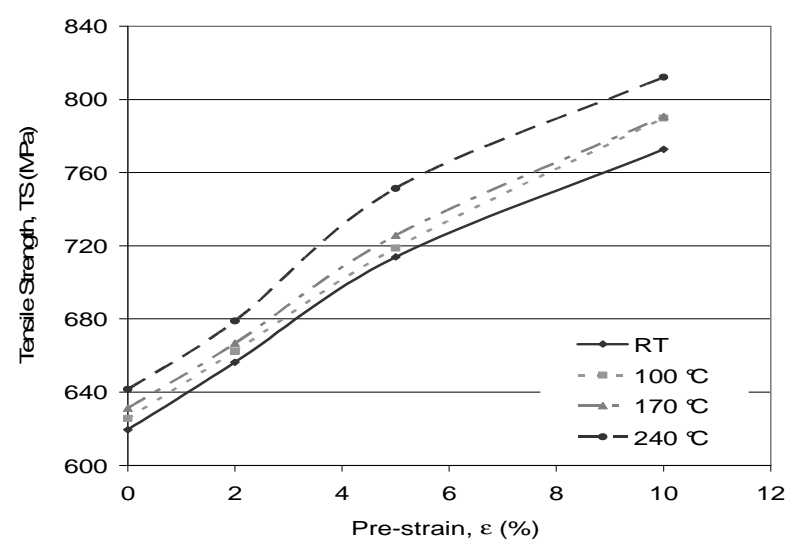

(c)

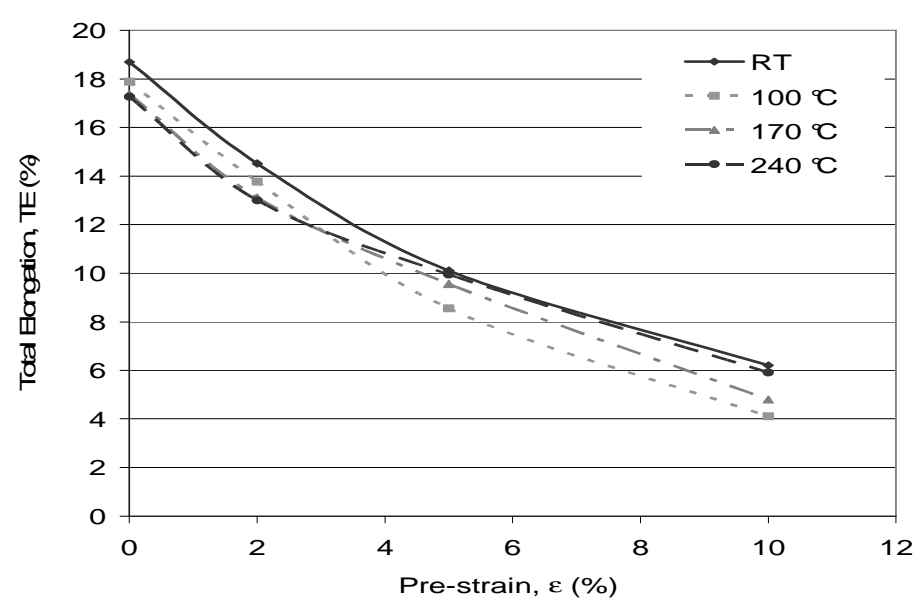

Fig. 42: Influence of pre-strain and aging temperature on the mechanical properties. The samples are pre-strained using a tension test to set up uniaxial conditions with different degrees of pre-strain. The sample aged at different temperatures for a holding time of $20 \mathrm{~min}$. 
Error! Reference source not found. depicts the mechanical behavior of the DP-steel pre-strained under to biaxial conditions to different degrees of pre-strain. Similar to the pre-strain conditions, the yield and tensile strength increases exhibit a moderately linear dependence on the degree of prestrain at all the aging temperature levels (Error! Reference source not found.(a)-(b)). In general, the strength level increases with increasing of pre-strain and temperature. The highest strength, but lowest ductility (Error! Reference source not found.(c)) was observed for the condition with the highest degree of pre-strain aged at $240{ }^{\circ} \mathrm{C}$. Comparing the uniaxial and biaxial conditions, it can be seen that a higher strength level with lower ductility is found for the biaxial condition.

(a)
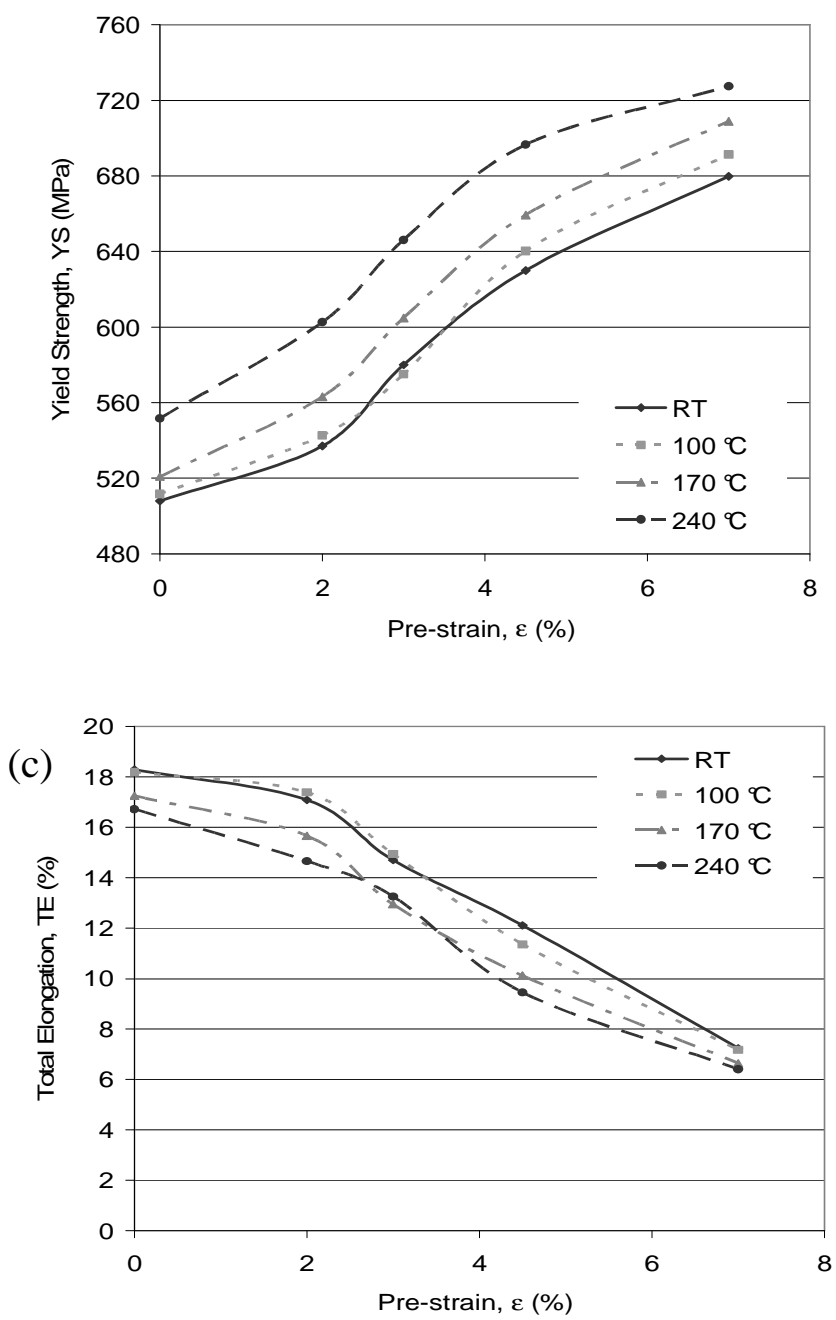

(b)

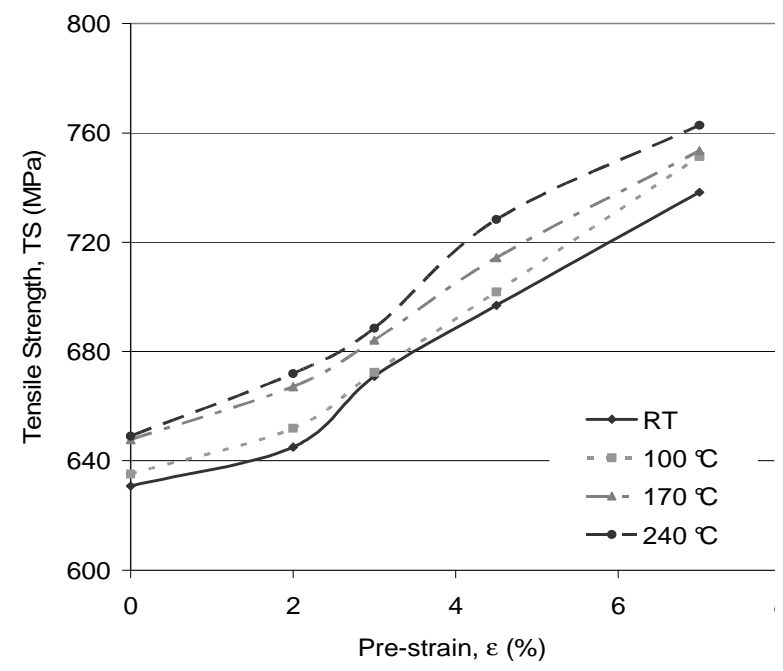

Fig. 43. Influence of pre-strain and aging temperature on mechanical properties. The samples were pre-strained using Marciniak test to set up the biaxial condition with different degrees of prestrain.The sample was aged at different temperatures for a holding time of $20 \mathrm{~min}$.

Fig. 44 describes the aging process of pre-strained specimens with respect to the change in mechanical properties under plane strain conditions at different aging temperatures. It is seen that the yield strength (Fig. 44(a)) and tensile strength (Fig. 44(b)) initially increase with pre-strains of up to $2 \%$ and reach a maximum whereafter they remain almost constant. This saturation stage corresponds to the completion of the Cottrell atmosphere formation as described in [74]. In specimens pre-strained up to $2 \%$, there is a significant increase in yield and tensile strength beyond the first stage of aging at higher temperatures. This could be due to clustering of solute atoms or precipitation of low temperature carbides [74]. The most important aspect of these results is that the maximum increase in yield and tensile strength at the completion of the first stage of aging is the same for all aging conditions. 
The results reveal that up to saturation, the amount of pre-strain does not influence the increase in yield stress during the formation of the atmosphere. Most importantly, at saturation, the degree of atmosphere formation is the same for all the pre-strain levels. Hence the strengthening resulting from such atmosphere formation was found to be the same for all degrees of pre-strain.

(a)

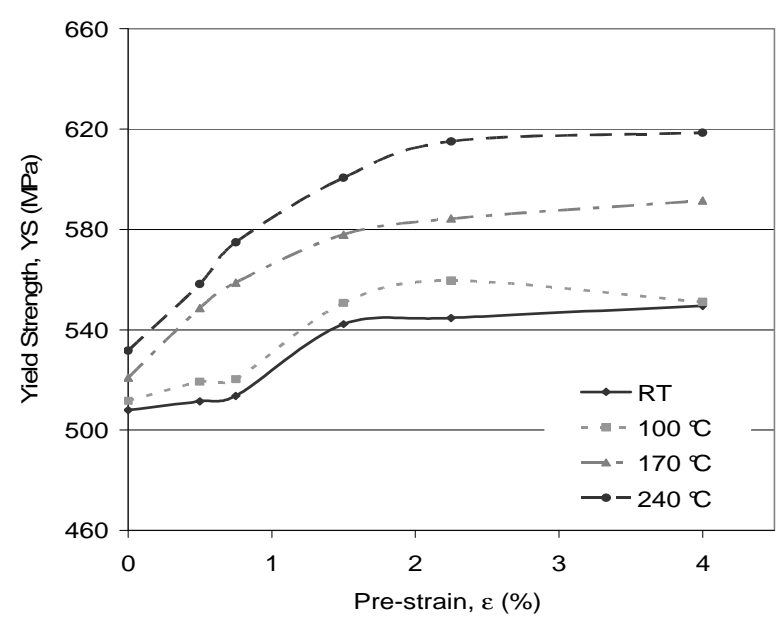

(b)

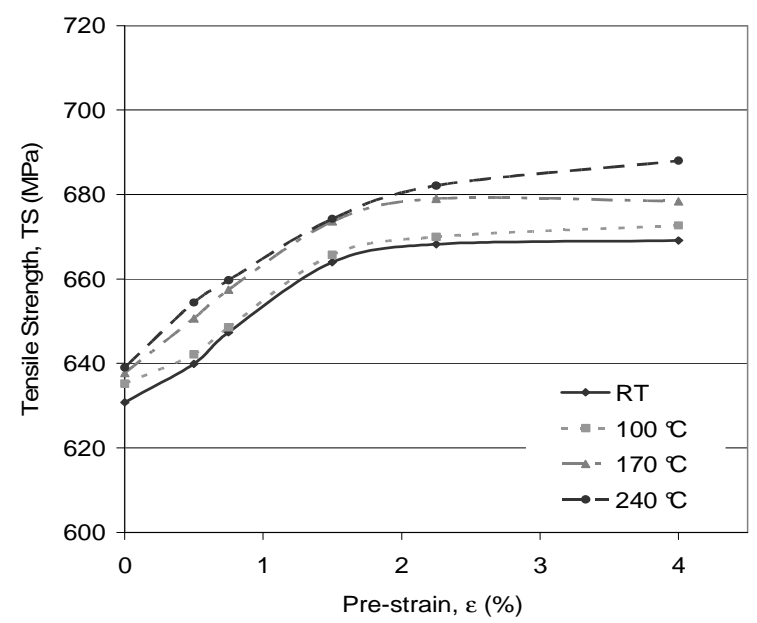

(c)

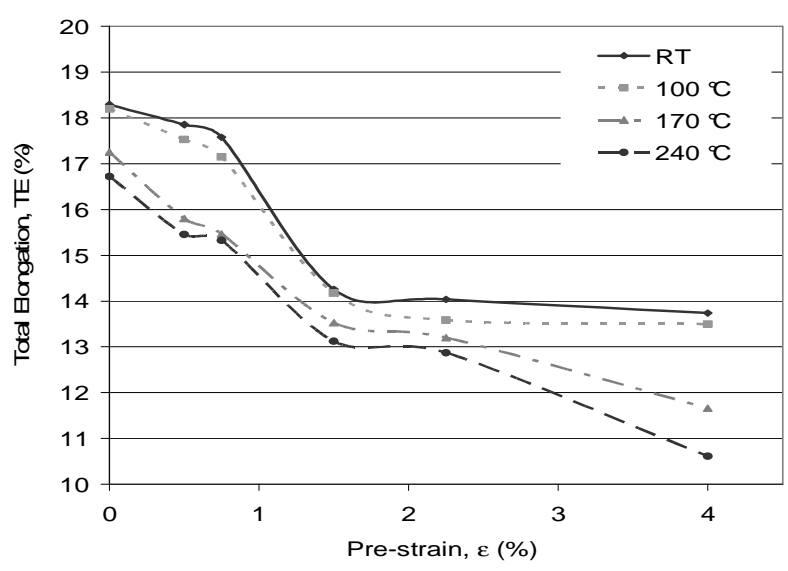

Fig. 44: Influence of pre-strain and aging temperature on mechanical properties. The samples were pre-strained according to the Vegter model to set up plane strain conditions with different degrees of pre-strain. The sample was aged at different temperatures for a holding time of $20 \mathrm{~min}$.

For all pre-straining conditions, an aging treatment at $100{ }^{\circ} \mathrm{C}$ exhibited no influence on the mechanical properties. Aging at temperatures of $170{ }^{\circ} \mathrm{C}$ and $240{ }^{\circ} \mathrm{C}$ led to increase the yield and tensile strengths and decrease the total elongation. This could be due to clustering of solute atoms or precipitation carbides at high temperature [74].

\section{Summary}

In this paper, the potential was discussed for setting-up scaled, local material properties in AHSS steels. AHSS steels are characterized by good formability, continuous yielding, and high strength as well as a bake hardening effect. Two methods were presented to achieve a locally restricted strengthening effect (local deformation and local heat treatment) for their implementation as highstrength structural components. Furthermore, the results of the locally adjusted material properties and aging were discussed. The most significant results are as follows: 
- An increase in hardness and strengthening following local deformation through bending and embossing result from work hardening. An aging treatment at temperatures between $170{ }^{\circ} \mathrm{C}$ and $240{ }^{\circ} \mathrm{C}$ lead to a further enhancement of the mechanical properties.

- The local heat treatment using laser beam as well as electron beam lead to a significant improvement of mechanical properties (hardness and strength) and to the material's local strengthening.

- The reason for the enhancement of the mechanical properties of samples, which were treated with LHT at lower temperatures, compared to the non-laser treated condition, could be contributed to the bake hardening effect. The presence of high volume fractions of martensite and bainite at even higher temperatures (above the annealing temperature) lead to the formation of local plastic zones, having a high dislocation density, in polygonal ferrite and local strengthening due to phase transformation. This conclusion was confirmed by examinations of the microstructure using LOM and TEM.

- This research demonstrated that LHT can affect the microstructure of samples to a specific depth from the surface and produce improve local properties by means of higher hardness values, strength and residual compressive stresses.

- For the samples which were locally heat treated by EB at low powers, an increase in hardness and strength without changing the initial microstructure was observed. This could be also explained by the aging effect.

- The influence of over aging in locally strengthened regions was investigated. The results show that for the parameters considered, the locally adjusted strengthening effect is stable.

- In order to completely describe the aging effects, the influence of type and degree of prestrain as well as the effect of the aging parameters was investigated within this research project. The results revealed that these parameters have an affect on the aging behaviour of steels.

- Local strengthening of AHSS opens up new fields of application for the local use of aging and represents a modification of an existing process. The opportunity is provided for influencing only those regions of interest and thereby unlocking the potential for energy-saving.

\section{Perspectives for further investigations}

The aims of the project for the next application period are to investigate and develop processes for multiphase steels which enable the aging effect to be specifically and locally set. A local increase in strength can be obtained either by locally introducing thermal energy into the previously homogeneously deformed material or by specifically deforming regions and subsequently partially or globally heat treating the material. The results from the first application period have shown that both approaches are productive and can be exploited for increasing the material's strength.

Specifically and locally setting the aging effect is to be investigated with regard to the implications for the component's behavior. For this purpose, the data from first phase is customized by means of random tests to verify the transferability of the results from first application period. Here, the aim is to develop and verify local mechanical/thermal strengthening of components. In addition to this, investigations are carried out regarding wrinkle formation and deformation direction by exploiting the local strengthening in U-profiles. In this connection, linear tracks are initially rolled into a sheet by means of a profiling roll in order set a local degree of deformation as a pre-strain. The tracks are subsequently rolled flat. U-profiles are manufactured from these sheets whereby the prestrain exists at the center of the lateral edges and at the profile's base. Finally, the components are heat treated at specific temperatures $\left(100\right.$ to $\left.240{ }^{\circ} \mathrm{C}\right)$ for $20 \mathrm{~min}$. Both the influence of the local prestraining as well as the buckling behavior is investigated by means of compression, bending and tensile tests. 
The effect of the local heating on the aging of sheets is being investigated in the project which is still currently running. The heat is supplied by means of a laser at a power of between $\mathrm{P}=0.6 \mathrm{~kW}$ and $2.8 \mathrm{~kW}$. This processing technology leads to a unidirectional, conically heated zone, which is introduced into the sheet, thereby grading the material behavior through the sheet thickness. According to the sheet thickness and the selected process conditions, it is possible to significantly influence the microstructure owing to the overheating phenomena. This grading and microstructural modification in particular regions certainly represents a technically interesting option. However in the current phase, focus is being concentrated on introducing a locally limited but homogeneous heated zone through the sheet thickness in order to obtain enhanced comparability with global heat treatment. The investigations are to be carried out at significantly lower laser powers. To achieve the local introduction of a heated zone, additional heat is to be supplied via an induction coil with which the energy supply can be controlled by means of the induction frequency. Using this device, we expect to produce a significantly more homogeneous locally influenced region.

In the initial phase of the present application period, a embossing machine was procured, which was delivered in the middle of 2009, to produce unrestricted geometries in the large sheet specimens. The investigation of sheets having different embossed geometries can therefore be continued in the second application period. These investigations and specimens represent an essential link to the production of larger structural components (reference components). With respect to this, it is interesting to develop an in-line process which enables the mechanical-thermal treatments to be carried out in a fixture.

Determining the correlation between hardness and local mechanical properties is another essential research task. According to the literature, this relationship is only known in regions where the hardness is homogeneous and the microstructural distribution is uniform [75]. A general relationship between hardness value and yield strength does not currently exist for homogeneous regions. This should produce mechanical parameters, which can be correlated to the measured hardness values, via simulating the heat flow in the treated specimens and tracing the thermal stresses for individual regions using the available deformation simulator. In order to carry this out, the dependency of the change in strength on the heat supply must be determined; also at the local scale.

Another focus of attention is an investigation of different loading paths as well as the level of deformation and the resulting properties. The influence of different loading paths on the mechanical properties and the effects on aging will be determined by means of specimens which were prestrained by means of tensile, biaxial and plane strain loading. The absolute loads for testing specimens, which were uniaxially and biaxially pre-strained, are to be inferred from the comprehensive results of the initial application period. No results currently exist for combined loads. The results will be used to develop a model for estimating the aging effect subject to combined loads and which will be used for optimizing the manufacturing processes in global and local regions of components. On successfully completing this sub-project, the product developer will be in possession of a computational tool which will enable the use of this material's potential to be credibly extended.

\section{Acknowledgements:}

The authors would like to thank the DFG "Deutsche Forschungsgemeinschaft", Bonn, Germany, for their financial support of the project as part of the Collaborative Research Center 675 namely "Creation of high strength metallic structures and joints by setting up scaled local material properties", which is a joint research program of the Clausthal University of Technology and the University of Hanover. The authors are also grateful to ThyssenKrupp Steel AG for providing the steels.

\section{References}

[1] T.B. Hilditch, I.B. Timokhina, L.T. Robertson, E.V. Pereloma and P.D. Hodgson: Met. Mat. Trans. A, Vol. 40 (2009), pp. 342-353

[2] S.K. Panda and Y. Zhou: Met. Mat. Trans. A, Vol. 40 (2009), pp. 1956-1967 
[3] R.H. Wagoner, J.H. Kim and J.H. Sung: Int. J. Mat. Form., Vol. 2 (2009), pp. 359-362

[4] L.N. López de Lacalle, A. Lamikiz, J. Muñoa, M.A. Salgado and J.A. Sánchez: Int. J. of Adv. Manufac. Tech., Vol. 29 (2005), pp. 49-63

[5] M. Steinhäusler: Diploma Thesis, University of Leoben, Austria (2004)

[6] D. Wu and L. Zhuang: ISIJ Int., Vol. 46 (2006), pp. 1059-1066

[7] T. Furukawa, M. Tanino, H. Morikawa and M. Endo: Trans. ISI, Vol. 24 (1984) No. 2, p. $113-121$

[8] R.G. Davies: Met. Mat. Trans. A, Vol. 9A (1978), pp. 41-52

[9] V. Colla, M. De Sanctis, A. Dimatteo, G. Lovicu, A. Solina and R. Valentini: Met. Mat. Trans. A, Vol. 40 (2009), pp. 2557-2567

[10]D. Das and P.P. Chattopadhyay: J. Mat. Sc., Vol. 44 (2009), pp. 2957-2965

[11] G.R. Speich and V.A. Demarest: Met. Mat. Trans. A, Vol. 12A (1981), pp. 1419-1428

[12]I.B. Timokhina, P.D. Hodgson and E.V. Pereloma: Met. Mat. Trans. A, Vol. 38A (2007), pp. 2442-2454

[13] A.H. Cottrell and B.A. Bilby: Proc. Phys. Soc., Vol. A62, pp. 49-62

[14] W.C. Jeong: Met. Mat. Trans. A, Vol. 29 (1998), pp. 463-467

[15]L. Samek, E. De Moor, J. Penning, J.G. Speer and B.C. De Cooman: Met. Mat. Trans. A, Vol 39 (2008), pp. 2542-2554

[16]H. Palkowski, G. Kugler and M. Asadi: TMS AIME, New Orleans, Louisiana (2008), pp. 225-236

[17]H. Palkowski and Th. Anke: Steel Research Int., Vol. 76 (2005), pp. 148-153

[18]R. Neugebauer, S. Scheffler, R. Poprawe and A. Weisheit: Prod. Eng. Res. Develop., Vol. 3 (2009), pp. 347-351

[19]A. Kopel and W. Reitz: Advanced Materials and Processes, ASM (1999)

[20]J.M. Amado, C. Álvarez and J.A. Pérez: Rev. Met. Madrid, Vol. 40 (2004), pp. 365-368

[21]J.A. Pérez, J.L. Ocaña and C. Molpeceres: Int. J. Adv. Manufact. Techn., Vol. 36 (2008), pp. 732-737

[22]D. Hillebrand: Dr.-Ing. Thesis, Bayreuth, Germany (2009)

[23] M. Kikuchi: Proc. of the Mat. Proc. Conf.-ICALEO, LIA (1981)

[24]T. Waterschoot, A.K. De, S. Vandeputte, and B.C. De Cooman: Met. Mat. Trans. A, Vol. 34A (2003), pp. 781-791

[25] A.K. De, S. Vandeputte, and B.C. De Cooman: Scripta Mat., Vol. 44 (2001), pp. 695-700

[26] R. Grange, R. Hribal and L. Porter: Met. Mat. Trans. A, Vol. 8A (1977), pp. 1775-1785

[27]P. Elsen: Dr.-Ing. Thesis RWTH Aachen, Aachen, Germany (1993)

[28] W. Bleck, S. Brühl and T. Gerber: Proc. of the 1st Int. Conf. on Steel in Cars and Trucks, Wiesbaden (2005), Verlag Stahleisen GmbH, Düsseldorf (2005), pp. 489-496

[29]H. Palkowski and A. Brück: Steel Research Int. Vol. 79 (2008) 3, pp. 12-17

[30]H. Palkowski and A. Brück: Advanced Materials Research Vol. 22 (2007) pp. 17-26 
[31]H. Palkowski and A. Brück: METEC InSteelCon (2007), Düsseldorf 11-15 June 2007, pp. 657-664

[32] J. Dutta Majumdar and I. Manna: Sadhana, Vol. 28 (2003), Parts 3 \& 4, pp. 495-562

[33] J.F. Ready, in: J.F. Ready (Ed.), LIA Handbook of Laser Materials Processing, LIA/Magnola Publishing Inc., Orlando, Forida (2001), pp. 167-204

[34] S.A. Astapchik, V.B. Babushkin and V.S. Ivashko: Physicotechnical Institute, Academy of Sciences of the Belorussian SSR. Translated from Metallovendenie i Termicheskaya Orbabotka. Metallov (1991), No. 2, pp. 2-5

[35]L. Su-qin, H. Jin-Hang, W. Shim-ring and D. Qi-ming: Tans. of Mat. and Heat Treatm. Proc. of the IFHTSE Congress, Vol.25 No.5 (2004), pp. 1017-1020

[36]C. Liu, Z.-B. Zhao, and D.O. Northwood: Mat. Sc. and Techn, Vol. 18 (2002), pp. 1325-1328

[37]H.K.D.H. Bhadeshia and J.W. Christian: Met. Mat. Trans. A, Vol. 21A (1990), pp. 767-797.

[38] Y. Huanga, Y. Zhangb, H. Zhai, C. Zhou and J. He: Mat. Sc. Forum, Vol. 475-479 (2005), pp. $97-100$

[39]P.C.M. Rodrigues, E.V. Pereloma and D.B. Santos: Mat. Sc. Eng., Vol. A283 (2000), pp. 136143

[40]I. Madariaga, I. Gutierrez and H.K.D.H. Bhadeshia: Met. Mat. Trans. A, Vol. 32A (2001), pp. 2187-2197

[41]A. Aghajani, Ch. Somsen and G. Eggler: Acta Materialia, Vol. 57 (2009), pp. 5093-5106

[42] N.J. Kim and G. Thomas: Met. Mat. Trans. A, Vol. 12A (1981), pp. 483-489

[43]A. Ghosh, R. Shukla, S. Das and S. Chatterjee: Steel Research Int., Vol. 77 (2006), pp. 276-283

[44]P.J. Jacques, J. Ladriére and F. Delannay: Met. Mat. Trans. A, Vol. 32 (2001), pp. 2759-2768

[45] S.T. Mandziej: Mater. Sc. Eng., Vol. A164 (1993), pp. 275-280

[46]B.L. Bramfitt and J.G. Speer: Met. Mat. Trans. A, Vol. 21 (1990), pp. 817-829

[47] S. Traint, A. Pichler, K. Spiradek-Hahn, P. Stiaszny, C. Krempaszky and E. Werner: Steel Research Int., Vol. 76 (2005), pp. 539-544

[48]H.K.D.H. Bhadeshia: Acta Metallurgica, Vol. 28 (1980), pp. 1103-1114

[49]D.Q. Bai, S. Yue, T.M. Maccagno, and J.J. Jonas: Met. Mat. Trans. A, Vol. 29 (1998), pp. 989-1001

[50]H.K.D.H. Bhadeshia: $2^{\text {nd }}$ ed., IOM Communications, Ltd., London (2001), pp. 19-62

[51]S.W. Thompson, D.J. Colvin and G. Krauss, Met. Mat. Trans. A, Vol. 21 (1990), pp. 1493-507

[52]L. Fenchao, A. Qing and G. Yingni: Sc. in China (serie E), Vol. 39 (1996), pp. 647-655

[53]C.H. Young, H.K.D.H. Bhadeshia, Mat. Sc. Technol. Vol. 10 (1994) 3, pp. 209-214

[54]R. Kaul, P. Ganesh, P. Tiwari, R.V. Nandedkar and A.K. Nath: J. Mat. Proc. Techn. 167 (2005), pp. 83-90

[55] K. Obergfell, V. Schulze and O. Vöhringer: Mat. Sc. Eng. A 355 (2003), pp. 348-356

[56] J.J.C. Hoo: ASTM International, West Conshohocken, PA (1993)

[57] M.F. Ashby and K.E. Easterling: Acta Metallurgica 32 (1984), pp. 1935-1937 
[58] ISO 683-17:1999: Heat-treated Steels, Alloy Steels and Free-Cutting Steels - Part 17: Ball and Roller Bearing Steels (1999)

[59] A. Roy and I. Manna: Opt. Laser. Eng. 34 (2000), pp. 369-383.

[60]Dilthey, U.: Springer-Verlag, Berlin, Heidelberg (2006), ISBN 978-3-540-33154-4, pp. 157-172

[61] Information on http://physicsnobelprize.net/ebw.html

[62] T. Waterschoot, A.K. De, S. Vandeputte and B.C. De Cooman: Met. Mat. Trans. A, Vol. 34A (2003), pp. 781-791

[63]U. Liedl: Dr.-Ing. Thesis, München, Germany (2003)

[64]H. Palkowski and Th. Anke: $2^{\text {nd }}$ Int. Conf. on Thermomechan. Proc. of Steels, Liege, Belgium (2004), pp. 107-144

[65]Th. Anke: Dr.-Ing. Thesis, Technische Universität Claustahl, Clausthal-Zellerfeld, Germany (2005)

[66]H.K.D.H. Bhadeshia: Maney Publishing, London (2001), J. Fatigue 26 (2004), p. 437-442

[67]H. Palkowski and A. Brück: In: Moderne thermomechanische Prozessstrategien in der Stahlumformung, Düsseldorf (2007), pp. 12-23

[68]H. Palkowski and Th. Anke: 134th Annual Meeting \& Exhibition, Proceedings TMS 2005, San Francisco, USA (2005)

[69] S.P. Keeler and W.A. Backofen: Trans. ASM Vol. 56 (1963), pp. 25-48

[70]H. Vegter, C. ten Horn, Y. An, E. Atzema, H. Pijlman, T. van den Boogaard and H. Huétink: VII Int. Conf. on Comput Plasticity, E. Oñate and D.R.J. Owen (Eds), Barcelona (2003)

[71]H. Vegter, Y. An , H.H. Pijlman, and J. Huétink: Keynote-lecture, in Proceedings Numisheet'99 (Besançon, France), J.C. Gelin, et. al. (Eds), University of Franche Comté (1999)

[72]H. Vegter: Dr.-Ing. Thesis, University of Twente, The Netherlands (1991)

[73]H. Vegter, Y. An, H.H. Pijlman and J. Huétink: In: First ESAFORM conference on Material Forming, Proceedings, Sophia-Antipolis, France (1998), pp. 499-514

[74]A.K. De, S. Vandeputte and B.C. De Cooman: Scripta Materialia Vol. 41 (8) (1999), pp. $831-837$

[75]A.E. Tekkaya: Steel Research Int. 71 (2000), pp. 1-14 